\title{
Chemical cross-linking methods for cell encapsulation in hydrogels
}

\author{
Cécile Echalier ${ }^{1,2}$, Laurine Valot ${ }^{1,2}$, Jean Martinez ${ }^{1}$, Ahmad Mehdi $^{2}$ and Gilles Subra ${ }^{1}$
}

${ }^{1}$ IBMM, Univ Montpellier, CNRS, ENSCM, Montpellier, France.

${ }^{2}$ ICGM, Univ Montpellier, CNRS, ENSCM, Montpellier, France.

Cell-encapsulating hydrogels are of tremendous interest in regenerative medicine. Tissue engineering relies on biomaterials able to act as artificial extracellular matrices to guide cells towards the development of new tissues. Therefore, considerable efforts have been made to design biomaterials which mimic cells' native environment, thus encouraging natural behavior. The choice of biomaterial in which cells are embedded is crucial for their survival, proliferation and differentiation. Being more stable, chemical hydrogels are preferred over physical hydrogels as cell-laden substrates. When designing chemical hydrogels, scientists must choose not only the nature of the network (synthetic and/or biopolymers) but also the type of cross-link bridging hydrogel constituents. For that purpose, numerous chemistries have been used (i) to introduce reactive functions on the hydrogel precursors and (ii) to form covalent bonds in the presence of living cells. The review will discuss the advantages and limitations of each strategy.

\section{Cell-encapsulating hydrogels.}

Cell-laden hydrogels are of paramount importance in tissue engineering. This area of research aims to produce living tissues to be used as tissue grafts to repair or replace damaged biological tissues/organs.[1,2] For this purpose, cells are seeded in a scaffold that will support them and provide signals to guide them towards the development of a new functional tissue. Ultimately, the engineered tissue will be transplanted into the patient where it is expected to restore biological tissue function. Alternatively, cells can be encapsulated in injectable hydrogels [36] to achieve cell delivery at the site of interest for in situ regeneration of a tissue. The hydrogel serves as temporary scaffold which provides mechanical support and appropriate signals until new tissue is formed by the injected cells. In both cases, the choice of the biomaterial in which cells are embedded is crucial for tissue development. This material must provide the cells with an environment which is as similar as possible to their native environment.

\subsection{Hydrogels as mimics of the ECM}

In biological tissues, cells are surrounded by a complex and bioactive extracellular matrix (ECM).[7-10] An interstitial fluid is entrapped in a network constituted of hydrated proteoglycans coiled around fibrous proteins such as collagen, fibronectin, elastin and laminin (Fig. 1). Collagen is the most abundant fibrous protein in the ECM, its fibers providing tensile strength to the surrounding tissue. Together, all these components confer a hydrogel-like consistency to the ECM. 


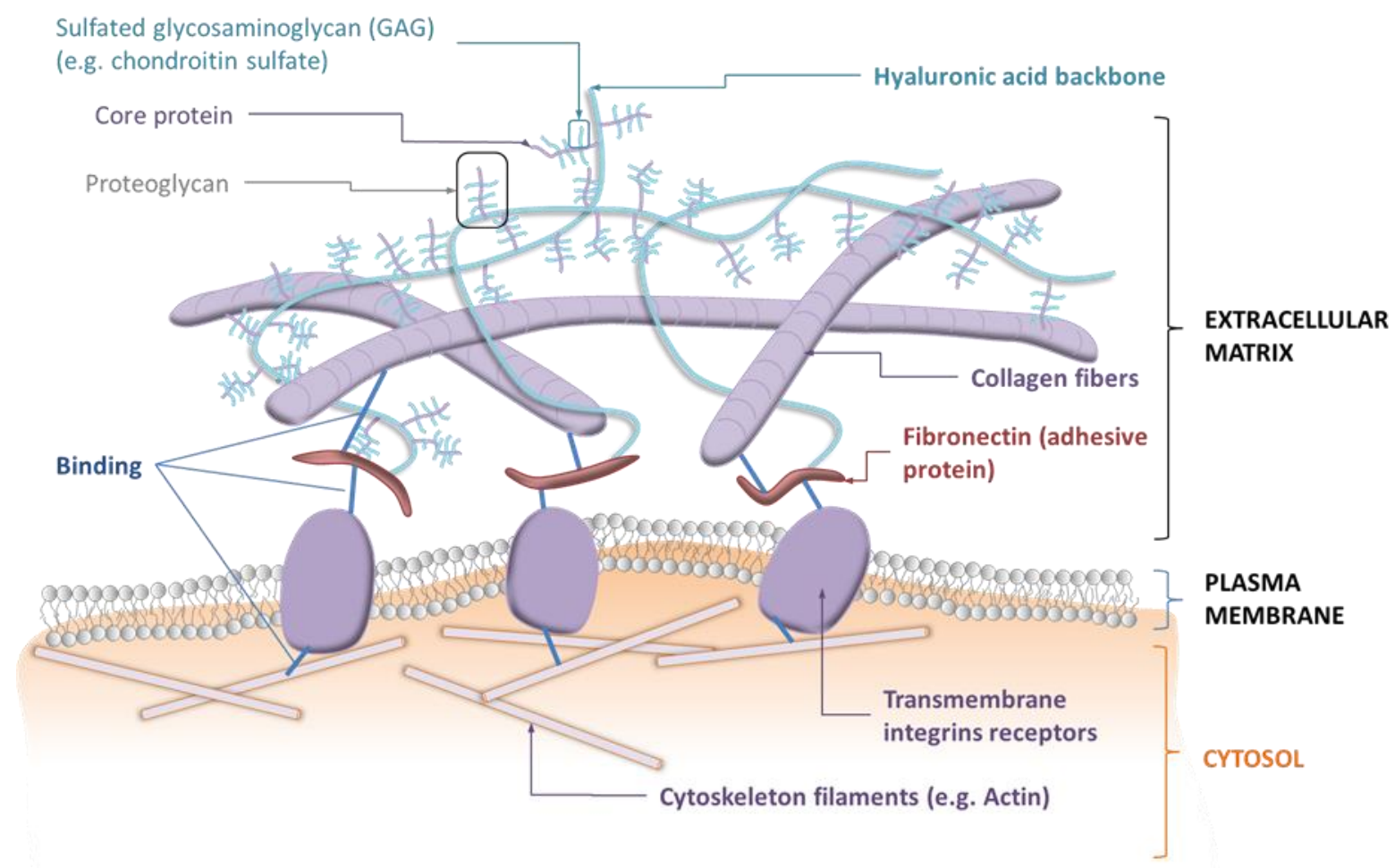

Fig. 1. Schematic representation of the extracellular matrix.[11]

The role of the ECM is not only to provide mechanical support to the cells but also to regulate their behavior. Indeed, ECM is involved in cell survival, proliferation, migration and differentiation. This matrix holds cells together in tissues and maintains cells in a buffered aqueous environment. It enables the diffusion of oxygen, nutrients and metabolic products. It sequesters and delivers growth factors and other biological signaling molecules while controlling the diffusion of cell-secreted substances. In addition, it provides cell-matrix interactions. For instance, fibronectin introduces cell adhesion sites to attachment-dependent cells. Mechanical signals from ECM also affect cell fate. Matrix rigidity greatly influences cell differentiation. Finally, ECM is highly dynamic, constantly undergoing remodeling by proteases and matrix metalloproteinases (MMPs) which allows cell migration and proliferation. Considering the importance of ECM to so many cellular processes, it is a challenge to design artificial matrices that faithfully replicate the structure and functions of native ECM.

Given their high water content (typically $\mathrm{w}_{\text {water }}>>\mathrm{w}_{\text {polymer, }}$ with $\mathrm{w}$ the mass fraction), hydrogels have been investigated as artificial ECM.[12-15] They are made of hydrophilic polymers crosslinked into water-insoluble polymeric networks. Their elastic properties provide a physical environment close to native soft tissues. Their mechanical properties can be tuned by modifying the degree of interaction (i.e. the non-covalent interactions or covalent cross-linking) between the polymer chains. However, although a high cross-linking density leads to high mechanical strength, it also results in lower swelling capabilities and decreased mesh sizes, which has an impact on biomolecule diffusion and cell migration. Therefore, a subtle balance should be struck between the physical properties of the hydrogel.

\subsection{Hydrogel precursors}


It seems obvious to use natural biopolymers as hydrogel network precursors and many hydrogels used for cell encapsulation are prepared from natural polymers, like collagen, hyaluronic acid (HA), alginate, chitosan, dextran and fibrin.[16,17]

Nonetheless, biopolymers suffer several drawbacks. They can be expensive to produce and often ill-defined. Their properties may vary from batch to batch and are difficult to tune. In addition, they could present a risk of contamination with pathogenic substances and they might be immunogenic. In contrast, synthetic polymers such as polyethylene glycol (PEG) and poly(vinyl alcohol) (PVA) are easy to produce on a large scale and are well-defined. Their chemical modification is simple and resulting hydrogels are highly reproducible. However, they are bio-inert, in the sense that they are biocompatible but cannot promote cell behavior. The term permissive hydrogels is used for them, as opposed to promoting hydrogels made of natural polymers.[20] Nevertheless, it is possible to confer some bioactivity to permissive hydrogels by functionalizing them.[35] The modification of artificial matrices with cell adhesive peptides is very common. Peptide sequences are often derived from ECM proteins.[36] Among them, the fibronectin-derived Arg-Gly-Asp (RGD) sequence which is a recognition motif for cell integrin receptors is the most frequently used.[37,38] Other peptide sequences of interest have proven to be useful in designing artificial ECM. Anseth and co-workers demonstrated that KLER sequence could promote cartilage-specific matrix deposition and organization by binding and stabilizing collagen.[39] Growth factors have also been introduced in artificial matrices. For instance, Phelps et al. engineered a system in which vascular endothelial growth factor (VEGF) was sequestrated within a hydrogel and delivered to the cells upon proteolytic degradation of the gel.[13] Tsurkan et al. described a PEG-heparin hydrogel in which heparin serves as reservoir for growth factors.[40]

\subsection{Physical and chemical hydrogels}

Depending on the type of interactions involved in the formation of the matrix, two types of hydrogels can be defined: physical and chemical hydrogels. Physical hydrogels result from the formation of a physical network involving weak interactions such as ionic interactions, hydrogen bonds, $\pi$ - $\pi$ stacking, Van der Waals forces and hydrophobic interactions.[18] Physical hydrogels are mostly obtained from biopolymers [16,17] assembled through multiple non covalent interactions whose weakness is counterbalanced by their large number. Alginate in particular has been extensively investigated as ECM substitute due to its ease of gelation driven by complexation of calcium cations.[19] Alternately, small synthetic molecules, called hydrogelators, may self-assemble in water to form three-dimensional supramolecular networks.[20] Self-assembling peptides hold a prime position among hydrogelators [2126]][27]. One of the main advantages of physical hydrogels is that no reactive functional group is required for cross-linking and establishment of the tridimensional network. Thus, the synthesis of precursors is straightforward (no further modification with reactive groups is required) and cross-reactions in vivo are avoided. However, physical hydrogels often suffer from poor mechanical properties owing to the weak interactions involved in their formation. While shear-thinning behavior is an asset for hydrogel injection, it prevents applications, such as articular cartilage repair, in which the hydrogel will be subjected to shear forces. Overall, the mechanical properties of physical hydrogels are difficult to tune since it is impossible to play with the cross-linking density. The concentration in precursors can be increased to get stiffer gels but it may create large osmotic gradients in vivo. It is also difficult to control the degradability of physical hydrogels. When associations between the molecules are formed by weak individual interactions, the local concentration can be reduced over time by dilution with physiological fluids, which leads to loss of structural integrity. On the other hand, chemical hydrogels are cross-linked through covalent chemical bonds, providing improved mechanical properties and stability to the resulting hydrogels compared to physical hydrogels. This makes 
them more suitable for long-lasting tissue engineering applications. A wide range of precursors, displaying reactive functions, is available to prepare chemical hydrogels via different methods. The second part of the review will discuss the advantages and limitations of each strategy.

Mechanical properties of hydrogels (e.g. rheological behavior, swelling) are governed by the nature of the (bio)polymer, its size and concentration, and by the cross-linking density. Another way of tuning properties of a chemical hydrogel is to prepare an interpenetrating network by adding another (bio)polymer forming a physical hydrogel into the cross-linked one.[28,29] It is worth noting that the nature of the chemical cross-linkage itself will have a limited impact on the mechanical properties.

However, the degradation of the network which is mainly dependent on the nature of the (bio)polymer, can also be tuned by the stability of the cross-linkages. This is an important feature as it allows cell growth and migration, leading to the replacement of an artificial matrix by natural tissue.[35,41] Hydrolysable bonds (e.g. esters) can be introduced in the network providing a time-dependent degradation.[42-44] More interestingly, cell-responsive hydrogels can be obtained with enzyme-sensitive peptide cross-linkers, ensuring that the gel degradation will match cell growth. Patterson and Hubell reported hydrogels sensitive to matrix metalloproteinases (MMPs).[45,46] This review focuses on the different chemical reactions that can be used to cross-link cell-laden hydrogels. As already mentioned, the choice of chemistry has little influence on the mechanical properties of the resulting materials. Therefore, the mechanical properties of the hydrogels will not be discussed herein. However, we will highlight the cleavage of the bonds leading to the degradation of the network.

\section{Strategies for the synthesis of chemical hydrogels for cell encapsulation}

\subsection{Cell encapsulation: implications for hydrogel cross-linking methods and elementary bricks}

Herein, we will discuss cross-linking methods leading to a covalent hydrogel compatible with live cell encapsulation. The main parameters for cell-friendly embedment are summarized below.

- Avoidance of organic solvents

- Gelation in an aqueous solution isotonic to cytosol

- Maintenance of $\mathrm{pH}$ between 7.2 and 7.5

- Phosphate-buffered saline and, better yet, cell culture media (recommended)

- Temperature maintained at between room temperature and $40^{\circ} \mathrm{C}$. Ideally, the in vitro gelation process should be performed at $37^{\circ} \mathrm{C}$ in a humidified $5 \% \mathrm{CO}_{2}$ atmosphere.[30]

These requirements have a strong impact on the hydrogel precursors and the cross-linking chemistry. First of all, cross-linking must proceed in aqueous conditions. Therefore, hydrogel precursors should be water-soluble. For a homogeneous cell distribution within the hydrogel, the precursor solution must transform into a solid hydrogel relatively quickly to avoid sedimentation of the cells after their introduction. Precursors, catalysts, initiators, cofactors, additional reagents, etc. must be cytocompatible and the cross-linking reaction should not generate cytotoxic by-products. This is one of the reasons why macromolecular precursors are often preferred, since most of them are less cytotoxic than small molecules. The cytotoxicity is often related to a lack of selectivity of the reactive functions borne by the precursors. For example, aldehydes and epoxides may react with biomolecules from live cells, thus interfering with native biological processes. Indeed small bifunctional molecules such as 
epichlorohydrin,[31] glyoxal[32] and 1,4-butanediol diglycidyl ether[33] have been used to cross-link polymers, but presented some cytotoxicity because of their lack of selectivity. The 'bio-orthogonality', which regarding materials is the selectivity of precursors for network formation versus reaction with unwilling natural biomolecules, is crucial for the design of convenient hydrogels.[34] Therefore, we will report herein only bio-orthogonal cross-linking strategies (Table 1). Recent reviews summarizing advances in cross-linking chemistries are available; $[35,36]$ these are focused on commonly used PEG-based hydrogels.

Table 1. Examples of cross-linking reactions used to prepare cell-encapsulating hydrogels 


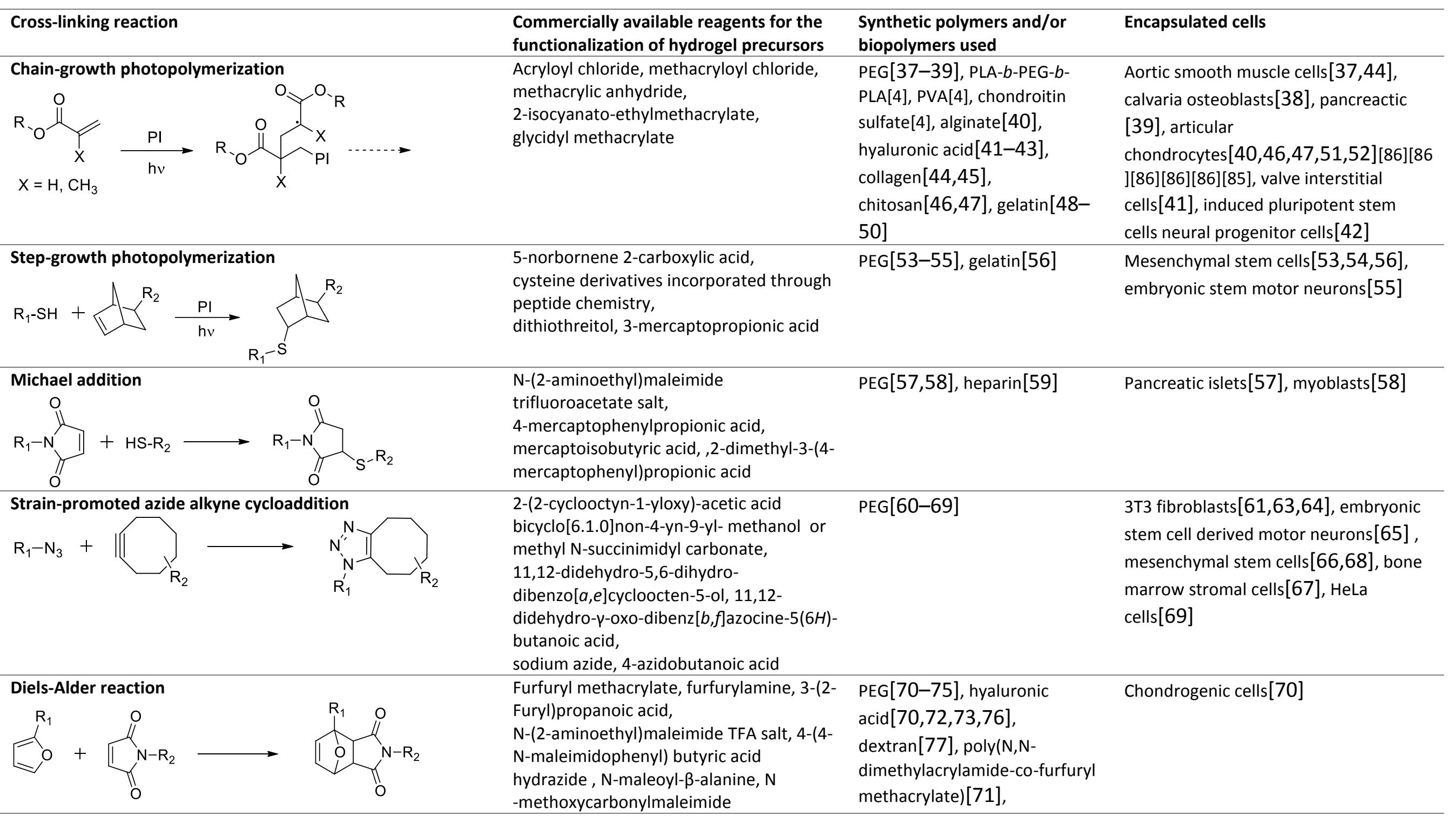




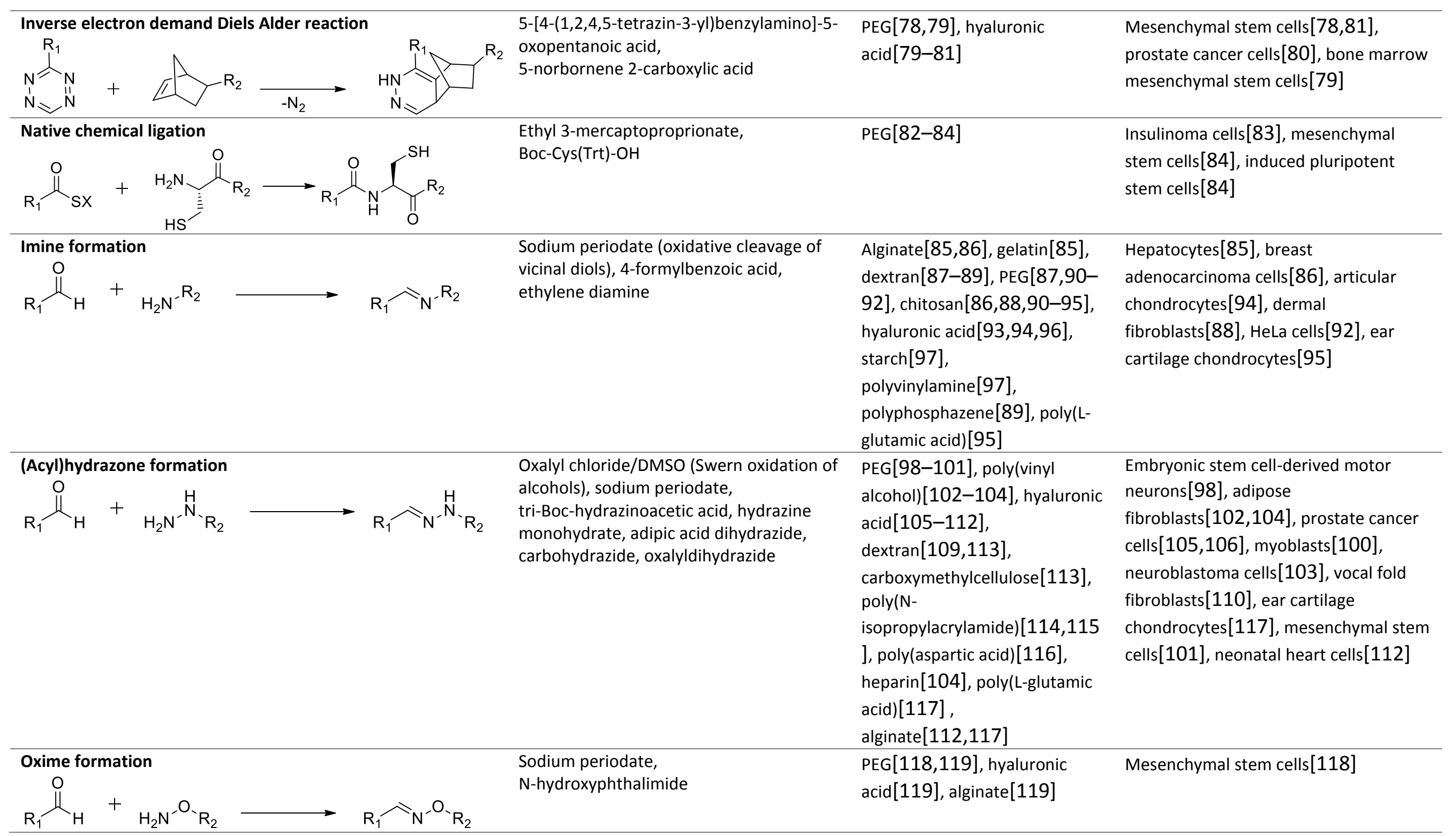




\begin{tabular}{|c|c|c|c|c|}
\hline Disulfide formation & & Dithiobis(propanoic or butyric) & Hyaluronic acid[120], & Adipose fibroblasts[120] \\
\hline $\mathrm{R}_{1}-\mathrm{SH}+\mathrm{R}_{2}-\mathrm{SH} \quad[\mathrm{ox}]$ & $R_{1}-S S^{-}-R_{2}$ & $\begin{array}{l}\text { dihydrazide, } \mathrm{N}, \mathrm{N}^{\prime} \text {-Bis(acryloyl)cystamine } \\
\text { (require a reducing step), thioacetic acid } \\
\text { (requires saponification), } \mathrm{N} \text {-acetyl-L- } \\
\text { cysteine or L-cysteine }\end{array}$ & $\begin{array}{l}\text { chitosan[121], PEG[122,123], } \\
\text { gellan gum[124], } \\
\text { copoly(acrylamide)[125] }\end{array}$ & \\
\hline $\begin{array}{l}\text { Sol-gel } \\
\qquad \mathrm{R}_{1}-\mathrm{Si}(\mathrm{OEt})_{3}+\mathrm{R}_{2}-\mathrm{Si}(\mathrm{OEt})_{3}\end{array}$ & 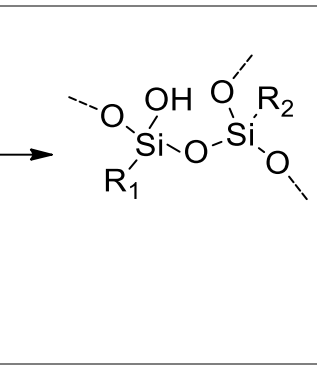 & $\begin{array}{l}\text { 3-isocyanatopropyltriethoxysilane, 3- } \\
\text { (glycidoxypropyl)triethoxysilane, 3- } \\
\text { aminopropyltriethoxysilane }\end{array}$ & $\begin{array}{l}\text { PEG[126,127], } \\
\text { gelatin[128,129], } \\
\text { chitosan[130-132], } \\
\text { collagen[133], alginate[134], } \\
\text { hydroxypropylmethylcellulose[ } \\
\text { 135], collagen-inspired } \\
\text { undecapeptide[136] }\end{array}$ & $\begin{array}{l}\text { Articular chondrocytes }[135,137] \text {, } \\
\text { cardiomyocytes[138], chondrosarcoma } \\
\text { cells[135,139], mesenchymal stem } \\
\text { cells }[136,140,141]\end{array}$ \\
\hline
\end{tabular}




\subsection{Free-radical photopolymerization}

Light-activated cross-linking is of particular interest as it offers spatial and temporal control of the hydrogel formation. Indeed, the gelation is triggered by a light beam that can be targeted with high precision, at well-defined times, on the precursor solution. Free-radical photopolymerization is the most common method to prepare hydrogels under physiological conditions.[142,143] Multifunctional macromolecular precursors can undergo chain-growth or step-growth polymerization depending on the chosen functionalizing moieties.

\subsubsection{Chain-growth photopolymerization}

Vinyl-functionalized macromolecules are subjected to chain-growth polymerization. This process requires a photoinitiator (PI). Upon irradiation at the appropriate wavelength, the photoinitiator absorbs the light energy and dissociates into free-radical reactive species (Fig. 2). These reactive species add to vinyl groups on macromolecular precursors by opening homolytically the $\pi$-bond and forming new free radical species. Hence, the reactive center is propagated as covalent bonds are formed between precursors, resulting in the formation of a polymer network within seconds to minutes.

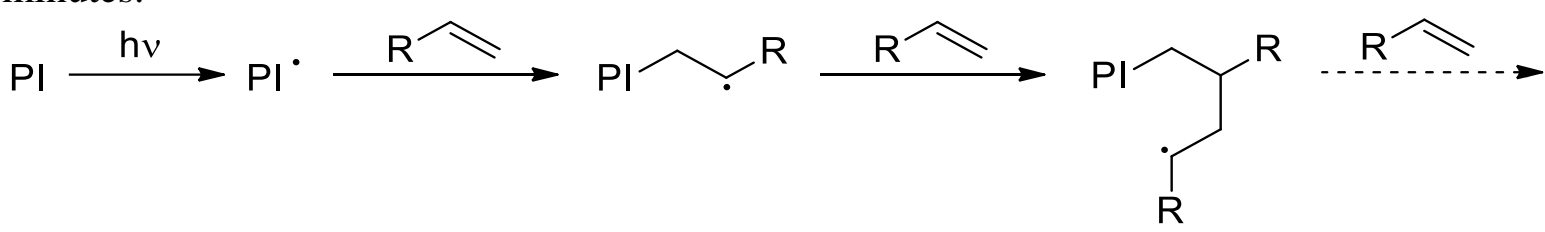

Fig. 2. Chain-growth photopolymerization mechanism. PI: photoinitiator, hv: light source.

Usually, ultra-violet light is chosen to trigger the polymerization, $365 \mathrm{~nm}$ being the most common wavelength.[37] Among the different vinyl groups introduced in precursors (Fig. 3), acrylates are among the most popular. They can be introduced in hydroxyl groups using acryloyl chloride in the presence of a base (e. g. trimethylamine).[38,144] Yang et al. investigated osteogenesis of bone marrow stromal cells in a 3D environment formed by photopolymerization of commercially available PEG-diacrylate (PEGDA) and a PEG acrylate functionalized with peptide ligands promoting cell adhesion.[145] Peyton et al. used the same strategy to study smooth muscle cell behavior in a 3D model system.[146] Methacrylate groups are also suitable for hydrogel photopolymerization. Weber et al. encapsulated murine pancreatic islets in dimethacrylated PEG (PEGDM) hydrogels for insulinproducing cell delivery applications[39] while Russell et al. used it to study the impact of PEGDM rheological properties on oligodendrocyte precursor cell differentiation.[147] PEGDM can be mixed with other synthetic or natural methacrylated polymers. Bryant et al. designed degradable hydrogels by copolymerizing PEG with PLA.[51] The same group also prepared hydrogels from PVA and a natural polymer, chondroitin sulfate. Both polymers were functionalized with methacrylate by reacting their hydroxyl groups with 2-isocyanatoethymethacrylate and methacrylic anhydride respectively.[52] Poly-D,L-lactic acid/polyethylene glycol/poly-D,L-lactic acid (PDLLA-PEG) was also methacrylated and polymerized to make a biodegradable hydrogel suitable for 3D-culture of MSCs.[148] Methacrylated alginate[40], gelatin[48-50], collagen[45] and hyaluronic acid[41-43] were also described. More recently, a zwitterionic carboxybetaine methacrylate precursor was reported.[149] Diacrylamide groups are less common than (meth)acrylates. However, PEG diacrylamide conjugated to collagen has enabled the preparation of a hydrogel in which the co-culture of both endothelial cells and fibroblasts led to the formation of capillary vessel-like networks.[150] 4-arm PEG-methacrylamide has also been mixed with gelatin-methacrylamide to encapsulate bone marrow mesenchymal stem cells.[151]

It is noteworthy that this type of cross-linking strategy has been applied to 3D bioprinting of cellembedded hydrogels, as UV-irradiation is now widely implemented in 3D printers. Extrusion-based bioprinting, for example, has been performed with PEG-DMA [152], PEG-DA/acrylated-peptides 
[153], gelatin-MA/PEG-DA [154], Gelatin-MA/hyaluronic acid-MA/4-arm-PEG-acrylate [155], diacrylated-PCL-PEG-PCL [156] and silk-MA [157]. Furthermore, stereolithography (SLA)/digital light processing (DLP) has been used successfully for gelatin-MA $[158,159]$ and gelatin-MA/glycidal methacrylate-hyaluronic acid [160] bioprinting.<smiles>[R]OC(=O)C=C</smiles><smiles>[R]NC(=O)C=C</smiles><smiles>[R]OC(=O)C(=C)C</smiles>

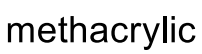<smiles>[R]NC(=O)C(=C)C</smiles>

methacrylamido<smiles>[R]NC(=O)c1ccc(C=C)cc1</smiles>

Fig. 3. Chemical structures of vinyl groups used for preparation of hydrogels by chain-growth photopolymerization.

Although this chain-growth photopolymerization cross-linking strategy has been successfully applied to the preparation of numerous cell-laden hydrogels, careful consideration must be taken in choosing the photoinitiating conditions. Investigation of cytotoxicity of several photoinitiators $[37,161,162]$ found cell viability in their presence to be dependent on cell types and cell division rate. Irgacure 2959 (2-hydroxy-1-(4-(2-hydroxyethoxy)phenyl)-2-methylpropan-1-one, Fig. 4) proved to be welltolerated by a broad range of mammalian cells, and is the most frequently-used photoinitiator for cell encapsulation.[38,51,163] Nevertheless, Fedorovitch et al. observed adverse effects of Irgacure 2959initiated photopolymerization on MSC monolayers.[164] Likewise, Rouillard et al. demonstrated that Irgacure 2959-photogenerated radical species were cytotoxic and led to cell viability below 70\%.[40] To overcome these issues, another UV-photoinitiator, lithium phenyl(2,4,6trimethylbenzoyl)phosphinate (LAP) was developed. Less toxic than Irgacure because of its absorbance in near-UV at $365 \mathrm{~nm}$, it is also highly soluble in water, yielding higher polymerization rates.[165,166] 
<smiles>CC(C)(O)C(=O)c1ccc(OCCO)cc1</smiles>

Irgacure 2959

$\lambda_{\text {max }}=280 \mathrm{~nm}$<smiles>Cc1cc(C)c(C(=O)P(=O)(O)c2ccccc2)c(C)c1</smiles>

LAP

$\lambda_{\text {max }}=365 \mathrm{~nm}$<smiles>O=C1OC2(c3ccccc31)c1cc(Br)c(O)c(Br)c1Oc1c2cc(Br)c(O)c1Br</smiles>

\section{Eosin $Y$}

$\lambda_{\text {max }}=524 \mathrm{~nm}$<smiles>Cc1cc2nc3c(=O)[nH]c(=O)nc-3n(CC(O)C(O)C(O)CO)c2cc1C</smiles>

Riboflavin

$\lambda_{\max }=450 \mathrm{~nm}$

Fig. 4. Structures of some photoinitiators used for hydrogel preparation by photopolymerization.

Another factor to be considered is the use of UV versus visible light. UV photons carry more energy than visible-light photons, which is why UV wavelengths were selected in the first instance for efficient photoactivation. Yet it is well-known that UV exposure can damage cells.[164,167] As a consequence, significant efforts have been made in developing visible light-initiated systems[168], usually using visible blue light. Eosin Y (Fig. 4) and triethanolamine have been used several times as photoinitiator and co-initiator respectively, sometimes with $\mathrm{N}$-vinylpyrrolidone (NVP) to accelerate gelation.[169,170] For instance, this initiator solution allowed the visible-light cross-linking of collagen methacrylamide.[44] Methacrylated glycol chitosan, obtained by reacting commercially available glycol chitosan with glycidyl methacrylate, was photocross-linked at 400-500 nm with the riboflavin photoinitiator.[46,47] Hoshikawa et al. described the photopolymerization of styrenemodified gelatin with camphorquinone photoinitiator.[171]

Cells can be damaged even when visible light is used to initiate the polymerization process. Indeed, during the chain-growth polymerization, molecular oxygen acts as a radical scavenger leading to the formation of reactive oxygen species (ROS). ROS are known to generate oxidative stress in cells.[172] J. J. Roberts and S. J. Bryant showed that chondrocytes exhibited high levels of intracellular ROS immediately after their encapsulation in a PEGDA hydrogel.[173] According to these authors, step-growth polymerization is preferred since this mechanism consumes ROS.

\subsubsection{Step-growth photopolymerization}

Step-growth photopolymerization requires two functional groups, a vinyl and a thiol. Thus, it is often referred to as thiol-ene photopolymerization.[174] The process can be initiated under similar experimental conditions to those of chain-growth photopolymerization (UV or visible light, same photoinitiators). Upon irradiation, the photoinitiator decomposes into free-radical species. A radical atracts a hydrogen atom from a thiol group to produce a thiyl radical that reacts with a double bond (Fig. 5). The resulting alkane radical attracts a hydrogen atom from another thiol group, thus forming a thioether bond, and regenerating a thiyl radical. The thiol-ene coupling and the thiyl radical 
generation occur alternatively in a stoichiometric ratio until one of the precursors is entirely consumed. When precursors are multi-functionalized, a 3D network with thioether linkages is formed.

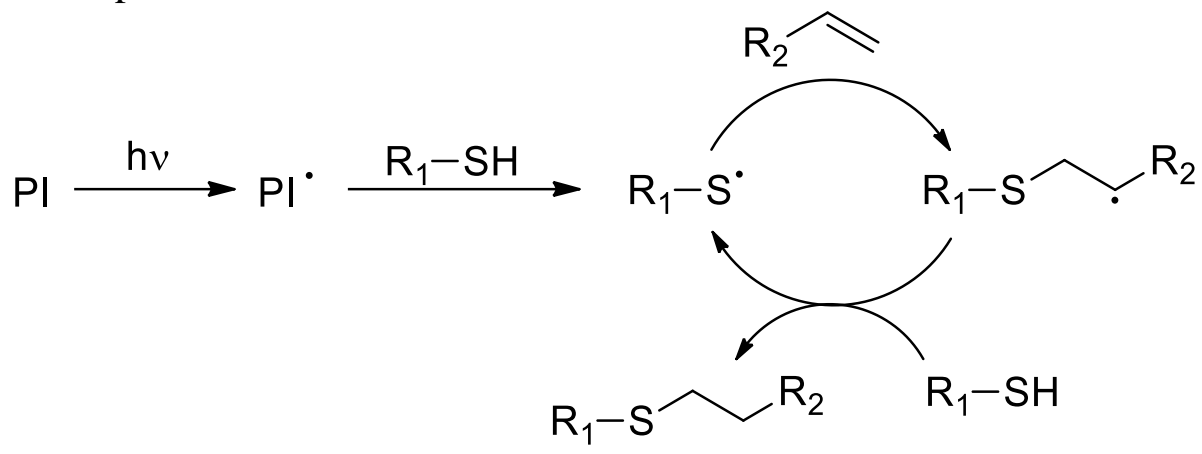

Fig. 5. Step-growth photopolymerization mechanism. PI: photoinitiator, hv: light source.

The radical-mediated process can be propagated by ROS which results in low ROS levels in the hydrogel. As a consequence, step-growth polymerization has been found to be cell-friendlier than chain-growth mechanism.[173,175] In addition, PEG hydrogels formed by step-growth mechanisms display superior physical properties than PEG hydrogels obtained by chain-growth mechanism. The resulting network is more homogeneous and has a higher functional group conversion.[175]

When (meth)acrylates are chosen as vinyl moieties for thiol-ene photopolymerization, the stepgrowth mechanism is no longer guaranteed and a mixed-mode photopolymerization can occur. In this case, the free-radical species formed by irradiation of the photonitiator can react both with the thiol and (meth)acrylate groups leading to a combination of step- and chain-growth polymerization. After studying the formation of thiol-acrylate networks through mixed-mode photopolymerization and investigating the mechanical properties and degradation behavior of the resulting hydrogels,[176] Anseth and co-workers applied this strategy to the encapsulation of human mesenchymal stem cells (hMSCs).[177] The hydrogel was obtained by mixed-mode photopolymerization of PEGDA with cell-adhesion peptides containing a cysteine. Hao et al. used the same strategy with visible-light irradiation.[178] In another study, these authors compared gelation kinetics when using different tetra-functionalized PEG (acrylate, methacrylate, acrylamide and allylether) in a mixed-mode thiolene polymerization.[179] More recently, hMSCs were cultured in a hydrogel obtained by visiblelight-mediated cross-linking of thiolated heparin and methacrylated hyaluronic acid.[180] The thiol functionalized heparin was prepared by converting carboxyl groups of heparin into thiol groups while methacrylate groups were introduced into hyaluronic acid by reaction with methacrylic anhydride. Alternatively, commercial thiolated hyaluronic acid has been cross-linked with hyper-branched PEGdiacrylate to encapsulate MSCs.[181] The primary alcohol functions of hyaluronic acid were reacted with pentenoic anhydride to yield pentenoate functionalized HA, which could be cross-linked with dithiothreitol after light irradiation at $312 \mathrm{~nm}$ of Irgacure 2959 allowing cell encapsulation.[182] HA functionalized with allyl glycidyl ether, was mixed with dithiothreitol and chondrocytes, to be 3D bioprinted by extrusion (followed by UV-irradiation) or DLP.[183]

To ensure a step-growth mechanism, a thiol-norbornene combination can be chosen for thiol-ene photopolymerization.[184] This system was developed by Fairbanks et al.[53] They first described the preparation of a proteolitically degradable hydrogel by step-growth photopolymerization of a norbornene-functionalized 4-arm PEG (Fig. 6) and a chymotrypsin-degradable peptide containing two cysteines. The norbornene moieties were introduced on PEG by coupling norbornene acid activated as a symmetrical anhydride. The thiol groups derived from the side-chains of the cysteines. hMSCs were successfully encapsulated in this hydrogel using Irgacure 2959 (Fig. 4) as the photoinitiator with irradiation at $352 \mathrm{~nm}$. Aziz et al. also used this type of hydrogel functionalized with a cysteine-bearing-RGD sequence, and cross-linked through dithiol-MMP-sensitive peptide sequences, for the encapsulation of hMSCs.[185] Lin et al. reported a similar system with irradiation at $365 \mathrm{~nm}$.[175] Ooi et al. also used $365 \mathrm{~nm}$ irradiation to cross-link alginate-norbornene with 
thiolated-PEG and thiolated-RGD, after extrusion-bioprinting.[165] The thiol-norbornene photopolymerization was then adapted for initiation with visible light.[186,187,55,56] In this system, homopolymerization between norbornenes does not happen which guarantees a step-growth mechanism. In numerous examples, bioactive peptides have been introduced into ene-funtionalized polymer networks taking advantage of the cysteine thiol group. The mirror reaction is also possible as demonstrated by reacting allyloxycarbonyl (Alloc) -protected amino-acids with thiolfunctionnalized star-PEG.[188]

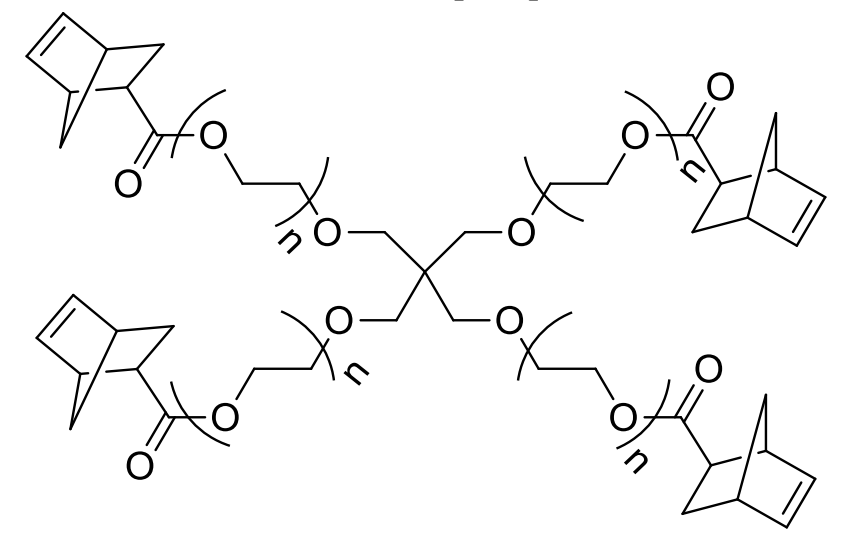

Fig. 6. 4-arm PEG norbornene.

Together, these examples all demonstrate the utmost importance of free-radical photopolymerization for the preparation of cell-laden biomimetic hydrogels. The main advantage of this cross-linking strategy is the spatial and temporal control over gelation kinetics. The main limitation of this method is the adverse effects on encapsulated cells. Whatever the polymerization mechanism (chain- or stepgrowth) and the wavelength used for irradiation, the radical species involved may interact with encapsulated cells and be detrimental to their survival and differentiation.

Also of interest is the covalent functionalization of hydrogels with bioactive molecules. It is theoretically possible to mix hydrogel precursors with either vinyl-modified or thiol-containing molecules to covalently attach these molecules to the network during its formation by photopolymerization. However, the immobilization efficiency of pendent mono-functionalized bioactive molecules on the cross-linked network is often rather low and the unreacted free bioactive molecules can lead to undesired biological responses. To overcome this issue, two separate chemistries have to be used: the first one to conjugate the bioactive molecule to multifunctional macromolecular precursor and the second one to cross-link these precursors.

\subsection{Click chemistry}

Click chemistry was first defined by Sharpless and co-workers in 2001.[189] Although this term immediately brings to mind the azide alkyne cycloaddition, it is not restricted to this reaction. Indeed, it refers to a whole class of modular reactions that rapidly proceed to completion with high selectivity for a single reaction product. These reactions are characterized by a high thermodynamic driving force. Insensitive to oxygen and water, they occur one-pot to provide the desired product in high yields. Only inoffensive by-products are formed. These criteria allow click reactions to occur in the presence of living systems without interfering with biological processes (bio-orthogonality) and thus made click reactions ideal candidates for biomimetic hydrogel preparation.[190-193] Amide-forming reactions, while extensively used to synthesize various bioconjugates through carboxylic acid activation (such as N-hydroxysuccinimidyl esters (NHS)), will not be discussed here, as they are not bioorthogonal. Indeed they should be avoided in the preparation of cell-encapsulating hydrogels, given that cells and the cell culture medium contain reactive amines. This theoretical requirement was not always taken into consideration as robust cells lines (HeLa and 3T3 fibroblasts) were encapsulated 
in polyamidoamine dendrimer cross-linked by PEG-NHS chemistry with rather good cell viability (80\%) after two days.[194]

\subsubsection{Michael-type addition}

Michael addition is the 1,4- addition of a nucleophile to an $\alpha, \beta$-unsaturated system (Fig. 7). This conjugate addition was discovered by Arthur Michael in 1887.[195] It involves a Michael donor, the nucleophile, and a Michael acceptor, the $\alpha, \beta$-unsaturated system. Enolates and amines can be used as Michael donors but thiols are preferred due to their higher nucleophilicity and selectivity under physiological conditions.[196,197] Michael acceptors are electron-deficient ene such as (meth)acrylates, acrylamides, vinyl sulfones and maleimides (Fig. 8). Although the Michael addition of a thiol precursor to an activated double bond yields a thioether, the reaction mechanism is completely different from the thiol-ene photopolymerization described above, which involves radical species.

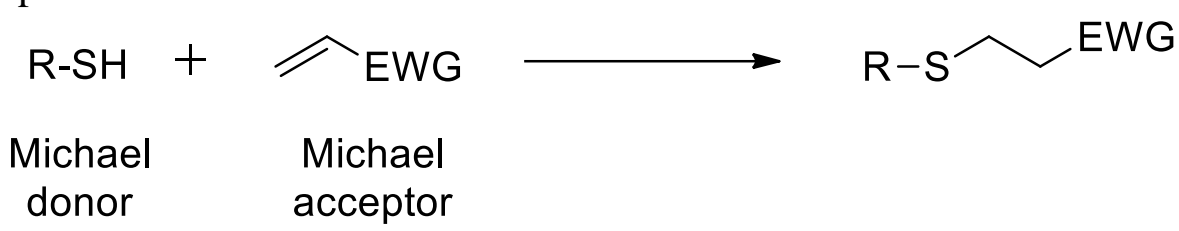

Fig. 7. Michael-type addition involving a thiol as the Michael donor. EWG: Electron-withdrawing group.<smiles>[R]OC(=O)C(=C)C</smiles>

methacrylates<smiles>[R]C(=O)C=C</smiles>

acrylates $(X=O)$ acrylamides $(X=\mathrm{NH})$<smiles>[R]S(=O)(=O)C=C</smiles>

vinyl sulfone maleimide

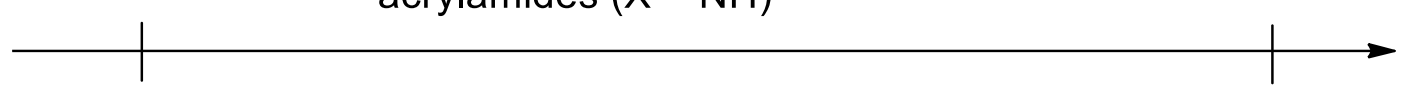

low REACTIVITY

high

Hubbell and colleagues pioneered the use of Michael-type additions to prepare cell-encapsulating hydrogels. They reported hydrogels resulting from the cross-linking of branched PEG multi-vinyl sulfone with a MMP-sensitive peptide containing two cysteines (e.g., Ac-GCRD-GPQG $\downarrow$ IWGQDRCG).[198,199] Vinyl sulfone groups were introduced by reacting divinylsulfone with PEG treated with sodium hydride. Acrylated polymers were also used as Michael acceptors to prepare hydrogels.[200] In particular, chondrocytes and embryonic stem cells were encapsulated in hydrogel formed by cross-linking thiol-functionalized dextran with a tetra-acrylated 4-arm PEG.[201] As another example, Zheng Shu et al. investigated the reaction of thiol-functionalized hyaluronan with PEG diacrylate, dimethacrylate, diacrylamide and dimethacrylamide in order to encapsulate fibroblasts.[202] More recently, Speidel et al. described the encapsulation of cardiac stem cells in a hydrogel made of 4-arm PEG cross-linked by heparin-binding peptides via Michael addition with cysteines.[203] To increase degradability, Stevens et al. introduced acrylate function in collagen through NHS-PEG-acrylate cross-linked in the presence of hMSCs, with thiolated MMP-degradable peptides.[204,205]

Triethanolamine and HEPES (2-[4-(2-hydroxyethyl)piperazin-1-yl]ethanesulfonic acid) have often been used as catalysts to facilitate the Michael addition reaction.[206] At high concentrations, these compounds might be toxic to cells. To overcome this issue, Garcia et al. investigated the reactivity of PEG maleimide, PEG vinyl-sulfone and PEG-acrylate as Michael acceptors. They demonstrated 
that PEG maleimide afforded the fastest reaction kinetics and required less triethanolamine to form a gel, resulting in a higher encapsulated cell viability.[58] They illustrated these results through the encapsulation of pancreatic islets in a hydrogel obtained by Michael addition of a cross-linking degradable peptide containing 2 cysteines on a 4-arm PEG tetra-maleimide (Fig. 9). In this example, the Michael addition chemistry was also used to functionalize the hydrogel with a cell-adhesion peptide and VEGF.[57] Recently, Lim et al. prepared an hydrogel from a cysteine-modified protein (modified gamma-prefoldin (SpyTag- $\gamma$ PFD-Cys)) cross-linked with a 4-arm PEG maleimide to encapsulate human embryonic stem cells.[207] The same strategy was used elsewhere, replacing the protein by thiolated hyaluronic acid and adding cysteine-containing adhesion peptides (RGD, IKVAV and YIGSR sequences). 3D culture of $\mathrm{H} 9$ human embryonic stem cells was performed in these gels.[208]

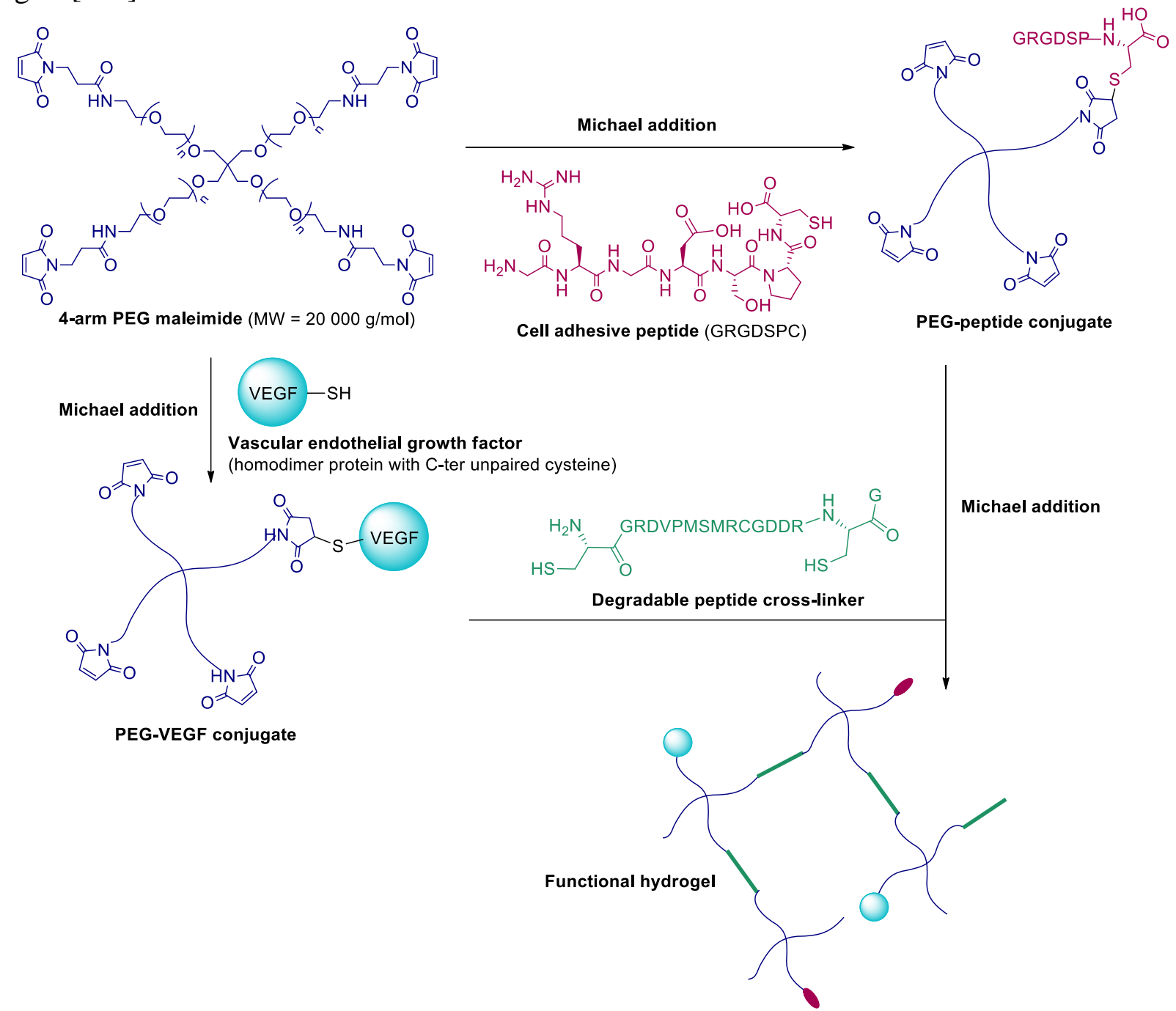

Fig. 9. Example of a functional hydrogel prepared by Michael addition.[57]

Baldwin and Kiick showed that the succinimide thioether linkage resulting from the Michael addition of thiols to maleimides could undergo retro and exchange reactions at physiological $\mathrm{pH}$ and temperature.[209] It is possible to stabilize the thioether linkage by opening the succinimide ring. Alternatively, the authors proposed taking advantage of these properties to control the release of a drug and to tune the degradability of the hydrogel.[59]

Although the thiol-Michael addition is attractive for the design of biomimetic hydrogels, a limitation of this strategy can arise from the use of thiol-functionalized molecules for in vivo gelation. Indeed, thiols are naturally occurring chemical groups. Thus, their administration in vivo can lead to undesired cross-reactivity, oxidation or metabolism. 


\subsubsection{Azide-alkyne cycloaddition}

Cycloaddition of monosubtituted alkynes and azides gives 1,2,3-triazoles. While the thermal Huisgen 1,3-dipolar cycloaddition often produces a mixture of two regioisomers, the copper(I)-catalyzed alkyne-azide cycloaddition (CuAAC) gives selectively 1,4-disubstituted regioisomers (Fig. 10).[210]

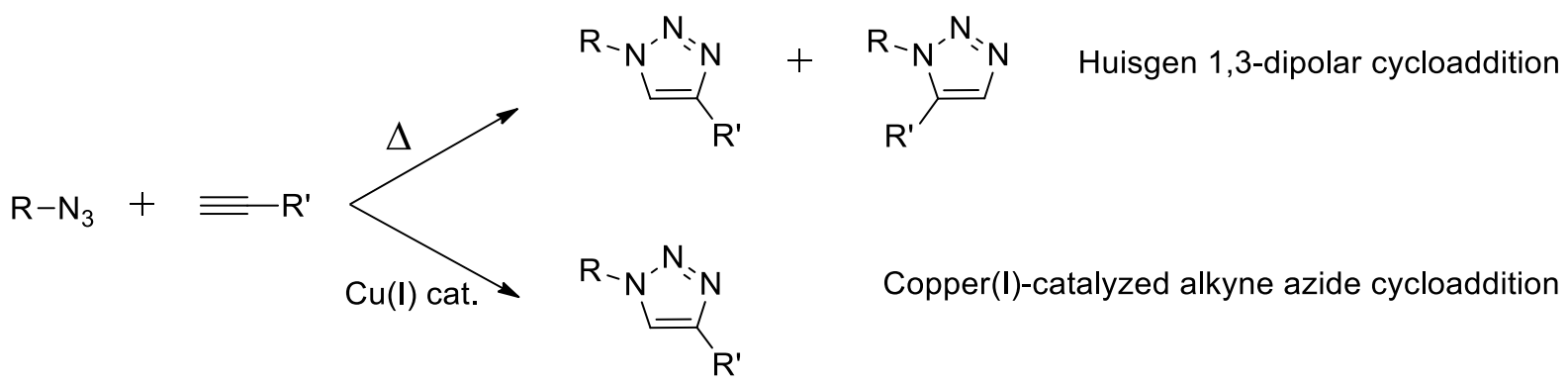

Fig. 10. Alkyne-azide cycloadditions yielding 1,2,3-triazoles.

This reaction can proceed under physiological conditions and is bio-orthorgonal since it involves two mutual reactive groups, azides and alkynes, which are not found naturally in living cells. $\mathrm{Cu}(\mathrm{I})$ species can be used directly to catalyze the reaction. Usually, however, the $\mathrm{Cu}(\mathrm{I})$ active catalyst is generated in situ from $\mathrm{Cu}(\mathrm{II})$ salts using a reducing agent such as sodium ascorbate. Alternatively, Adzima et al. demonstrated that $\mathrm{Cu}(\mathrm{II})$ could be photochemically reduced to $\mathrm{Cu}(\mathrm{I})$, affording spatial and temporal control over CuAAC-based gelations.[211] In contrast to the concerted Huisgen cycloaddition mechanism, CuAAc proceeds through a stepwise mechanism (Fig. 11).[212] It starts with the formation of a copper acetylide. Then, the azide binds to the copper acetylide and a sixmembered copper(III) metallacyle forms. Ring contraction to a triazolyl-copper derivative and protonolysis yield the 1,4-disubtituted 1,2,3-triazole derivative.

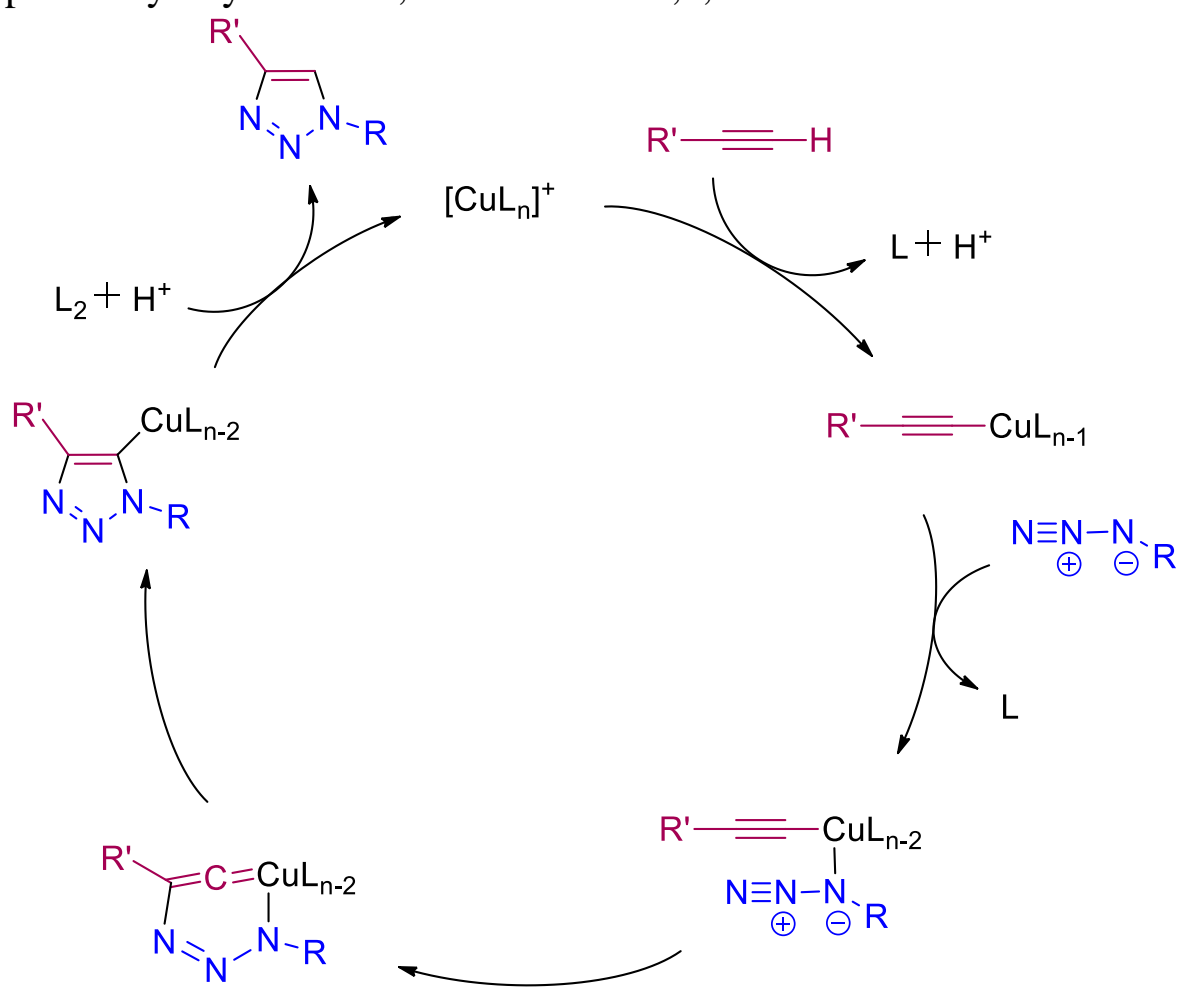

Fig. 11. Proposed mechanism for the Copper(I)-catalyzed alkyne-azide cycloaddition.[212] L: ligand, $\mathrm{H}_{2} \mathrm{O}$ for example. 
Ossipov and Hilborn were the first to apply CuAAC to the preparation of hydrogels using alkyne and azide-functionalized PVA and PEG.[213] Alkyne and azide groups were introduced on polymers by reaction with propargylamine derivatives and either 2-azidoethylamine or sodium azide respectively. Several hydrogels have been prepared with the CuAAC strategy,[214-218] but only Crescenzi et al. reported the encapsulation of cells in a CuAAC cross-linked hyaluronan hydrogel.[219] Indeed, the major limitation of $\mathrm{CuAAC}$ strategy is the cytotoxicity of copper ions and their ability to generate ROS in vivo.[220]

To avoid the use of toxic copper ions, an alternative, metal-free approach was developed in which ring strain was used to promote the azide-alkyne cycloaddition.[221] The reaction between a strained cyclooctyne and an azide, called strain-promoted alkyne-azide cycloaddition (SPAAC), proceeds under physiological conditions without additional reagent (Fig. 12).

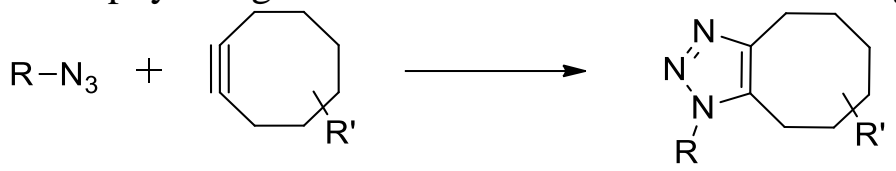

Fig. 12. Strain-promoted azide alkyne cycloaddition (SPAAC) between an azide and a cyclooctyne.

SPAAC has been successfully applied to the preparation of injectable hydrogels[60] and cellencapsulating hydrogels. DeForest and Anseth have worked extensively on SPAAC crosslinking.[61-66] In their system, gelation was achieved by a SPAAC reaction between a cyclooctynefunctionalized 4-arm PEG and a bis(azide)-functionalized peptide, $[63,64,66]$ or alternatively between a 4-arm PEG azide and a cyclooctyne-functionalized peptide.[61,62] For most of their studies,[6164] Deforest and co-workers chose a gem-difluoro cyclooctyne (DIFO, Fig. 13) since the presence of strong electron withdrawing fluorines enhanced the SPAAC kinetics and afforded a faster gelation.[222] Dibenzylcyclooctyne-functionalized PEG were also reported for hydrogel preparation allowing cell encapsulation.[67,68,65] Zhan et al. used a star-PEG-bicyclo[6.1.0]nonyne (BCN, Fig. 13) with a 4-arm-azide-star-PEG-containing MMP-sensitive sequences to create an enzymaticallydegradable hydrogel by a copper-free SPAAC, allowing encapsulation of HeLa cells. [69]

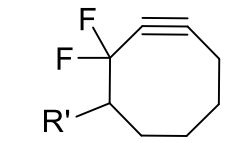

Difluorocyclooctyne (DIFO)

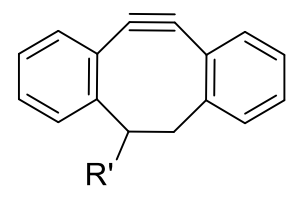

Dibenzylcyclooctyne

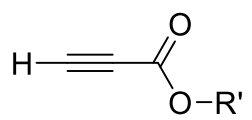

Propiolic ester

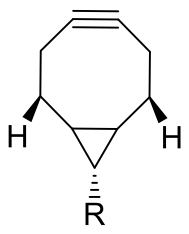

Bicyclo[6.1.0]nonyne $(\mathrm{BCN})$

Fig. 13. Structure of activated yne groups used for metal-free azide-alkyne cycloaddition.

The main limitation of the SPAAC cross-linking strategy comes from the synthesis of cyclooctyne derivatives that involves over 10 steps with a low overall yield. Recently, Truong et al. overcame this issue by taking advantage of the reaction of azides with propiolic esters (Fig. 13).[223] In propiolic esters, the triple bond is activated by the neighboring electron-withdrawing ester group. The electrondeficiency of the alkyne allowed the cycloaddition to proceed without catalyst. Truong et al. demonstrated that a cell-laden hydrogel could be obtained from 3-arm PEG propiolate and azidefunctionalized chitosan.[224] Proceeding under physiological conditions between two functions that are not found in the biomolecules of living organisms without any additional reagent, the cycloaddition between azides and propiolic esters appears to be a promising tool for biomimetic hydrogel preparation.

\subsubsection{Diels-Alder cycloaddition}

The Diels-Alder reaction (DA) refers to a [4+2] cycloaddition of a conjugated diene to a dienophile (Fig. 14). Ideally, it occurs between an electron-rich diene and an electron-deficient double bond. It was first reported in 1928 by Otto Diels and Kirk Alder.[225] The reaction is spontaneous under 
physiological conditions. Neither catalyst nor additional reagent is needed, and no by-product is formed. It proceeds through a concerted mechanism and the reaction rate is advantageously enhanced in water compared to organic solvents.[226,227]

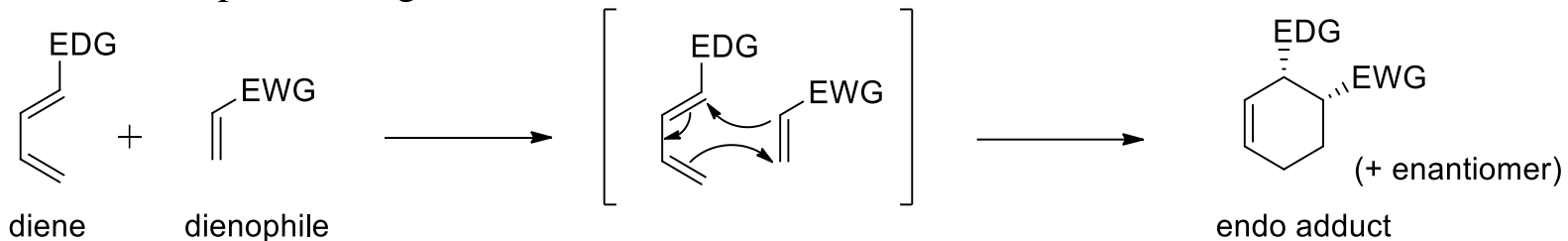

Fig. 14. Diels-Alder reaction. EDG: Electron-donating group, EWG: Electron-withdrawing group.

Furan and maleimide are the most commonly used diene and dienophile for the preparation of DielsAlder cross-linked hydrogels (Fig. 15).[71,72,76,228,73,74,229] Yu et al. functionalized hyaluronic acid (HA) with furylamine, after activation of HA carboxyl groups with (4,6-dimethoxy-1,3,5-triazin2-yl)-4-methylmorpholiniumchloride (DMTMM). The resulting HA-furan and the commercially available bis(maleimide)-PEG underwent Diels-Alder reaction in DPBS. Murine chondrocytic cells were successfully encapsulated during the process.[70]<smiles>[R]c1ccco1</smiles>

Fig. 15. Diels-Alder reaction between furane and maleimide moieties.

Furthermore, it has been shown that the Diels-Alder adducts were reversible, and that the equilibrium could be shifted towards the reverse Diels-Alder reaction under physiological conditions.[230] This reversibility was advantageously used to modulate the degradation of hydrogels, [75] to promote the controlled release of a drug[231,232] and to prepare self-healing hydrogels. [77]

The click Diels-Alder reaction with its reversibility seems attractive for the preparation of engineered biocompatible hydrogels. Yet, very few authors reported direct encapsulation of cells in the gels using the Diels-Alder strategy. This may be attributed to rather long gelation time (>50 min)[70]. Another limitation could arise from the reactivity of maleimide towards thiol-containing biomolecules in vivo, undergoing Michael-type 1,4-addition yielding thioether ligation products.

Notably, a second type of Diels-Alder cycloaddition was investigated as a coupling tool: the inverse electron demand Diels-Alder reaction.[233,234] This reaction involves an electron deficient diene and an electron rich dienophile to yield a formal [4+2] Diels-Alder adduct (Fig. 16). 1,2,4,5Tetrazines are the most popular dienes for this reaction. In the presence of strained dienophiles such as norbornene or trans-cylooctene, they undergo an inverse electron demand hetero-Diels-Alder reaction, instantly followed by a retro Diels-Alder reaction releasing nitrogen (Fig. 17).

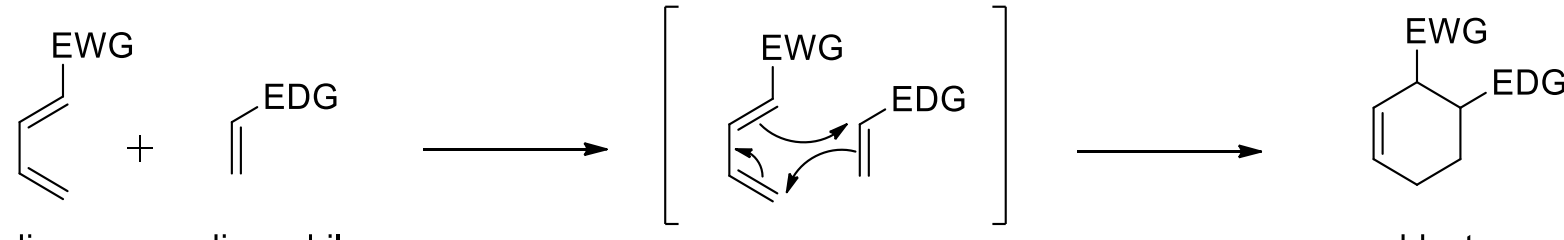

diene dienophile

adduct

Fig. 16. Inverse electron demand Diels-Alder reaction. EDG: Electron-donating group, EWG: Electron-withdrawing group.

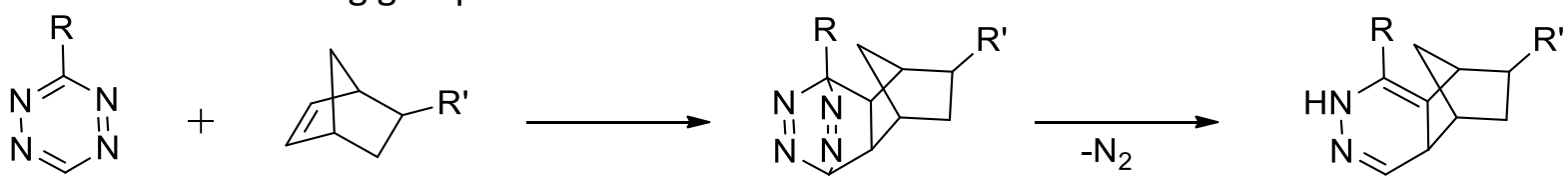


Fig. 17. Tetrazine-norbornene inverse electron demand hetero Diels-Alder-retro-Diels-Alder cascade.

Anseth and fellow researchers applied the inverse electron demand Diels-Alder reaction to the preparation of cell-encapsulating hydrogels. The hydrogel formed within minutes from a multi-arm PEG tetrazine and a cell degradable dinorbornene cross-linker peptide (norb-KGPQGIWGQKKnorb). When functionalized with a norbornene-bearing cell adhesion peptide, these hydrogels allowed the encapsulation of hMSC with high viability.[78] In another example, Jia and Fox encapsulated prostate cancer LNCaP cells in hydrogel microspheres by reacting tetrazine-modified hyaluronic acid with a bis-trans-cyclooctene cross-linker.[80] They also decorate this hydrogel with TCOfunctionnalized RGD and MMP-degradable peptides to create tunable hydrogel for hMSCs culture.[81] Zhang et al. also used tetrazine-modified HA, but cross-linked it with 4-arm PEG-transcyclooctene in the presence of bone marrow mesenchymal stem cells.[79]

\subsubsection{Native chemical ligation}

Native chemical ligation (NCL) was initially developed for polypeptide and protein syntheses.[235] This method allows the coupling of two unprotected peptide sequences through the formation of a peptide bond. Generally, the reaction occurs between a C-terminal thioester peptide and an N-terminal cysteine residue from the other peptide. The first step is a reversible, chemoselective and regioselective transthioesterification (Fig. 18). The thiol side-chain of the cysteine residue attacks the thioester to form a thioester intermediate. Then, an intramolecular $\mathrm{S} \rightarrow \mathrm{N}$-acyl shift results in the formation of a 'native' amide bond.

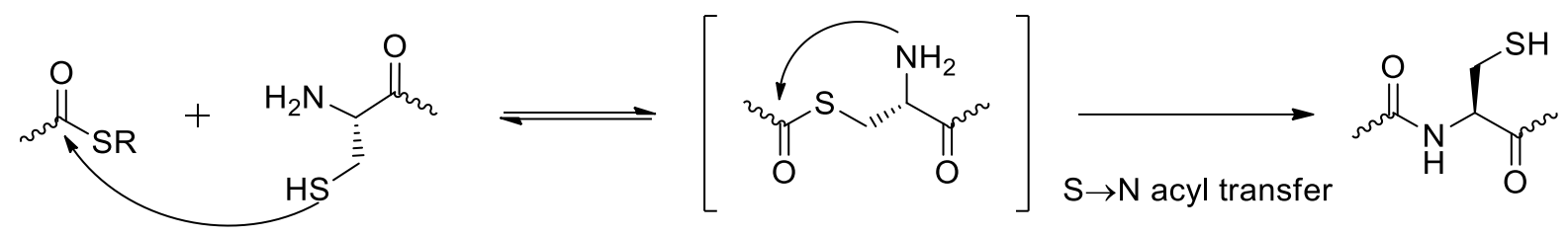

thioester N-ter cysteine

Fig. 18. Native chemical ligation.

Messersmith and co-workers were the first to describe hydrogels cross-linked by NCL.[82] They prepared thioester-terminated PEG by coupling ethyl 3-mercaptoproprionate succinic acid onto PEG amine. Cysteine-terminated PEGs were obtained by coupling either Boc-Cys(Trt)-OH or the dipeptide Boc-Cys(Trt)-AA-OH onto PEG amine followed by Boc removal in acidic conditions. Later on, they reported encapsulation of pancreatic islets and stem cells in these PEG-based hydrogels.[83,84] Notably, NCL ligation has also been used to chemically cross-link physical hydrogels.[236]

The oxo-ester mediated chemical ligation (OMNCL) was proposed as a variant of the NCL reaction, in which thioesters were replaced by activated oxo-esters such as para-nitrophenyl ester.[237] Messersmith and colleagues applied this reaction to the cross-linking of hydrogels.[238] They successfully encapsulated cells in an OMNCL cross-linked hydrogel. The hydrogel network resulted from the amide bond formation between 8-arm PEG functionalized with N-hydroxysuccinimide oxoesters and cysteines via an OMNCL reaction. However, due to the reactivity of the para-nitrophenyl ester, side products generated by direct nucleophilic addition of primary amino groups (lysine side chains, protein $\mathrm{N}$ terminus) were highly probable.

NCL is still under investigation as a cross-linking method. The hydrolytic instability of thioesters may be a limitation for its applications. In addition, the use of free sulfhydryl cysteine residues may require the presence of reducing agents to prevent formation of disulfide bonds. It may also lead to cross-reactions in vivo with cysteine-containing proteins, which are commonly present in the cell membrane. Last but not least, special attention has to be paid to the thiol leaving group that could generate adverse biological effects. 


\subsubsection{Imine, hydrazone and oxime formation}

Imines, hydrazones, acylhydrazones and oximes are formed through the reversible reaction of a carbonyl group (an aldehyde or a ketone) with an amino group (a primary amine, a hydrazine, a hydrazide or a hydroxylamine respectively) (Fig. 19). These reactions expand the toolbox of crosslinking strategies. Aldehydes are usually chosen as carbonyl groups because of their high reactivity towards nucleophiles compared to ketones.

A

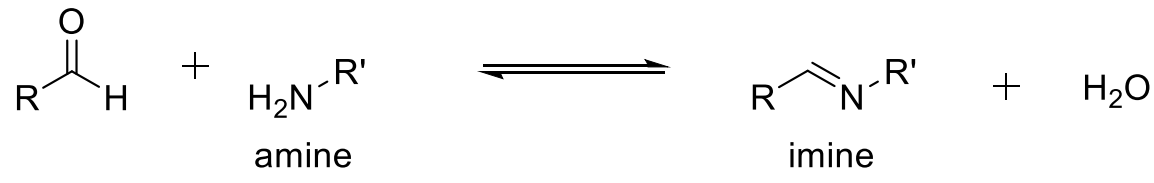

B

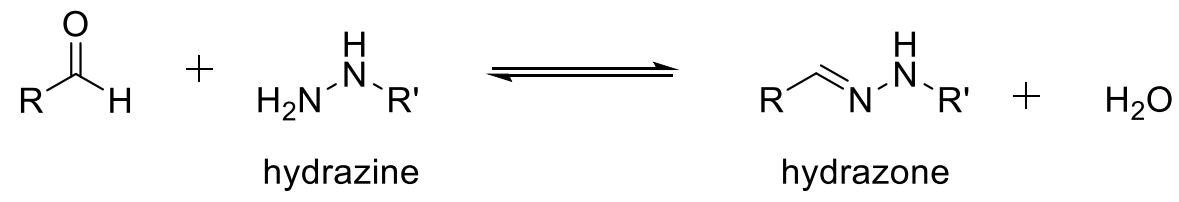

C
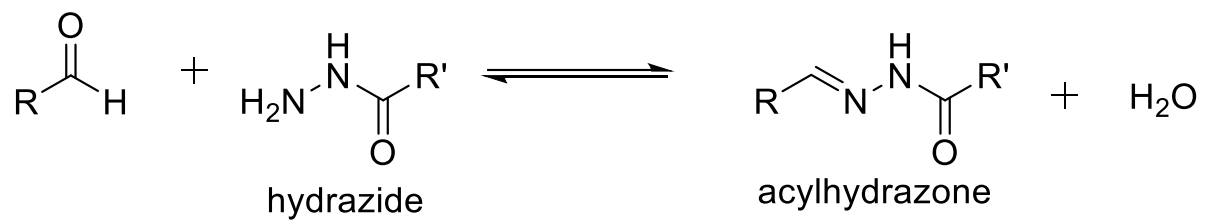

D
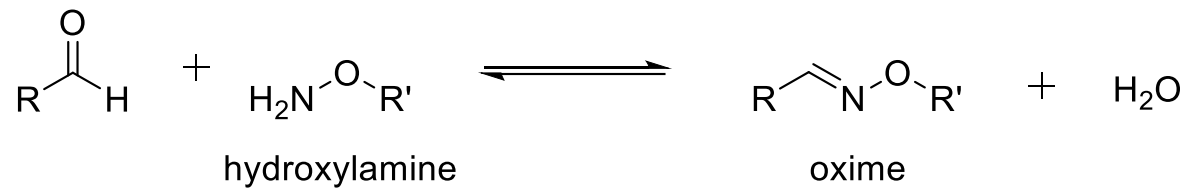

Fig. 19. Reaction of an aldehyde with a primary amine, a hydrazine, a hydrazide and a O-substituted hydroxylamine to form an imine, a hydrazine, an acylhydrazone and an oxime respectively.

Hydrogel preparation through imine formation, also known as Schiff's base formation, is limited by the low hydrolytic stability of imine bonds. Nevertheless, it has been investigated by several groups.[85,87,93,96,90,91,97,86,89] In particular, Tan et al. developed an imine cross-linked hydrogel for cartilage tissue engineering. The hydrogel was obtained from modified chitosan and aldehyde-functionalized HA.[94] Weng et al. described in situ gelable hydrogels by imine formation between aldehyde groups from oxidized dextran and amino groups from N-carboxyethyl chitosan.[88] Most of the time, imine cross-linked hydrogels involved aldehyde groups from an oxidized polysaccharide since such polysaccharides were easy to access. But synthetic aldehyde derivatives could also be used. For instance, Yang et al. reported an injectable cell therapy carrier hydrogel by cross-linking glycol chitosan with a bis(formyl)PEG.[92] Another injectable hydrogel obtained from aldehyde-modified poly(L-glutamic acid) and modified chitosan was described by Yin's team.[95,239]

Unfortunately, this strategy is not properly bio-orthogonal. Indeed, the nucleophile used is a primary amine which, as already stated in this manuscript, is commonly found in proteins (lysine side chains and $\mathrm{N}$ terminus). Thus, the use of more potent nucleophiles at physiological $\mathrm{pH}$ (hydrazines, hydrazides, $O$-substituted hydroxylamines) seems more attractive to increase the selectivity of the reaction, and minimize unwanted biological material-reagent side reactions.

(Acyl)hydrazone bonds exhibit higher hydrolytic stability than imines and thus afford a hydrogel degradation rate more compatible with drug delivery and tissue engineering applications.[240] Hydrazone and acylhydrazone cross-linking has been widely used for injectable hydrogel preparation.[107,109,113,241,114-116,99] As far as 3D culture systems are concerned, McKinnon et al. introduced a hydrogel to 3D culture mouse myoblasts made from hydrazine and aldehyde- 
modified multi-arm PEGs, in combination with an aldehyde-functionalized cell adhesion peptide (benzaldehyde-KGRGDS).[100] Then, they showed how this hydrogel could be used to study the biophysical forces involved in neurite extension.[98] Following the work of Ossipov et al.,[103] Martens and colleagues reported cell encapsulation in acylhydrazone cross-linked PVA or PVAheparin hydrogels.[102,242] Gurski et al. developed a 3D matrix for in vitro anti-cancer drug screening and the study of cancer cell motility. The system consisted of an acylhydrazone crosslinked HA hydrogel encapsulating cancer cells.[105,106] Wang et al. demonstrated the feasibility of 3D-bioprinting fibroblast encapsulated inside this hydrogel.[243] Many more examples of (acyl)hydrazone cross-linked hydrogels exist.[108,110,111,117,101,244-246] As a final illustration, we can mention the hydrogels developed by Dahlmann et al. for myocardial tissue engineering. They produced spontaneously contracting bio-artificial cardiac tissues by encapsulating neonatal rat heart cells in acylhydrazone cross-linked alginate-HA hydrogels containing human type I collagen.[112] Oxime bonds are close relatives to imines and hydrazones but they exhibit a higher hydrolytic stability.[247] They have received little attention as cross-linkages. Grover et al. worked on oxime cross-linked hydrogels.[118,119] They cross-linked an aminoxy-8arm-PEG with glutaraldehyde in the presence of a ketone-containing cell adhesion peptide (5-aminolevulinic acid-GRGDSPG). Although glutaraldehyde is known to be cytotoxic,[248,249] they showed that MSC could be encapsulated in this hydrogel with high viability.[118]

Due to their reversibility, imine, hydrazine, acylhydrazone and, to a lesser extent, oxime bonds are dynamic cross-links. They can provide self-healing properties to materials and enable a controlled degradation.[250] Aldehyde groups are preferred to ketones for their higher reactivity. However, because of this high reactivity, aldehydes can react in vivo with amines from biomolecules and lead to toxicity.

\subsubsection{Disulfide formation}

Disulfide bonds play a key role in protein folding and stability.[251,252] They result from the oxidation of two thiol groups (Fig. 20). Mild oxidizers, such as $\mathrm{O}_{2}$, are sufficient to drive the oxidative coupling. Thus, cross-linking of thiol-containing polymers can be achieved under physiological conditions with atmospheric oxygen. Prestwich and co-workers functionalized hyaluronic acid with dithiobis(propanoic dihydrazide) and dithiobis(butyric dihydrazide).[120,253] The initial disulfide bonds were reduced with dithiothreitol to give thiolated HA that could turn into a hydrogel upon oxidation of the thiols with air. They demonstrated that encapsulated L929 fibroblasts could proliferate in this disulfide cross-linked HA hydrogel.[120] Liu et al. used this hydrogel with addition of thiolated-icariin, a flavonoid facilitating the chondrogenesis of mesenchymal stem cells (MSCs).[254] Chitosan,[121] PEG[122] and gellan[124] were also modified by thiol moieties and cross-linked into hydrogels. Thiol groups were often introduced via the coupling of a cysteine residue. However, Swindle-Reilly et al. prepared hydrogels from thiolated poly(acrylamide) obtained by copolymerization of acrylamide and bisacryloylcystamine.[125]

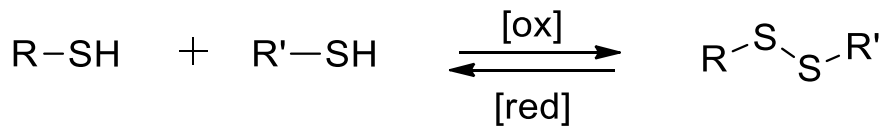

Fig. 20. Disulfide bond formation and reduction.

Cross-linking of hydrogels through oxidation of free thiols often requires long gelation times. Alternatively, polymers can be cross-linked via thiol-disulfide exchange reaction (Fig. 21).[255] This reaction is a nucleophilic substitution between a thiol and an activated disulfide that leads to the formation of a new disulfide and a thiol. Unlike the disulfide bond formation from sulfhydryl derivatives, this strategy ensures the formation of intermolecular linkages, avoiding the risk of intermolecular cyclized side products. Choh et al. used pyridyl-disulfide-modified HA and PEG 
dithiol to encapsulate several cell types in a disulfide cross-linked hydrogel.[256] In this case, cellular effects of thiols released during thiol-disulfide exchange reactions have to be carefully studied.

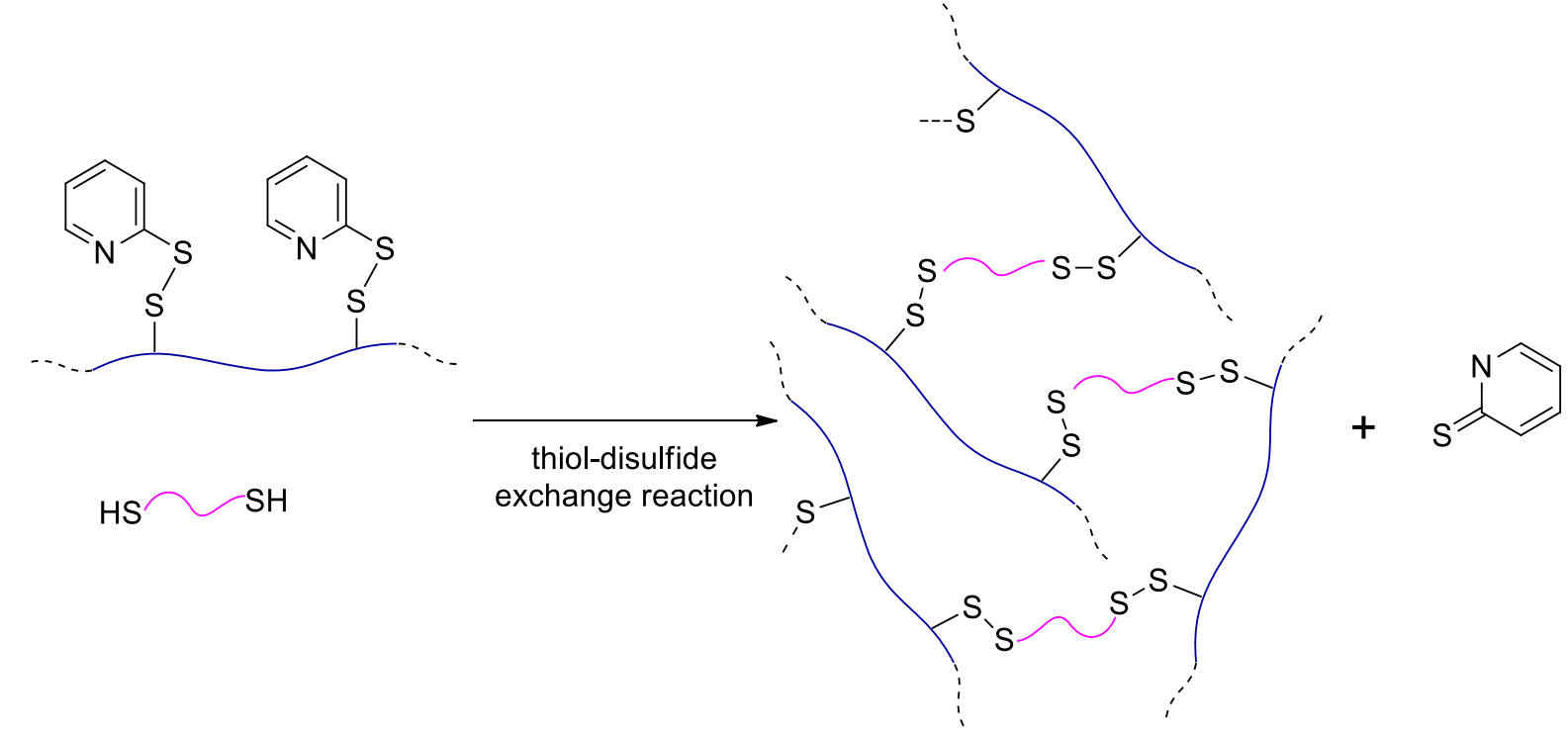

Fig. 21. Example of thiol-disulfide exchange reaction used by Choh and co-workers to prepare a hydrogel.[256]

Lee et al. showed that compression or tension applied to PEG hydrogels with disulfide linkages induced disulfide bond rupture. They took advantage of the compression-induced generation of free sulfhydryl groups to functionalize these hydrogels with a maleimide-containing fluorophore through a Michael-type addition.[123] Nonetheless, disulfide bond rupture in response to applied force could be limiting for applications of disulfide cross-linked hydrogels as ECM substitutes for tissues subjected to high physical forces. In addition, disulfide cross-linked hydrogels are rapidly reduced by glutathione [H-Glu(CysGlyOH)-OH], a naturally occurring anti-oxidant tripeptide synthesized in human cells. Therefore, they are more appropriate for short-term applications. As already mentioned for Michael-type additions and native chemical ligation, thiols can lead to cross-reactivity with proteins and peptides in vivo.

Overall, the application of click reactions to the cross-linking of hydrogels has led to ground- breaking development in the field of biomaterials. However, the design of cell-encapsulating hydrogels remains a challenge. Some other bio-orthogonal ligation reactions are only starting to be explored by a few groups. For instance, Stabler et al. worked on Staudinger ligation and showed that this reaction could be advantageously used to encapsulate pancreatic islets in alginate-PEG hydrogels.[257,258] Tamate and co-workers cross-linked a hydrogel through photoinduced dimerization of coumarin moieties.[259] Zong et al. have focused their efforts on tetrazole-alkene photo-click chemistry but have not yet proved that this method allows cell encapsulation.[260,261] Reversible covalent bonds such as phenylboronate-salicylhydroxamate cross-links and boronic ester bonds have also been sporadically investigated to design hydrogels with dynamic properties.[262]

\subsection{Enzyme-mediated cross-linking}

It is well known that enzymes catalyze specific reactions with high selectivity and efficiency. Their potential has been used in chemical synthesis as a convenient alternative to traditional organic chemistry.[263,264] As enzymes work under physiological conditions, they are suitable for biocompatible cross-linking strategies.[265] 
Enzymes can be used in two ways for hydrogel formation: either as a means to generate initiators in situ for free-radical polymerization of hydrogel precursors, or to catalyze specific covalent bond formation between two mutually reactive moieties displayed by hydrogel precursors.

\subsubsection{Enzyme-triggered free-radical polymerization}

The oxidation of glucose by the glucose oxidase enzyme (GOx) produces hydrogen peroxide. In the presence of $\mathrm{Fe}^{2+}$, hydrogen peroxide generates hydroxyl radicals that can initiate polymerization through the mechanism described above in section 2.2.1. (Fig. 22, pathway A). Bowman and Anseth used GOx to cross-link PEGDA.[266-268] This system was applied to the coating of cellencapsulating hydrogels but was never described as a cross-linking method to prepare cell-laden hydrogels.[267] Recently, Wei et al. combined two enzyme-mediated redox reactions in a single system (Fig. 22, pathway B). The hydrogen peroxide released by GOx oxidation of glucose was used by horseradish peroxidase (HRP) to oxidize acetyl acetone, a diketone mediator, as a ternary initiating system to trigger the radical-mediated polymerization of PEG methacrylate (Fig. 22).[269] In these cases, enzymes are not directly involved in the cross-linking process, they are used as initiators for chain-growth polymerization. In that sense, enzyme-triggered free-radical polymerization cannot be properly considered as an enzyme-mediated cross-linking method.

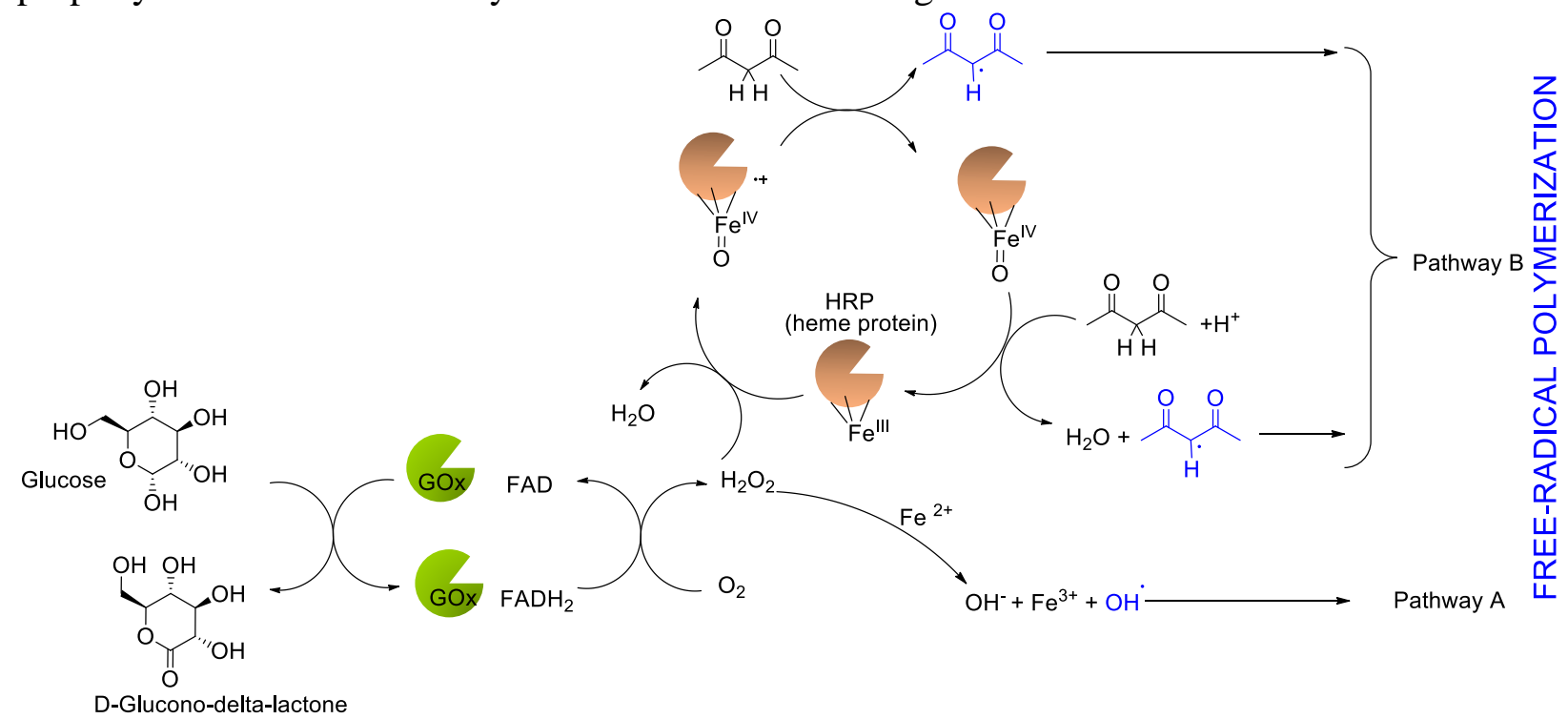

Fig. 22. Enzyme-mediated redox reactions triggering free-radical polymerization

\subsubsection{Enzyme-mediated ligation}

The potential of enzymes can more usefully be used to catalyze the reaction between two reactive groups leading to the formation of a cross-link.

Horseradish peroxidase (HRP), reported above for triggering free-radical polymerization, can also catalyze the oxidative coupling of phenol moieties in the presence of hydrogen peroxide. A crosslink is formed between two carbon-centered radicals at the ortho-position to the phenolic hydroxyl groups, or between an ortho-carbon radical and a phenolic hydroxyl group (Fig. 23). Wang et al. functionalized gelatin with 3-(4-hydroxyphenyl)propionic acid (HPA) (Fig. 24) and reported the encapsulation of hMSCs in a hydrogel formed by the HRP-catalyzed cross-linking of HPA groups.[270] Likewise, Menzies et al. prepared cell-laden hydrogels from branched-PEG-HPA.[271] Tyramine and tyrosine derivatives can also undergo HRP-mediated cross-linking.[272-274] For instance, Chen and co-workers encapsulated chondrocytes in a HRP cross-linked hydrogel obtained from carboxymethyl pullulan-tyramine and chondroitin sulfate-tyramine.[275] With the same strategy, human MSCs were encapsulated in a HRP cross-linked hyaluronan-tyramine hydrogel.[276] More recently, Nguyen et al. used $\mathrm{HRP} / \mathrm{H}_{2} \mathrm{O}_{2}$ to cross-link 8-arm PEG-norbornene with bis-cysteinebearing peptides in presence of murine NIH/3T3 fibroblasts.[277] 


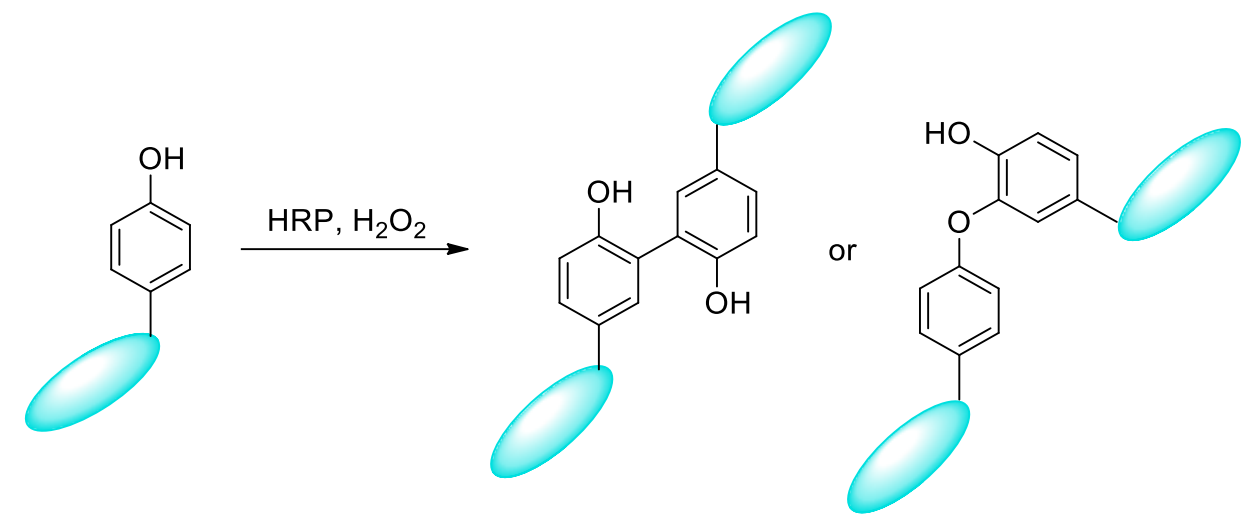

Fig. 23. Horseradish peroxidase (HRP)-mediated oxidative cross-linking of phenol derivatives.<smiles>O=C(O)CCc1ccc(O)cc1</smiles>

3-(4-hydroxyphenyl) propionic acid HPA<smiles>NCCc1ccc(O)cc1</smiles>

tyramine<smiles>N[C@@H](Cc1ccc(O)cc1)C(=O)O</smiles>

(L)-tyrosine<smiles>N[C@@H](Cc1ccc(O)c(O)c1)C(=O)O</smiles>

(L)-3,4-dihydroxyphenylalanine DOPA

Fig. 24. Chemical structures of carboxylic acid derivatives coupled to hydrogel precursors to enable enzyme-mediated oxidative cross-linking.

Tyrosinase is another oxidative enzyme able to cross-link phenol and catechol-functionalized molecules in the absence of hydrogen peroxide (Fig. 25). This is of interest given the adverse cellular effects of $\mathrm{H}_{2} \mathrm{O}_{2}$. However, few studies have investigated tyrosinase-mediated cross-linking for biomedical applications.[278-280] Das et al. reported the encapsulation of mesenchymal progenitor cells in a silk fibroin-gelatin hydrogel. In this study, mushroom tyrosinase was used to create crosslinks between tyrosine residues of silk and gelatin.[281] Tyramine and DOPA derivatives were also used to enable tyrosinase-mediated cross-linking.[278,280] Notably, the oxidative coupling of DOPA-bearing polymers can also be achieved with a chemical oxidant such as sodium periodate.[278,282-284] 


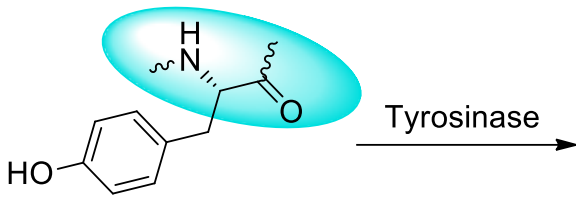

Tyrosine residue

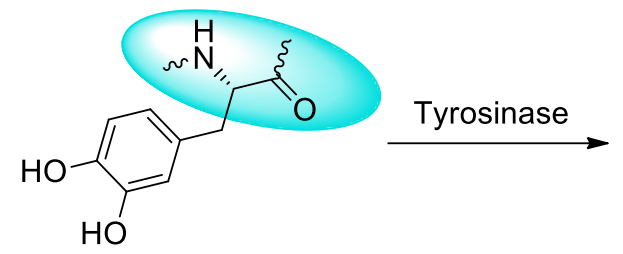

DOPA residue (catechol)

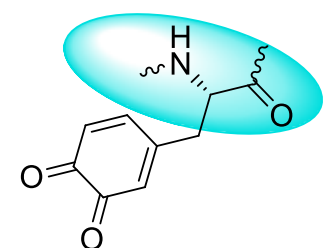

Quinone
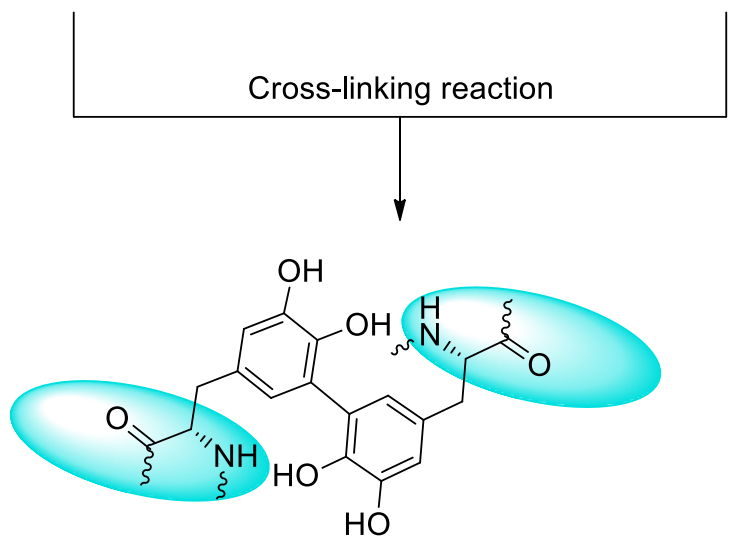

Fig. 25. Oxidative coupling of tyrosine residues by tyrosinase.

Transglutaminase (TG) cross-links peptides and proteins by catalyzing an acyl-transfer between the side-chain of a glutamine residue and the side-chain of lysine residue in the presence of its cofactor, $\mathrm{Ca}^{2+}$ ion (Fig. 26). This reaction is highly selective for the two substrates (i.e. the lysine containing sequence acting as acyl acceptor and the glutamine-containing peptide acting as acyl donor). Thus, macromolecules that are functionalized with two rationally designed TG substrates can be crosslinked by TG. This strategy was used by Hu and Messersmith, who conjugated TG peptide substrates with PEG chains and demonstrated hydrogel formation under physiological conditions.[285] Prior to this study, Sperinde and Griffith had already obtained TG cross-linked hydrogels from a glutaminamide-functionalized PEG and a poly(LysPhe) peptide.[286] McHale et al. reported chondrocyte encapsulation in an elastin-like polypeptide hydrogel with TG-mediated gelation.[287] A thermally responsive gelation system was developed by Sanborn and co-workers based on the controlled release of the enzyme cofactor. Calcium-loaded liposomes allowed TG activation only when the system temperature was raised to $37^{\circ} \mathrm{C}$, releasing the calcium ions during the phase transition of the liposome.[288] Finally, Ehrbar et al. engineered cell-laden hydrogels whose network was formed by combining different molecules functionalized with TG peptide substrates, in particular multi-arm PEGs, cell adhesion peptide and MMP-sensitive peptide.[289-291] Interestingly, the latter lent the resulting network tunable enzymatic degradation properties. With a different goal, Zhou et al. used TG to cross-link methacryloylated gelatin, to tune the rheological properties of a bioink encapsulating C2C12 Myoblasts before its extrusion and UV-cross-linking.[292] 


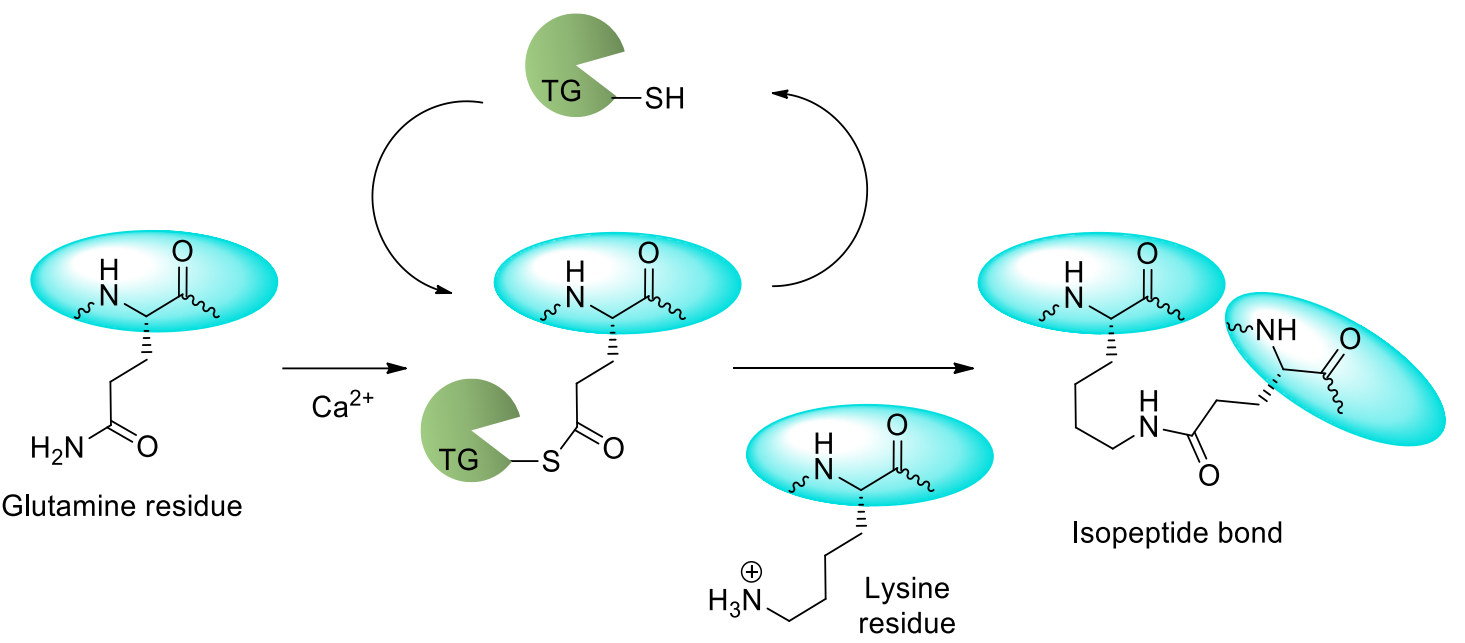

Fig. 26. Transglutaminase (TG)-catalyzed acyl transfer between glutamine and lysine side-chains.

Thrombin is an enzyme involved in the clotting reaction of blood. It has the ability to cleave the Nterminus part of its alpha and beta chains of fibrinogen, a hexameric glycoprotein, forming fibrinopeptides side products. This cleavage leads to the self-assembly of its D and E domains resulting in polymerization, turning it into fibrin fibers (Fig. 27). Cox et al. used this highly specific reaction to encapsulate dermal fibroblast[293], while Dare et al. used it to prepare hydrogels allowing chondrogenic differenciation.[294]

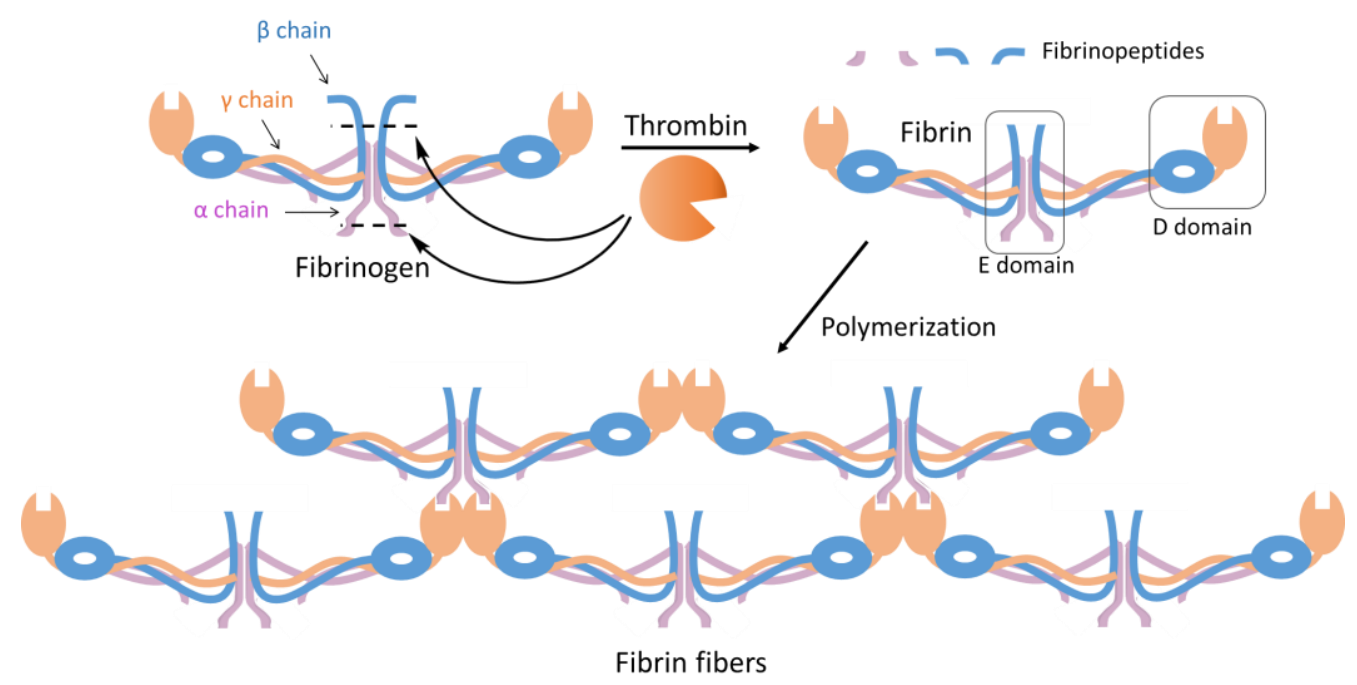

Fig. 27. Thrombin-catalyzed cleavage of fibrinogen yielding polymerization into fibrin.

Finally, the phosphopantetheinyl transferase (PPTase) was also successfully used for tissue engineering applications. This enzyme catalyzes the covalent attachment of the 4-phosphopantetheine moiety of coenzyme A (CoA) to a specific serine residue on the apo-acyl carrier protein (ACP) (Fig. 28). Hydrogels were formed from 3-arm PEG multi-functionalized with CoA and an engineered ACP dimer. The PPTase-mediated cross-linking was conducted in the presence of cells, demonstrating its biocompatibility.[295] 


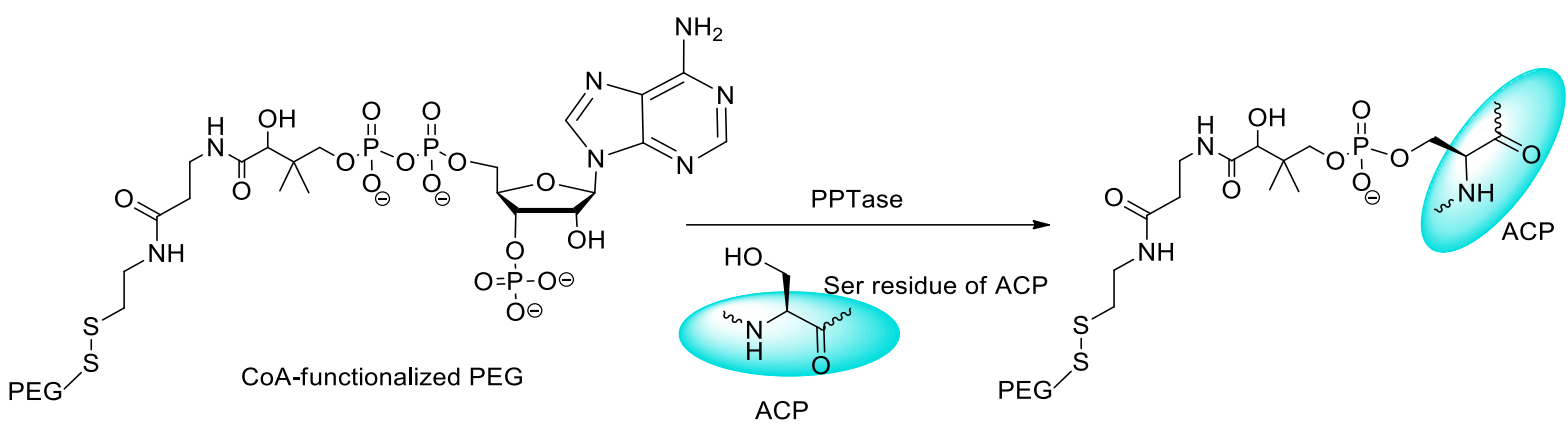

Fig. 28. Phosphopantetheinyl transferase (PPTase)-catalyzed reaction between serine residue of ACP and CoA-functionalized PEG.

Examples discussed in this section show that enzymes are well-suited for the cross-linking of hydrogels. Nevertheless, special attention must be paid to enzymes that work in an oxidative medium either because they require $\mathrm{H}_{2} \mathrm{O}_{2}$ or because they generate it.[296] In addition, the enzymes used for cross-linking are either not physiologically present in cell culture media or they are present in too low quantities to avoid their additional introduction during hydrogel formation. It implies that they could lead to immune responses and cross-reactions in vivo. Finally, diffusion of enzymes in the medium during the gelation process is limited, which often results in heterogeneous hydrogels with poor mechanical properties.

\subsection{Genipin-mediated cross-linking}

Genipin is an aglycone moiety derived from an iridoid glycoside extracted form Gardenia jasminoides' fruit. This natural molecule has the ability to spontaneously cross-link two amino groups of proteins or polysaccharides. When used at $0.5 \mathrm{mM}$ concentration and lower, it is considered biocompatible.[297] Interestingly, the reaction with amines occurs in physiological conditions without the need of any other reagent or catalyst. The genepin core is then included into the network, bridging two (bio)polymer chains (Fig. 29) and yielding a blue coloration due to the conjugate unsaturated bonds of the resulting bicycle. It is noteworthy that the reaction can be monitored by absorbance or fluorescence emission. [298] The mechanism proposed involves first the attack of the double bond of the dihydro-pyranol by an amine to give - after ring opening and water elimination an aldehyde and a secondary amine. Finally, the lone electron pair of the amine can react with the aldehyde leading to water elimination and dihydro-pyridine formation. At the same time, another amine of the biomolecule can attack the ester, resulting in an amide bond and methanol release.[299,300] Special attention must be paid to the number of equivalents used in the cross-linking reaction, avoiding increasing it by much, as the genipin may also dimerize.[299]

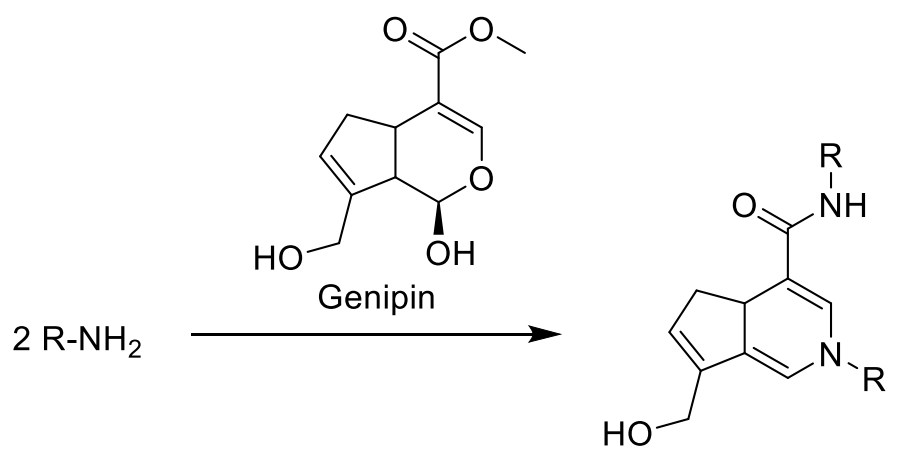

Fig. 29. Genipin cross-linking of two amine-bearing polymers. 
Cross-linking with genipin in the presence of cells has been done with chitosan,[301-303] fibrin,[304] and collagen[298]. All of these hydrogels were prepared for tissue engineering applications such as spinal cord injury repair[298] or cartilage regeneration[304].

\subsection{Sol-gel chemistry}

Pioneered in the $19^{\text {th }}$ century by Ebelmen[305,306] and Graham[307], the sol-gel process refers to an inorganic polymerization of molecular precursors to form an oxide network at low temperatures and under mild conditions. It is characterized by a transition from a sol (stable suspension of colloidal particles within a liquid) to a gel (3-dimensionnally interconnected solid network holding large amounts of solvent). Precursors are generally metal alkoxides among which silicon alkoxides, $\mathrm{Si}(\mathrm{OR})_{4}$, are the most commonly used. One strength of the sol-gel chemistry resides in its compatibility with many processing methods (e. g. spinning, dip coating, casting, spray-drying) that lead to a wide range of products: fibers, coatings, films, xerogels, aerogels, nanoparticles, etc. It enables the preparation of advanced tailor-made materials. [308] But its utmost attracting feature for the synthesis of materials containing fragile biomolecules is that the sol-gel process may proceed in water, at room temperature under mild conditions and in a very selective way (see 2.6.1). For this reason, it was given the label "Chimie douce" by Jacques Livage.[309] The silicon alkoxydes react together without affecting other chemical functions present in biomolecules. In that respect, sol-gel may be considered a bio-orthogonal reaction. Interestingly, homogeneous multi-component systems can be easily accessed by simply mixing different molecular precursors. Sol-gel was thus used to synthesize numerous hybrid inorganic/organic and bioorganic materials but its potential as an inorganic crosslinking method for cell encapsulation in hydrogels has only recently been explored.

\subsubsection{Mechanism of the sol-gel process: hydrolysis and condensation}

The sol-gel process is based on two steps, hydrolysis and condensation. It starts with the hydrolysis of alkoxysilyl groups (Si-OR) into silanols ( $\mathrm{Si}-\mathrm{OH}$ ) (Fig. 30, a). At neutral pH, this reaction is very slow (Fig. 31). However, acids, bases and nucleophiles can be used as catalysts to increase the reaction rate.

(a) $(\mathrm{RO})_{3}-\mathrm{Si}-\mathrm{OR}+\mathrm{H}_{2} \mathrm{O} \longrightarrow(\mathrm{RO})_{3}-\mathrm{Si}-\mathrm{OH}+\mathrm{R}-\mathrm{OH}$

$$
\begin{aligned}
&(\mathrm{RO})_{3}-\mathrm{Si}-\mathrm{OH}+(\mathrm{RO})_{3}-\mathrm{Si}-\mathrm{OH} \stackrel{\text { oxolation }}{\longrightarrow}(\mathrm{RO})_{3}-\mathrm{Si}-\mathrm{O}-\mathrm{Si}-(\mathrm{OR})_{3}+\mathrm{H}_{2} \mathrm{O} \\
&(\mathrm{RO})_{3}-\mathrm{Si}-\mathrm{OH}+(\mathrm{RO})_{3}-\mathrm{Si}-\mathrm{OR} \stackrel{\text { alkoxolation }}{\longrightarrow}(\mathrm{RO})_{3}-\mathrm{Si}-\mathrm{O}-\mathrm{Si}-(\mathrm{OR})_{3}+\mathrm{R}-\mathrm{OH}
\end{aligned}
$$

Fig. 30. (a) Overall equation of the hydrolysis of a silicon alkoxide into silanol. (b) Condensation reactions via oxolation or alkoxolation. 


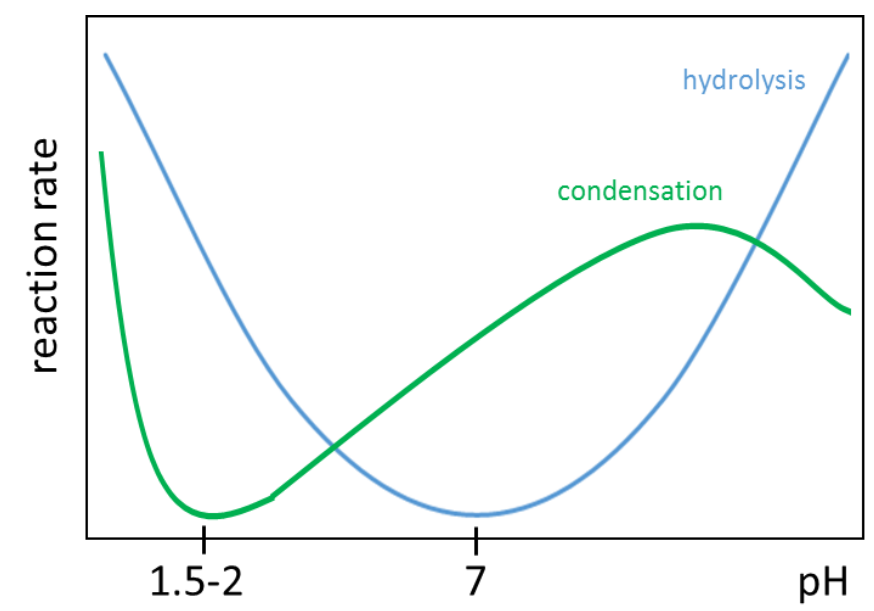

Fig. 31. Reaction rates of tetraethyl orthosilicate hydrolysis (blue curve) and condensation (green curve) as a function of $\mathrm{pH} .[310]$

In the acid-catalyzed process, an oxygen from an alkoxysilyl group is protonated (Fig. 28, a). This protonation increases the electrophilicity of the silicon atom and favors the nucleophilic attack of water. Furthermore, it makes $\mathrm{ROH}$ a better leaving group. Both effects contribute to a high hydrolysis rate. Under basic conditions, hydroxyl ions add to the silicon center to yield a penta-coordinate silicon intermediate with a negative charge (Fig. 28, b) which makes the silicon center more nucleophilic.[311] The product of hydrolysis results from the release of an alcoholate. The overall reaction rate is lower than the acid-catalyzed reaction. Alternatively, nucleophile catalysts can be used to accelerate the process at neutral or physiological $\mathrm{pH}$. Owing to their high affinity for silicon, fluorides hold a prime position as nucleophile catalysts for this reaction. The addition of a fluoride to a silicon atom produces a penta-coordinate silicon intermediate similar to the intermediate observed in the base-catalyzed reaction (Fig. 282, cErreur! Source du renvoi introuvable.). The pentacoordinate silicon is transformed into a hexa-coordinate silicon upon attack of a water molecule. The product of hydrolysis is formed upon release of an alcohol and regeneration of the fluoride catalyst.

(a)

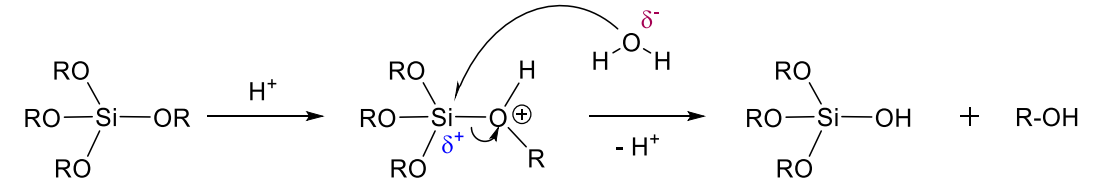

(b)

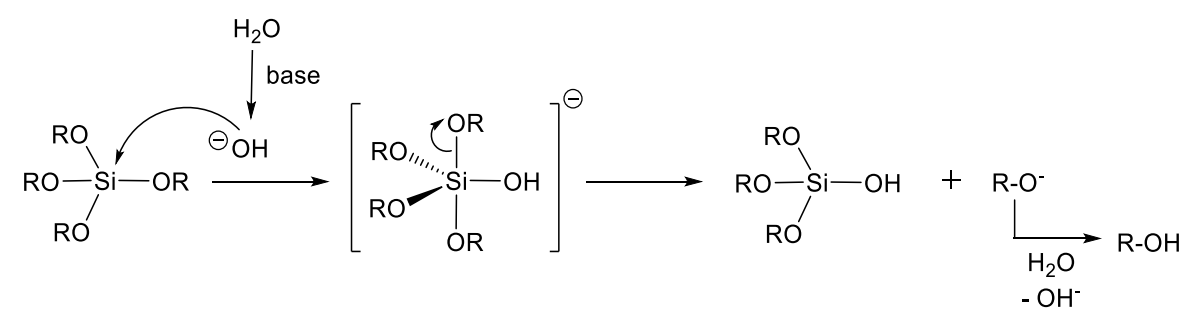

(c)

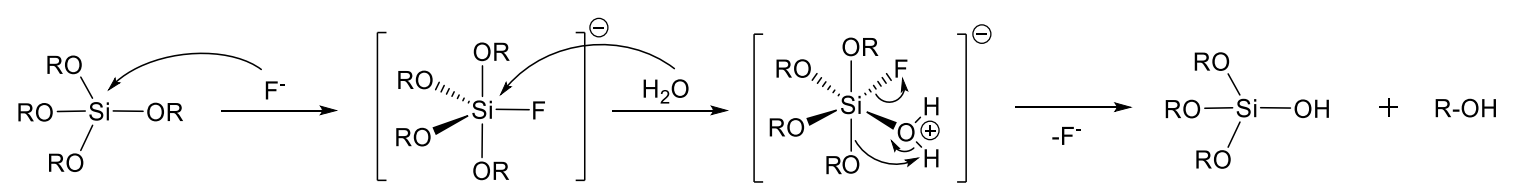

Fig. 282. Acid- (a), base- (b) and fluoride- (c) catalyzed hydrolysis of a silicon alkoxide group.

The precursor may undergo four successive hydrolyses until $\mathrm{Si}(\mathrm{OH})_{4}$ forms but as soon as one alkoxide group has been hydrolyzed, condensation can also start. 
The condensation step leads to the formation of siloxane bonds ( $\mathrm{Si}-\mathrm{O}-\mathrm{Si}$ ). When the condensation reaction occurs between two hydroxysilyl groups with release of water, it is called oxolation (Fig. 30, b). When it involves a hydroxide and an alkoxide with release of an alcohol, it is called alkoxolation. Acids, bases and nucleophiles can also catalyze the condensation step. The reaction mechanism is exactly the same than the mechanism of hydrolysis except that silanols and silanolates are the nucleophilic species instead of $\mathrm{H}_{2} \mathrm{O}$ and $\mathrm{HO}^{-}$under acidic and basic conditions respectively. Likewise, in the presence of fluorides, a penta-coordinate silicon fluoride is formed and evolves towards a hexacoordinate silicon center upon nucleophilic attack of a silanol. The condensation reaction ends with the release of $\mathrm{H}_{2} \mathrm{O}$ (oxolation) or $\mathrm{ROH}$ (alkoxolation) and the regeneration of the fluoride ion.

\subsubsection{Cell-encapsulation in hybrid hydrogels cross-linked by the sol-gel process}

The encapsulation of cells in sol-gel materials started with the embedment of yeast cells [312,313] and bacteria [314-317] in $\mathrm{SiO}_{2}$ hydrogels. Amorphous silica is considered non-toxic, being used commonly as an additive in food and drugs and recognized as safe (GRAS) by the American Food and Drug Administration. [318] Although it has also been demonstrated that animal cells encapsulated in sol-gel silica were viable,[313] in order to obtain a cell-friendly environment, it is important to keep the amount of silicon as low as possible to maximize the resemblance of the hydrogel with native ECM and limit the release of alcohol when alkoxide precursors are used. This can be achieved by using silicon atoms only as hydrogel cross-linkers. Precursors of such hydrogels are 'hybrid' molecules in the sense that they display both a (bio)organic moiety and inorganic alkoxysilane groups. They can be obtained by modifying covalently a (bio)polymer to introduce a trialkoxysilane moiety. In this case, the silicon atom is linked to the polymer via a C-Si bond. The network results from the formation of siloxane bonds (Fig. 3). Since the C-Si bond is hydrolytically stable, the network can be degraded either by hydrolysis of the siloxane bonds or by biodegradation of the backbone by pathways specific to each polymer. Depending on the chosen silylation reagent, the link between the polymer and the silylation reagent can also be specifically cleaved. Toxicity may arise from silylation reagents left unreacted in the hydrogel. To overcome this problem, it is possible to perform the modification of the polymer separately from the formation of the hydrogel. Washings between the two steps enable the elimination of free reagents and potential side-products.

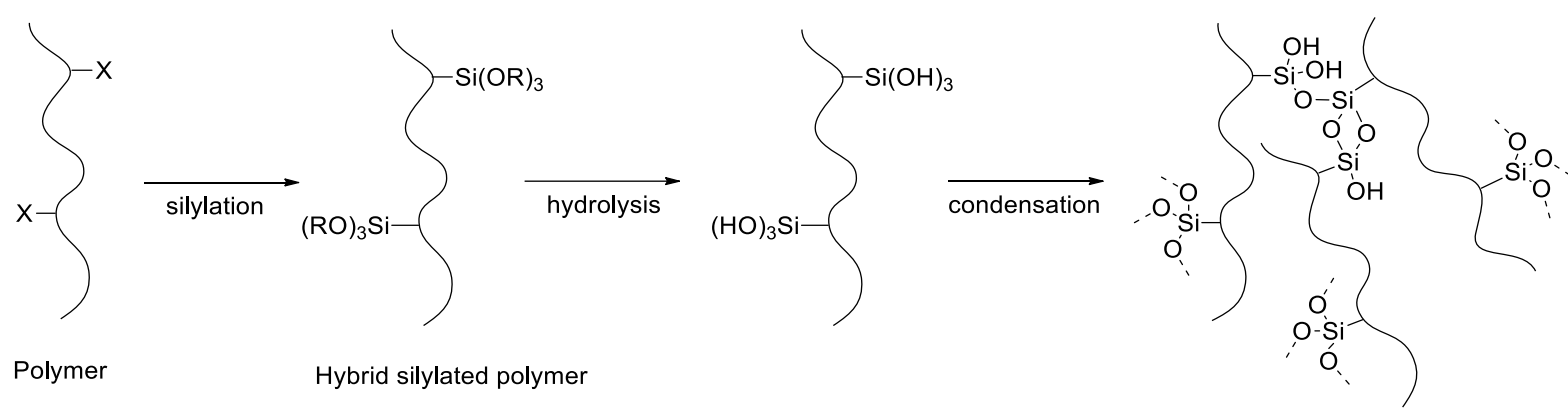

Fig. 33. Sol-gel cross-linking of a hybrid silylated polymer. X: reactive function of the polymer.

Hybrid precursors are obtained by covalent modification of polymers with alkoxysilane moieties (Fig. 343). The choice of silylation reagent depends on the available reactive functions (e.g. alcohol, amine, carboxylic acid) displayed by the polymer (Fig. 34). Jo and Park described the functionalization of the hydroxyl extremities of PEG and Pluronic F-127 (block copolymer $\mathrm{HO}-\left[\mathrm{CH}_{2} \mathrm{CH}_{2} \mathrm{O}\right]_{\mathrm{n}^{-}}$ $\left[\mathrm{CH}\left(\mathrm{CH}_{3}\right) \mathrm{CH}_{2} \mathrm{O}\right]_{\mathrm{m}}-\left[\mathrm{CH}_{2} \mathrm{CH}_{2} \mathrm{O}\right]_{\mathrm{n}}-\mathrm{H}$ with $\mathrm{n} \approx 98$ and $\mathrm{m} \approx 67$ ) with 3-isocyanatopropyl triethoxysilane (ICPTES), but they used a sol-gel procedure involving ethanol, acidic $\mathrm{pH}$ and solvent evaporation.[127] Our group proposed a different procedure to prepare hydrogels from ICPTESmodified PEG.[126] The process was catalyzed by fluoride and carried out at physiological $\mathrm{pH}$ in a phosphate buffer at $37^{\circ} \mathrm{C}$. Although the encapsulation of cells in these hydrogels during their 
formation was not investigated, this procedure was cell-friendlier than the one described by Jo and Park.<smiles>[R]O[Si]([R9])(CCCN=C=O)O[R]</smiles><smiles>[R]O[Si]([R])([R])CCCOCC1CO1</smiles><smiles>[Y]CC(O)COCCC[Si]([R20])([R])O[R6]</smiles><smiles>[R]O[Si]([R])(CCCN)O[R]</smiles><smiles></smiles>

Fig. 34. Functionalization of polymers with trialkoxysilylated reagents.

Silylated biopolymers such as gelatin[128,137,319,320], chitosan[131,132], collagen[133] or even alginate[134] were already used to prepare hydrogels. However, they were prepared in nonbiocompatible conditions and extensively washed after gelation or freeze-dried and re-swelled before being cell-seeded. Shirosaki et al. added GPTMS to chitosan in $0.25 \mathrm{M}$ acetic acid aqueous solution. These conditions allowed both the covalent modification of chitosan with a trimethoxysilane group and the acid-catalyzed hydrolysis of methoxy groups into hydroxyl groups. Under such acidic conditions, condensation was quite slow. Therefore, the solution was neutralized with sodium hydroxide to promote condensation. At this stage, the hybrid chitosan solution was injectable. A 2 wt $\%$ chitosan solution could turn into a gel at $37^{\circ} \mathrm{C}$ within few hours. This hydrogel was intended to be used as a resorbable vehicle for bone graft; however, even though it is biocompatible, it does not encapsulate cells.[130] Finally, Weiss and co-workers developed hybrid cellulose-based hydrogels. They functionalized different cellulose derivatives, in particular hydroxypropylmethylcellulose (HPMC), with either GPTMS or 3-glycidopropylmethyldiethoxysilane (GPMDS) via a Williamson reaction between the hydroxyl groups of the biopolymer and the epoxide.[321,322] In organic solvents, the cellulose derivatives were not soluble and the reaction occurred in heterogeneous medium. In order to increase modification homogeneity, these authors developed and patented a silylation method in homogeneous medium by using ionic liquids. [323] Their sol-gel procedure consisted of a hydrolysis step at $\mathrm{pH}>12.3$ and condensation upon neutralization. At high $\mathrm{pH}$, the hybrid polymer, named Si-HPMC, is in sodium silanolate form. The charge repulsion prevents condensation and allows the storage of the solution as a viscous liquid for a prolonged period. Condensation occurs upon neutralization at room or body temperature. They demonstrated that SiHPMC hydrogels could encapsulate chondrocytes and be injected for cartilage tissue repair.[135] Eventually, they used Si-HPMC as a base for the development of several materials for tissue regeneration.[140,139,324,137,325,138,141]

Recently, our group proposed a synthetic hydrogel obtained in one step by sol-gel polymerization of a silylated nonapeptide derived from the consensus collagen sequence [Pro-Hyp-Gly]. Three tripeptide repeats were used and flanked by two lysine residues whose side chains were modified by triethoxysilane groups (Fig. ). The size of the hybrid peptide was too small to expect formation of a triple helix, but long enough to adopt a well-defined PPII structure.[326] Sodium fluoride was used as a catalyst to induce both the condensation and the hydrolysis process, at physiological $\mathrm{pH}$ and 
$37^{\circ} \mathrm{C}$. Mesenchymal stem cells (MSC) were poured into the solution before gelation. Their viability was fully conserved after more than 24 hours, demonstrating that the short hybrid peptide was able to provide a cell-friendly environment. More recently, a silylated-HMPC based hydrogel obtained from an isolated silylated biopolymer precursor, was also used for direct cell encapsulation and allowed the extrusion-based 3D-bioprinting of stem cells with a good viability (T. Montheil et al., Sol-gel bioprinting, publication under consideration).

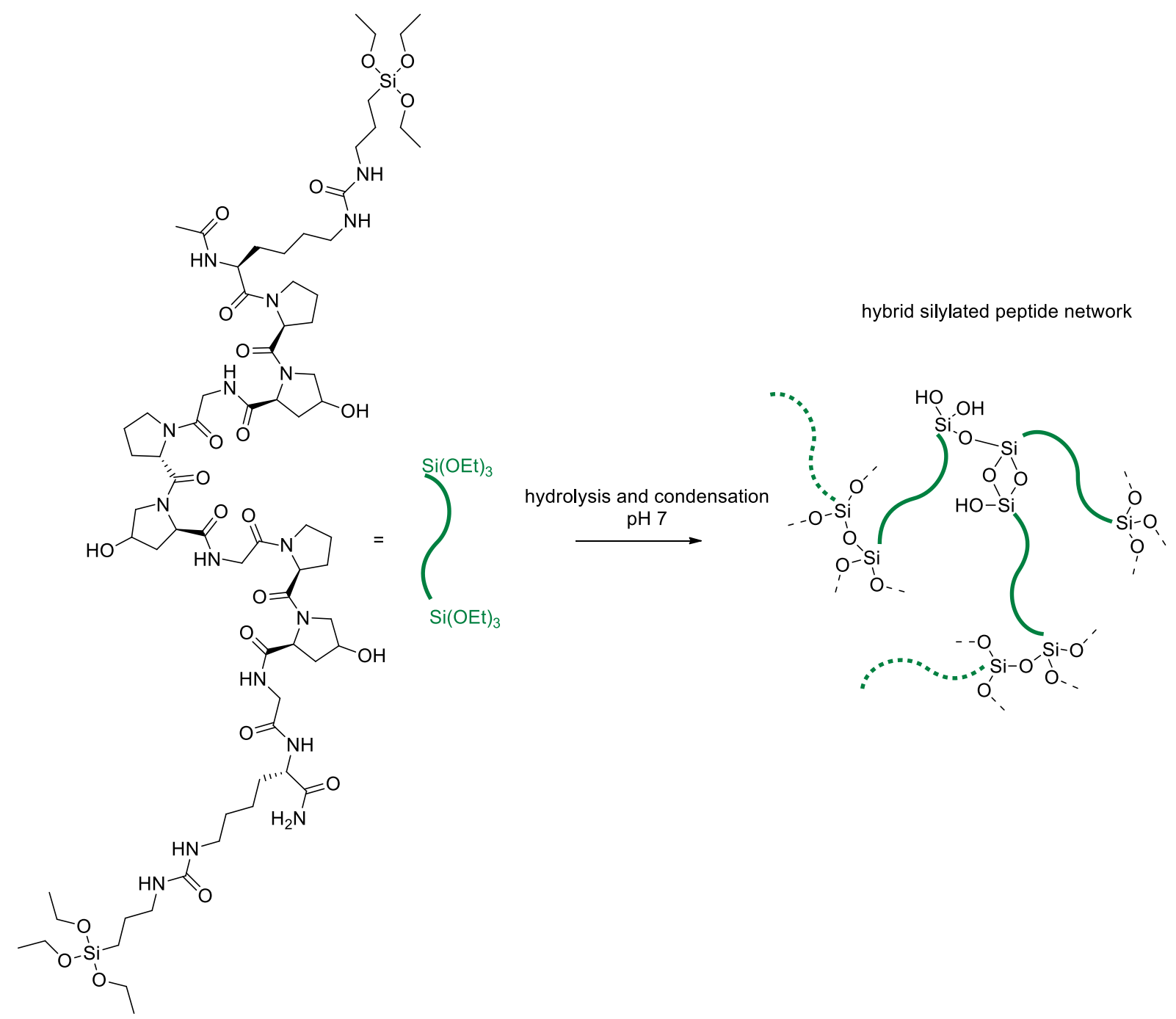

Fig. 35. Bisilylated hybrid peptide as precursor for a cell-containing, collagen-inspired chemical hydrogel.

\section{Conclusions and future direction}

Cell therapy is becoming one of the treatments of choice to repair damaged tissues, treat enzyme and hormone deficiencies, and fight cancers. Further developments in the field require the design of customized artificial biomimetic matrices providing cells adequate support but also communicating to them the signals they need to behave as required. So far, considerable efforts have been made to develop hydrogel scaffolds addressing a particular health issue. The development of more universal systems (i.e. applicable to each type of tissues) would be a significant breakthrough. To build up the hydrogel network with good control over the resulting physicochemical properties (density, biodegradability, hydrophilic/hydrophobic balance, etc.) and, at the same time, to decorate it with 
various cell-stimulating molecules, each starting building block has to be chemically modified with one or several 'clickable' moieties. This is where the greatest challenge for the chemist probably lies: the assembly process must preserve cell viability upon encapsulation, it should be simple enough to allow the combination of different building blocks at a chosen ratio and it should proceed, if possible, in a single or limited number of steps. In addition, chemistries compatible with different shaping procedures would be an asset. Indeed, injection of cell-laden hydrogels at the site of interest constitutes a minimally invasive treatment while 3D printing enables access to structurally complex scaffolds and in vivo cell delivery in a well-organized manner. The easy preparation of bioinks sharing the same reticulation chemistry but displaying different compositions in bioactive components would simplify the reconstitution of spatially non-homogeneous tissues.

\section{Acknowledgements}

C. Echalier's PhD was partly funded by the "Region Languedoc Roussillon", grant attributed to G. Subra, through the program 'Chercheur d'Avenir'.

L. Valot's PhD was funded by the ANR (Agence Nationale de la Recherche), the French National Research Agency (ANR-16-CE18-0003).

\section{References}

[1] R.P. Lanza, R.S. Langer, J. Vacanti, eds., Principles of tissue engineering, Fourth edition, Academic Press, an imprint of Elsevier, Amsterdam, 2014.

[2] C.A. van Blitterswijk, P. Thomsen, eds., Tissue engineering, Elsevier, Acad. Press, Amsterdam, 2008.

[3] A. Sivashanmugam, R. Arun Kumar, M. Vishnu Priya, S.V. Nair, R. Jayakumar, An overview of injectable polymeric hydrogels for tissue engineering, Eur. Polym. J. 72 (2015) 543-565. doi:10.1016/j.eurpolymj.2015.05.014.

[4] M. Patenaude, N.M.B. Smeets, T. Hoare, Designing Injectable, Covalently Cross-Linked Hydrogels for Biomedical Applications, Macromol. Rapid Commun. 35 (2014) 598-617. doi:10.1002/marc.201300818.

[5] H. Tan, K.G. Marra, Injectable, Biodegradable Hydrogels for Tissue Engineering Applications, Materials. 3 (2010) 1746-1767. doi:10.3390/ma3031746.

[6] T. Portnov, T.R. Shulimzon, M. Zilberman, Injectable hydrogel-based scaffolds for tissue engineering applications, Rev. Chem. Eng. 33 (2017). doi:10.1515/revce-2015-0074.

[7] A.D. Theocharis, S.S. Skandalis, C. Gialeli, N.K. Karamanos, Extracellular matrix structure, Adv. Drug Deliv. Rev. 97 (2016) 4-27. doi:10.1016/j.addr.2015.11.001.

[8] B. Yue, Biology of the Extracellular Matrix: An Overview, J. Glaucoma. (2014) S20-S23. doi:10.1097/IJG.0000000000000108.

[9] R.P. Mecham, ed., The extracellular matrix: an overview, Springer Verlag, Berlin ; New York, 2011.

[10] C. Frantz, K.M. Stewart, V.M. Weaver, The extracellular matrix at a glance, J. Cell Sci. 123 (2010) 4195-4200. doi:10.1242/jcs.023820.

[29] Adapted from Pearson Education, Inc., publishing as Benjamin Cummings.

[12] M.W. Tibbitt, K.S. Anseth, Hydrogels as extracellular matrix mimics for 3D cell culture, Biotechnol. Bioeng. 103 (2009) 655-663. doi:10.1002/bit.22361.

[13] H. Geckil, F. Xu, X. Zhang, S. Moon, U. Demirci, Engineering hydrogels as extracellular matrix mimics, Nanomed. 5 (2010) 469-484. doi:10.2217/nnm.10.12.

[14] B.V. Slaughter, S.S. Khurshid, O.Z. Fisher, A. Khademhosseini, N.A. Peppas, Hydrogels in Regenerative Medicine, Adv. Mater. 21 (2009) 3307-3329. doi:10.1002/adma.200802106.

[15] B.-S. Kim, I.-K. Park, T. Hoshiba, H.-L. Jiang, Y.-J. Choi, T. Akaike, C.-S. Cho, Design of artificial extracellular matrices for tissue engineering, Prog. Polym. Sci. 36 (2011) 238-268. doi:10.1016/j.progpolymsci.2010.10.001. 
[16] S.F. Badylak, D.O. Freytes, T.W. Gilbert, Extracellular matrix as a biological scaffold material: Structure and function, Acta Biomater. 5 (2009) 1-13. doi:10.1016/j.actbio.2008.09.013.

[17] H. Kim, H. Jeong, S. Han, S. Beack, B.W. Hwang, M. Shin, S.S. Oh, S.K. Hahn, Hyaluronate and its derivatives for customized biomedical applications, Biomaterials. 123 (2017) 155-171. doi:10.1016/j.biomaterials.2017.01.029.

[18] E.M. Ahmed, Hydrogel: Preparation, characterization, and applications: A review, J. Adv. Res. 6 (2015) 105-121. doi:10.1016/j.jare.2013.07.006.

[19] T. Andersen, P. Auk-Emblem, M. Dornish, 3D Cell Culture in Alginate Hydrogels, Microarrays. 4 (2015) 133-161. doi:10.3390/microarrays4020133.

[20] X. Du, J. Zhou, J. Shi, B. Xu, Supramolecular Hydrogelators and Hydrogels: From Soft Matter to Molecular Biomaterials, Chem. Rev. 115 (2015) 13165-13307. doi:10.1021/acs.chemrev.5b00299.

[21] P. Worthington, D.J. Pochan, S.A. Langhans, Peptide Hydrogels - Versatile Matrices for 3D Cell Culture in Cancer Medicine, Front. Oncol. 5 (2015). doi:10.3389/fonc.2015.00092.

[22] A. Dasgupta, J.H. Mondal, D. Das, Peptide hydrogels, RSC Adv. 3 (2013) 9117. doi:10.1039/c3ra40234g.

[23] T. Deming, ed., Peptide-Based Materials, Springer Berlin Heidelberg, Berlin, Heidelberg, 2012. http://link.springer.com/10.1007/978-3-642-27139-7 (accessed August 11, 2016).

[24] A.M. Jonker, D.W.P.M. Löwik, J.C.M. van Hest, Peptide- and Protein-Based Hydrogels, Chem. Mater. 24 (2012) 759-773. doi:10.1021/cm202640w.

[25] A. Altunbas, D.J. Pochan, Peptide-Based and Polypeptide-Based Hydrogels for Drug Delivery and Tissue Engineering, in: T. Deming (Ed.), Pept.-Based Mater., Springer Berlin Heidelberg, Berlin, Heidelberg, 2011: pp. 135-167. http://link.springer.com/10.1007/128_2011_206 (accessed August 11, 2016).

[26] X.-Q. Dou, C.-L. Feng, Amino Acids and Peptide-Based Supramolecular Hydrogels for ThreeDimensional Cell Culture, Adv. Mater. 29 (2017) 1604062. doi:10.1002/adma.201604062.

[27] M. Guvendiren, H.D. Lu, J.A. Burdick, Shear-thinning hydrogels for biomedical applications, Soft Matter. 8 (2011) 260-272. doi:10.1039/C1SM06513K.

[28] E.S. Dragan, Design and applications of interpenetrating polymer network hydrogels. A review, Chem. Eng. J. 243 (2014) 572-590. doi:10.1016/j.cej.2014.01.065.

[29] P. Matricardi, C. Di Meo, T. Coviello, W.E. Hennink, F. Alhaique, Interpenetrating Polymer Networks polysaccharide hydrogels for drug delivery and tissue engineering, Adv. Drug Deliv. Rev. 65 (2013) 1172-1187. doi:10.1016/j.addr.2013.04.002.

[30] R.I. Freshney, Culture of Animal Cells: A Manual of Basic Technique and Specialized Applications, John Wiley \& Sons, 2011.

[31] I.M. Garnica-Palafox, F.M. Sánchez-Arévalo, C. Velasquillo, Z.Y. García-Carvajal, J. GarcíaLópez, C. Ortega-Sánchez, C. Ibarra, G. Luna-Bárcenas, L. Solís-Arrieta, Mechanical and structural response of a hybrid hydrogel based on chitosan and poly(vinyl alcohol) cross-linked with epichlorohydrin for potential use in tissue engineering, J. Biomater. Sci. Polym. Ed. 25 (2014) 32-50. doi:10.1080/09205063.2013.833441.

[32] L. Wang, J.P. Stegemann, Glyoxal Crosslinking of Cell-Seeded Chitosan/Collagen Hydrogels for Bone Regeneration, Acta Biomater. 7 (2011) 2410-2417. doi:10.1016/j.actbio.2011.02.029.

[33] R. Yang, L. Tan, L. Cen, Z. Zhang, An injectable scaffold based on crosslinked hyaluronic acid gel for tissue regeneration, RSC Adv. 6 (2016) 16838-16850. doi:10.1039/C5RA27870H.

[34] E.M. Sletten, C.R. Bertozzi, Bioorthogonal Chemistry: Fishing for Selectivity in a Sea of Functionality, Angew. Chem. Int. Ed Engl. 48 (2009) 6974-6998. doi:10.1002/anie.200900942.

[35] C.-C. Lin, Recent advances in crosslinking chemistry of biomimetic poly(ethylene glycol) hydrogels, RSC Adv. 5 (2015) 39844-39853. doi:10.1039/C5RA05734E. 
[36] E. Bakaic, N.M.B. Smeets, T. Hoare, Injectable hydrogels based on poly(ethylene glycol) and derivatives as functional biomaterials, RSC Adv. 5 (2015) 35469-35486. doi:10.1039/C4RA13581D.

[37] I. Mironi-Harpaz, D.Y. Wang, S. Venkatraman, D. Seliktar, Photopolymerization of cellencapsulating hydrogels: Crosslinking efficiency versus cytotoxicity, Acta Biomater. 8 (2012) 1838-1848. doi:10.1016/j.actbio.2011.12.034.

[38] J.A. Burdick, K.S. Anseth, Photoencapsulation of osteoblasts in injectable RGD-modified PEG hydrogels for bone tissue engineering, Biomaterials. 23 (2002) 4315-4323. doi:10.1016/S0142-9612(02)00176-X.

[39] L.M. Weber, C.G. Lopez, K.S. Anseth, The effects of PEG hydrogel crosslinking density on protein diffusion and encapsulated islet survival and function, J. Biomed. Mater. Res. A. 90 (2009) 720-729. doi:10.1002/jbm.a.32134.

[40] A.D. Rouillard, C.M. Berglund, J.Y. Lee, W.J. Polacheck, Y. Tsui, L.J. Bonassar, B.J. Kirby, Methods for Photocrosslinking Alginate Hydrogel Scaffolds with High Cell Viability, Tissue Eng. Part C Methods. 17 (2011) 173-179. doi:10.1089/ten.tec.2009.0582.

[41] K.S. Masters, D.N. Shah, L.A. Leinwand, K.S. Anseth, Crosslinked hyaluronan scaffolds as a biologically active carrier for valvular interstitial cells, Biomaterials. 26 (2005) 2517-2525. doi:10.1016/j.biomaterials.2004.07.018.

[42] S. Wu, R. Xue, B. Duan, P. Jiang, Three-Dimensional Hyaluronic Acid Hydrogel-Based Models for In Vitro Human iPSC-Derived NPC Culture and Differentiation, J Mater Chem B. (2017). doi:10.1039/C7TB00721C.

[43] Q. Feng, S. Lin, K. Zhang, C. Dong, T. Wu, H. Huang, X. Yan, L. Zhang, G. Li, L. Bian, Sulfated hyaluronic acid hydrogels with retarded degradation and enhanced growth factor retention promote hMSC chondrogenesis and articular cartilage integrity with reduced hypertrophy, Acta Biomater. 53 (2017) 329-342. doi:10.1016/j.actbio.2017.02.015.

[44] W.T. Brinkman, K. Nagapudi, B.S. Thomas, E.L. Chaikof, Photo-Cross-Linking of Type I Collagen Gels in the Presence of Smooth Muscle Cells: Mechanical Properties, Cell Viability, and Function, Biomacromolecules. 4 (2003) 890-895. doi:10.1021/bm0257412.

[45] T. Nguyen, K.E. Watkins, V. Kishore, Photochemically Crosslinked Cell-laden Methacrylated Collagen Hydrogels with High Cell Viability and Functionality, J. Biomed. Mater. Res. A. (2019). doi:10.1002/jbm.a.36668.

[46] J. Hu, Y. Hou, H. Park, B. Choi, S. Hou, A. Chung, M. Lee, Visible light crosslinkable chitosan hydrogels for tissue engineering, Acta Biomater. 8 (2012) 1730-1738. doi:10.1016/j.actbio.2012.01.029.

[47] H. Park, B. Choi, J. Hu, M. Lee, Injectable chitosan hyaluronic acid hydrogels for cartilage tissue engineering, Acta Biomater. 9 (2013) 4779-4786. doi:10.1016/j.actbio.2012.08.033.

[48] S. Pahoff, C. Meinert, O. Bas, L. Nguyen, T.J. Klein, D.W. Hutmacher, Effect of gelatin source and photoinitiator type on chondrocyte redifferentiation in gelatin methacryloyl-based tissueengineered cartilage constructs, J. Mater. Chem. B. 7 (2019) 1761-1772. doi:10.1039/C8TB02607F.

[49] I. Noshadi, S. Hong, K.E. Sullivan, E. Shirzaei Sani, R. Portillo-Lara, A. Tamayol, S.R. Shin, A.E. Gao, W.L. Stoppel, L.D. Black III, A. Khademhosseini, N. Annabi, In vitro and in vivo analysis of visible light crosslinkable gelatin methacryloyl (GelMA) hydrogels, Biomater. Sci. 5 (2017) 2093-2105. doi:10.1039/C7BM00110J.

[50] D. Gan, T. Xu, W. Xing, M. Wang, J. Fang, K. Wang, X. Ge, C.W. Chan, F. Ren, H. Tan, X. $\mathrm{Lu}$, Mussel-inspired dopamine oligomer intercalated tough and resilient gelatin methacryloyl (GelMA) hydrogels for cartilage regeneration, J. Mater. Chem. B. 7 (2019) 1716-1725. doi:10.1039/C8TB01664J.

[51] S.J. Bryant, R.J. Bender, K.L. Durand, K.S. Anseth, Encapsulating chondrocytes in degrading PEG hydrogels with high modulus: Engineering gel structural changes to facilitate 
cartilaginous tissue production, Biotechnol. Bioeng. 86 (2004) 747-755. doi:10.1002/bit.20160.

[52] S.J. Bryant, K.A. Davis-Arehart, N. Luo, R.K. Shoemaker, J.A. Arthur, K.S. Anseth, Synthesis and Characterization of Photopolymerized Multifunctional Hydrogels: Water-Soluble Poly(Vinyl Alcohol) and Chondroitin Sulfate Macromers for Chondrocyte Encapsulation, Macromolecules. 37 (2004) 6726-6733. doi:10.1021/ma0499324.

[53] B.D. Fairbanks, M.P. Schwartz, A.E. Halevi, C.R. Nuttelman, C.N. Bowman, K.S. Anseth, A Versatile Synthetic Extracellular Matrix Mimic via Thiol-Norbornene Photopolymerization, Adv. Mater. Deerfield Beach Fla. 21 (2009) 5005-5010. doi:10.1002/adma.200901808.

[54] H. Shih, C.-C. Lin, Cross-Linking and Degradation of Step-Growth Hydrogels Formed by Thiol-Ene Photoclick Chemistry, Biomacromolecules. 13 (2012) 2003-2012. doi:10.1021/bm300752j.

[55] D.D. McKinnon, A.M. Kloxin, K.S. Anseth, Synthetic hydrogel platform for threedimensional culture of embryonic stem cell-derived motor neurons, Biomater. Sci. 1 (2013) 460-469. doi:10.1039/C3BM00166K.

[56] F. Li, V.X. Truong, H. Thissen, J.E. Frith, J.S. Forsythe, Microfluidic Encapsulation of Human Mesenchymal Stem Cells for Articular Cartilage Tissue Regeneration, ACS Appl. Mater. Interfaces. 9 (2017) 8589-8601. doi:10.1021/acsami.7b00728.

[57] E.A. Phelps, K.L. Templeman, P.M. Thulé, A.J. García, Engineered VEGF-releasing PEGMAL hydrogel for pancreatic islet vascularization, Drug Deliv. Transl. Res. 5 (2015) 125-136. doi:10.1007/s13346-013-0142-2.

[58] E.A. Phelps, N.O. Enemchukwu, V.F. Fiore, J.C. Sy, N. Murthy, T.A. Sulchek, T.H. Barker, A.J. García, Maleimide Cross-Linked Bioactive PEG Hydrogel Exhibits Improved Reaction Kinetics and Cross-Linking for Cell Encapsulation and In Situ Delivery, Adv. Mater. 24 (2012) 64-70. doi:10.1002/adma.201103574.

[59] A.D. Baldwin, K.L. Kiick, Reversible maleimide-thiol adducts yield glutathione-sensitive poly(ethylene glycol)-heparin hydrogels, Polym. Chem. 4 (2012) 133-143. doi:10.1039/C2PY20576A.

[60] H. Jiang, S. Qin, H. Dong, Q. Lei, X. Su, R. Zhuo, Z. Zhong, An injectable and fast-degradable poly(ethylene glycol) hydrogel fabricated via bioorthogonal strain-promoted azide-alkyne cycloaddition click chemistry, Soft Matter. 11 (2015) 6029-6036. doi:10.1039/C5SM00508F.

[61] C.A. DeForest, B.D. Polizzotti, K.S. Anseth, Sequential Click Reactions for Synthesizing and Patterning 3D Cell Microenvironments, Nat. Mater. 8 (2009) 659-664. doi:10.1038/nmat2473.

[62] C.A. DeForest, E.A. Sims, K.S. Anseth, Peptide-Functionalized Click Hydrogels with Independently Tunable Mechanics and Chemical Functionality for 3D Cell Culture, Chem. Mater. 22 (2010) 4783-4790. doi:10.1021/cm101391y.

[63] C.A. DeForest, K.S. Anseth, Cytocompatible Click-based Hydrogels with DynamicallyTunable Properties Through Orthogonal Photoconjugation and Photocleavage Reactions, Nat. Chem. 3 (2011) 925-931. doi:10.1038/nchem.1174.

[64] C.A. DeForest, K.S. Anseth, Photoreversible Patterning of Biomolecules within Click-Based Hydrogels, Angew. Chem. Int. Ed Engl. 51 (2012) 1816-1819. doi:10.1002/anie.201106463.

[65] D.D. McKinnon, T.E. Brown, K.A. Kyburz, E. Kiyotake, K.S. Anseth, Design and Characterization of a Synthetically Accessible, Photodegradable Hydrogel for User-Directed Formation of Neural Networks, Biomacromolecules. 15 (2014) 2808-2816. doi:10.1021/bm500731b.

[66] C.A. DeForest, D.A. Tirrell, A photoreversible protein-patterning approach for guiding stem cell fate in three-dimensional gels, Nat. Mater. 14 (2015) 523-531. doi:10.1038/nmat4219.

[67] J. Xu, T.M. Filion, F. Prifti, J. Song, Cytocompatible Poly(ethylene glycol)-co-polycarbonate Hydrogels Cross-Linked by Copper-Free, Strain-Promoted Click Chemistry, Chem. - Asian J. 6 (2011) 2730-2737. doi:10.1002/asia.201100411. 
[68] J. Zheng, L.A. Smith Callahan, J. Hao, K. Guo, C. Wesdemiotis, R.A. Weiss, M.L. Becker, Strain-Promoted Cross-Linking of PEG-Based Hydrogels via Copper-Free Cycloaddition, ACS Macro Lett. 1 (2012) 1071-1073. doi:10.1021/mz3003775.

[69] H. Zhan, D.W.P.M. Löwik, A Hybrid Peptide Amphiphile Fiber PEG Hydrogel Matrix for 3D Cell Culture, Adv. Funct. Mater. (2019) 1808505. doi:10.1002/adfm.201808505.

[70] F. Yu, X. Cao, Y. Li, L. Zeng, J. Zhu, G. Wang, X. Chen, Diels-Alder crosslinked HA/PEG hydrogels with high elasticity and fatigue resistance for cell encapsulation and articular cartilage tissue repair, Polym. Chem. 5 (2014) 5116. doi:10.1039/C4PY00473F.

[71] H.-L. Wei, Z. Yang, L.-M. Zheng, Y.-M. Shen, Thermosensitive hydrogels synthesized by fast Diels-Alder reaction in water, Polymer. 50 (2009) 2836-2840. doi:10.1016/j.polymer.2009.04.032.

[72] C.M. Nimmo, S.C. Owen, M.S. Shoichet, Diels-Alder Click Cross-Linked Hyaluronic Acid Hydrogels for Tissue Engineering, Biomacromolecules. 12 (2011) 824-830. doi:10.1021/bm101446k.

[73] S.C. Owen, S.A. Fisher, R.Y. Tam, C.M. Nimmo, M.S. Shoichet, Hyaluronic Acid Click Hydrogels Emulate the Extracellular Matrix, Langmuir. 29 (2013) 7393-7400. doi:10.1021/la305000w.

[74] S. Kirchhof, M. Gregoritza, V. Messmann, N. Hammer, A.M. Goepferich, F.P. Brandl, DielsAlder hydrogels with enhanced stability: First step toward controlled release of bevacizumab, Eur. J. Pharm. Biopharm. Off. J. Arbeitsgemeinschaft Für Pharm. Verfahrenstechnik EV. 96 (2015) 217-225. doi:10.1016/j.ejpb.2015.07.024.

[75] S. Kirchhof, F.P. Brandl, N. Hammer, A.M. Goepferich, Investigation of the Diels-Alder reaction as a cross-linking mechanism for degradable poly(ethylene glycol) based hydrogels, J. Mater. Chem. B. 1 (2013) 4855. doi:10.1039/c3tb20831a.

[76] H. Tan, J.P. Rubin, K.G. Marra, Direct Synthesis of Biodegradable Polysaccharide Derivative Hydrogels Through Aqueous Diels-Alder Chemistry, Macromol. Rapid Commun. 32 (2011) 905-911. doi:10.1002/marc.201100125.

[77] Z. Wei, J.H. Yang, X.J. Du, F. Xu, M. Zrinyi, Y. Osada, F. Li, Y.M. Chen, Dextran-Based Self-Healing Hydrogels Formed by Reversible Diels-Alder Reaction under Physiological Conditions, Macromol. Rapid Commun. 34 (2013) 1464-1470. doi:10.1002/marc.201300494.

[78] D.L. Alge, M.A. Azagarsamy, D.F. Donohue, K.S. Anseth, Synthetically Tractable Click Hydrogels for Three-Dimensional Cell Culture Formed Using Tetrazine-Norbornene Chemistry, Biomacromolecules. 14 (2013) 949-953. doi:10.1021/bm4000508.

[79] Y.Zhang, H. Chen, T. Zhang, Y. Zan, T. Ni, M. Liu, R. Pei, Fast-forming BMSC-encapsulating hydrogels through bioorthogonal reaction for osteogenic differentiation, Biomater. Sci. (2018). doi:10.1039/C8BM00689J.

[80] H. Zhang, K.T. Dicker, X. Xu, X. Jia, J.M. Fox, Interfacial Bioorthogonal Cross-Linking, ACS Macro Lett. 3 (2014) 727-731. doi:10.1021/mz5002993.

[81] K.T. Dicker, J. Song, A.C. Moore, H. Zhang, Y. Li, D.L. Burris, X. Jia, J.M. Fox, Core-shell patterning of synthetic hydrogels via interfacial bioorthogonal chemistry for spatial control of stem cell behavior, Chem. Sci. 9 (2018) 5394-5404. doi:10.1039/C8SC00495A.

[82] B.-H. Hu, J. Su, P.B. Messersmith, Hydrogels Cross-Linked by Native Chemical Ligation, Biomacromolecules. 10 (2009) 2194-2200. doi:10.1021/bm900366e.

[83] J. Su, B.-H. Hu, W.L. Lowe, D.B. Kaufman, P.B. Messersmith, Anti-inflammatory peptidefunctionalized hydrogels for insulin-secreting cell encapsulation, Biomaterials. 31 (2010) 308314. doi:10.1016/j.biomaterials.2009.09.045.

[84] J.P. Jung, A.J. Sprangers, J.R. Byce, J. Su, J.M. Squirrell, P.B. Messersmith, K.W. Eliceiri, B.M. Ogle, ECM-incorporated hydrogels crosslinked 1 via native chemical ligation to engineer stem cell microenvironments, Biomacromolecules. 14 (2013). doi:10.1021/bm400728e. 
[85] B. Balakrishnan, A. Jayakrishnan, Self-cross-linking biopolymers as injectable in situ forming biodegradable scaffolds, $\quad$ Biomaterials. $26 \quad$ (2005) 3941-3951. doi:10.1016/j.biomaterials.2004.10.005.

[86] J. Shi, W. Guobao, H. Chen, W. Zhong, X. Qiu, M.M.Q. Xing, Schiff based injectable hydrogel for in situ pH-triggered delivery of doxorubicin for breast tumor treatment, Polym Chem. 5 (2014) 6180-6189. doi:10.1039/C4PY00631C.

[87] S.K. Bhatia, S.D. Arthur, H.K. Chenault, G.K. Kodokian, Interactions of polysaccharide-based tissue adhesives with clinically relevant fibroblast and macrophage cell lines, Biotechnol. Lett. 29 (2007) 1645-1649. doi:10.1007/s10529-007-9465-8.

[88] L. Weng, A. Romanov, J. Rooney, W. Chen, Non-cytotoxic, in situ gelable hydrogels composed of N-carboxyethyl chitosan and oxidized dextran, Biomaterials. 29 (2008) 39053913. doi:10.1016/j.biomaterials.2008.06.025.

[89] N.L. Morozowich, J.L. Nichol, H.R. Allcock, Hydrogels based on schiff base formation between an amino-containing polyphosphazene and aldehyde functionalized-dextrans, J. Polym. Sci. Part Polym. Chem. 54 (2016) 2984-2991. doi:10.1002/pola.28184.

[90] Y. Zhang, L. Tao, S. Li, Y. Wei, Synthesis of Multiresponsive and Dynamic Chitosan-Based Hydrogels for Controlled Release of Bioactive Molecules, Biomacromolecules. 12 (2011) 2894-2901. doi:10.1021/bm200423f.

[91] Y. Zhang, B. Yang, X. Zhang, L. Xu, L. Tao, S. Li, Y. Wei, A magnetic self-healing hydrogel, Chem. Commun. 48 (2012) 9305. doi:10.1039/c2cc34745h.

[92] B. Yang, Y. Zhang, X. Zhang, L. Tao, S. Li, Y. Wei, Facilely prepared inexpensive and biocompatible self-healing hydrogel: a new injectable cell therapy carrier, Polym. Chem. 3 (2012) 3235. doi:10.1039/c2py20627g.

[93] H. Tan, J.P. Rubin, K.G. Marra, Injectable in situ forming biodegradable chitosan-hyaluronic acid based hydrogels for adipose tissue regeneration, Organogenesis. 6 (2010) 173-180.

[94] H. Tan, C.R. Chu, K. Payne, K.G. Marra, Injectable In Situ Forming Biodegradable ChitosanHyaluronic acid Based Hydrogels for Cartilage Tissue Engineering, Biomaterials. 30 (2009) 2499-2506. doi:10.1016/j.biomaterials.2008.12.080.

[95] S. Yan, T. Wang, X. Li, Y. Jian, K. Zhang, G. Li, J. Yin, Fabrication of injectable hydrogels based on poly( L -glutamic acid) and chitosan, RSC Adv. 7 (2017) 17005-17019. doi:10.1039/C7RA01864A.

[96] H. Tan, H. Li, J.P. Rubin, K.G. Marra, Controlled Gelation and Degradation Rates of Injectable Hyaluronic Acid-based Hydrogels through a Double Crosslinking Strategy, J. Tissue Eng. Regen. Med. 5 (2011) 790-797. doi:10.1002/term.378.

[97] Y. Li, C. Liu, Y. Tan, K. Xu, C. Lu, P. Wang, In situ hydrogel constructed by starch-based nanoparticles via a Schiff base reaction, Carbohydr. Polym. 110 (2014) 87-94. doi:10.1016/j.carbpol.2014.03.058.

[98] D.D. McKinnon, D.W. Domaille, T.E. Brown, K.A. Kyburz, E. Kiyotake, J.N. Cha, K.S. Anseth, Measuring cellular forces using bis-aliphatic hydrazone crosslinked stress-relaxing hydrogels, Soft Matter. 10 (2014) 9230-9236. doi:10.1039/C4SM01365D.

[99] N.M.B. Smeets, E. Bakaic, M. Patenaude, T. Hoare, Injectable and tunable poly(ethylene glycol) analogue hydrogels based on poly(oligoethylene glycol methacrylate), Chem. Commun 50 (2014) 3306. doi:10.1039/c3cc48514e.

[100] D.D. McKinnon, D.W. Domaille, J.N. Cha, K.S. Anseth, Biophysically Defined and Cytocompatible Covalently Adaptable Networks as Viscoelastic 3D Cell Culture Systems, Adv. Mater. Deerfield Beach Fla. 26 (2014) 865-872. doi:10.1002/adma.201303680.

[101] N. Boehnke, C. Cam, E. Bat, T. Segura, H.D. Maynard, Imine Hydrogels with Tunable Degradability, Biomacromolecules. 16 (2015) 2101-2108. doi:10.1021/acs.biomac.5b00519.

[102] M.H. Alves, C.J. Young, K. Bozzetto, L.A. Poole-Warren, P.J. Martens, Degradable, click poly(vinyl alcohol) hydrogels: characterization of degradation and cellular compatibility, Biomed. Mater. 7 (2012) 024106. doi:10.1088/1748-6041/7/2/024106. 
[103] D.A. Ossipov, K. Brännvall, K. Forsberg-Nilsson, J. Hilborn, Formation of the first injectable poly(vinyl alcohol) hydrogel by mixing of functional PVA precursors, J. Appl. Polym. Sci. 106 (2007) 60-70. doi:10.1002/app.26455.

[104] J.J. Roberts, P. Naudiyal, L. Jugé, L.E. Bilston, A.M. Granville, P.J. Martens, Tailoring Stimuli Responsiveness using Dynamic Covalent Cross-Linking of Poly(vinyl alcohol)-Heparin Hydrogels for Controlled Cell and Growth Factor Delivery, ACS Biomater. Sci. Eng. (2015). doi:10.1021/acsbiomaterials.5b00321.

[105] L.A. Gurski, A.K. Jha, C. Zhang, X. Jia, M.C. Farach-Carson, Hyaluronic Acid-Based Hydrogels as 3D Matrices for in Vitro Evaluation of Chemotherapeutic Drugs Using Poorly Adherent Prostate Cancer Cells, Biomaterials. $30 \quad$ (2009) 6076-6085. doi:10.1016/j.biomaterials.2009.07.054.

[106] L.A. Gurski, X. Xu, L.N. Labrada, N.T. Nguyen, L. Xiao, K.L. van Golen, X. Jia, M.C. FarachCarson, Hyaluronan (HA) Interacting Proteins RHAMM and Hyaluronidase Impact Prostate Cancer Cell Behavior and Invadopodia Formation in 3D HA-Based Hydrogels, PLoS ONE. 7 (2012). doi:10.1371/journal.pone.0050075.

[107] X. Jia, G. Colombo, R. Padera, R. Langer, D.S. Kohane, Prolongation of sciatic nerve blockade by in situ cross-linked hyaluronic acid, Biomaterials. 25 (2004) 4797-4804. doi:10.1016/j.biomaterials.2003.12.012.

[108] X. Jia, Y. Yeo, R.J. Clifton, T. Jiao, D.S. Kohane, J.B. Kobler, S.M. Zeitels, R. Langer, Hyaluronic acid-based microgels and microgel networks for vocal fold regeneration, Biomacromolecules. 7 (2006) 3336-3344. doi:10.1021/bm0604956.

[109] Y. Luo, J.B. Kobler, J.T. Heaton, X. Jia, S.M. Zeitels, R. Langer, Injectable hyaluronic aciddextran hydrogels and effects of implantation in ferret vocal fold, J. Biomed. Mater. Res. B Appl. Biomater. 93B (2010) 386-393. doi:10.1002/jbm.b.31593.

[110] A.J.E. Farran, S.S. Teller, A.K. Jha, T. Jiao, R.A. Hule, R.J. Clifton, D.P. Pochan, R.L. Duncan, X. Jia, Effects of Matrix Composition, Microstructure, and Viscoelasticity on the Behaviors of Vocal Fold Fibroblasts Cultured in Three-Dimensional Hydrogel Networks, Tissue Eng. Part A. 16 (2010) 1247-1261. doi:10.1089/ten.tea.2009.0344.

[111] O.P. Oommen, S. Wang, M. Kisiel, M. Sloff, J. Hilborn, O.P. Varghese, Smart Design of Stable Extracellular Matrix Mimetic Hydrogel: Synthesis, Characterization, and In Vitro and In Vivo Evaluation for Tissue Engineering, Adv. Funct. Mater. 23 (2013) 1273-1280. doi:10.1002/adfm.201201698.

[112] J. Dahlmann, A. Krause, L. Möller, G. Kensah, M. Möwes, A. Diekmann, U. Martin, A. Kirschning, I. Gruh, G. Dräger, Fully defined in situ cross-linkable alginate and hyaluronic acid hydrogels for myocardial tissue engineering, Biomaterials. 34 (2013) 940-951. doi:10.1016/j.biomaterials.2012.10.008.

[113] S. Hudson, R. Langer, G.R. Fink, D.S. Kohane, INJECTABLE IN SITU CROSS-LINKING HYDROGELS FOR LOCAL ANTIFUNGAL THERAPY, Biomaterials. 31 (2010) 1444. doi:10.1016/j.biomaterials.2009.11.016.

[114] M. Patenaude, T. Hoare, Injectable, Degradable Thermoresponsive Poly( $N$ isopropylacrylamide) Hydrogels, ACS Macro Lett. 1 (2012) 409-413. doi:10.1021/mz200121k.

[115] M. Patenaude, T. Hoare, Injectable, mixed natural-synthetic polymer hydrogels with modular properties, Biomacromolecules. 13 (2012) 369-378. doi:10.1021/bm2013982.

[116] C. Lu, X. Wang, G. Wu, J. Wang, Y. Wang, H. Gao, J. Ma, An injectable and biodegradable hydrogel based on poly $(\alpha, \beta$-aspartic acid) derivatives for localized drug delivery, J. Biomed. Mater. Res. A. 102 (2014) 628-638. doi:10.1002/jbm.a.34725.

[117] S. Yan, T. Wang, L. Feng, J. Zhu, K. Zhang, X. Chen, L. Cui, J. Yin, Injectable in situ selfcross-linking hydrogels based on poly(L-glutamic acid) and alginate for cartilage tissue engineering, Biomacromolecules. 15 (2014) 4495-4508. doi:10.1021/bm501313t. 
[118] G.N. Grover, J. Lam, T.H. Nguyen, T. Segura, H.D. Maynard, Biocompatible Hydrogels by Oxime Click Chemistry, Biomacromolecules. 13 (2012) 3013-3017. doi:10.1021/bm301346e.

[119] G.N. Grover, R.L. Braden, K.L. Christman, Oxime Cross-Linked Injectable Hydrogels for Catheter Delivery, Adv. Mater. Deerfield Beach Fla. 25 (2013) 2937-2942. doi:10.1002/adma.201205234.

[120] X.Z. Shu, Y. Liu, Y. Luo, M.C. Roberts, G.D. Prestwich, Disulfide Cross-Linked Hyaluronan Hydrogels, Biomacromolecules. 3 (2002) 1304-1311. doi:10.1021/bm025603c.

[121] Z.M. Wu, X.G. Zhang, C. Zheng, C.X. Li, S.M. Zhang, R.N. Dong, D.M. Yu, Disulfidecrosslinked chitosan hydrogel for cell viability and controlled protein release, Eur. J. Pharm. Sci. 37 (2009) 198-206. doi:10.1016/j.ejps.2009.01.010.

[122] B.D. Fairbanks, S.P. Singh, C.N. Bowman, K.S. Anseth, Photodegradable, Photoadaptable Hydrogels via Radical-Mediated Disulfide Fragmentation Reaction, Macromolecules. 44 (2011) 2444-2450. doi:10.1021/ma200202w.

[123] J. Lee, M.N. Silberstein, A.A. Abdeen, S.Y. Kim, K.A. Kilian, Mechanochemical functionalization of disulfide linked hydrogels, Mater Horiz. 3 (2016) 447-451. doi:10.1039/C6MH00091F.

[124] H. Du, P. Hamilton, M. Reilly, N. Ravi, Injectable in situ Physically and Chemically Crosslinkable Gellan Hydrogel, Macromol. Biosci. $12 \quad$ (2012) 952-961. doi:10.1002/mabi.201100422.

[125] K.E. Swindle-Reilly, M. Shah, P.D. Hamilton, T.A. Eskin, S. Kaushal, N. Ravi, Rabbit Study of an In Situ Forming Hydrogel Vitreous Substitute, Investig. Opthalmology Vis. Sci. 50 (2009) 4840. doi:10.1167/iovs.08-2891.

[126] C. Echalier, C. Pinese, X. Garric, H. Van Den Berghe, E. Jumas Bilak, J. Martinez, A. Mehdi, G. Subra, Easy Synthesis of Tunable Hybrid Bioactive Hydrogels, Chem. Mater. 28 (2016) 1261-1265. doi:10.1021/acs.chemmater.5b04881.

[127] S. Jo, K. Park, Novel Poly(Ethylene Glycol) Hydrogels from Silylated PEGs, J. Bioact. Compat. Polym. 14 (1999) 457-473. doi:10.1177/088391159901400602.

[128] L. Ren, K. Tsuru, S. Hayakawa, A. Osaka, Synthesis and characterization of gelatin-siloxane hybrids derived through sol-gel procedure, J. Sol-Gel Sci. Technol. 21 (2001) 115-121.

[129] O. Mahony, S. Yue, C. Turdean-Ionescu, J.V. Hanna, M.E. Smith, P.D. Lee, J.R. Jones, Silicagelatin hybrids for tissue regeneration: inter-relationships between the process variables, J. SolGel Sci. Technol. 69 (2013) 288-298. doi:10.1007/s10971-013-3214-3.

[130] Y. Shirosaki, C.M. Botelho, M.A. Lopes, J.D. Santos, Synthesis and Characterization of Chitosan-Silicate Hydrogel as Resorbable Vehicle for Bonelike ${ }^{\circledR}$ Bone Graft, J. Nanosci. Nanotechnol. 9 (2009) 3714-3719. doi:10.1166/jnn.2009.NS56.

[131] L.S. Connell, F. Romer, M. Suárez, E.M. Valliant, Z. Zhang, P.D. Lee, M.E. Smith, J.V. Hanna, J.R. Jones, Chemical characterisation and fabrication of chitosan-silica hybrid scaffolds with 3-glycidoxypropyl trimethoxysilane, J Mater Chem B. 2 (2014) 668-680. doi:10.1039/C3TB21507E.

[132] D. Wang, F. Romer, L. Connell, C. Walter, E. Saiz, S. Yue, P.D. Lee, D.S. McPhail, J.V. Hanna, J.R. Jones, Highly flexible silica/chitosan hybrid scaffolds with oriented pores for tissue regeneration, J Mater Chem B. 3 (2015) 7560-7576. doi:10.1039/C5TB00767D.

[133] S. Chen, A. Osaka, T. Ikoma, H. Morita, J. Li, M. Takeguchi, N. Hanagata, Fabrication, microstructure, and BMP-2 delivery of novel biodegradable and biocompatible silicatecollagen hybrid fibril sheets, J. Mater. Chem. 21 (2011) 10942. doi:10.1039/c1jm10829h.

[134] K. Hosoya, C. Ohtsuki, T. Kawai, M. Kamitakahara, S. Ogata, T. Miyazaki, M. Tanihara, A novel covalently crosslinked gel of alginate and silane with the ability to form bone-like apatite, J. Biomed. Mater. Res. A. 71A (2004) 596-601. doi:10.1002/jbm.a.30189.

[135] C. Vinatier, D. Magne, P. Weiss, C. Trojani, N. Rochet, G.F. Carle, C. Vignes-Colombeix, C. Chadjichristos, P. Galera, G. Daculsi, J. Guicheux, A silanized hydroxypropyl methylcellulose 
hydrogel for the three-dimensional culture of chondrocytes, Biomaterials. 26 (2005) 66436651. doi:10.1016/j.biomaterials.2005.04.057.

[136] C. Echalier, S. Jebors, G. Laconde, L. Brunel, P. Verdié, L. Causse, A. Bethry, B. Legrand, H. Van Den Berghe, X. Garric, D. Noël, J. Martinez, A. Mehdi, G. Subra, Sol-gel synthesis of collagen-inspired peptide hydrogel, Mater. Today. 20 (2017) 59-66. doi:10.1016/j.mattod.2017.02.001.

[137] E. Rederstorff, G. Rethore, P. Weiss, S. Sourice, S. Beck-Cormier, E. Mathieu, M. Maillasson, Y. Jacques, S. Colliec-Jouault, B.H. Fellah, J. Guicheux, C. Vinatier, Enriching a cellulose hydrogel with a biologically active marine exopolysaccharide for cell-based cartilage engineering, J. Tissue Eng. Regen. Med. (2015). doi:10.1002/term.2018.

[138] P. Weiss, E. Mathieu, J. Guicheux, P. Lemarchand, Silylated biomolecule-based hydrogel for culturing cardiomyocytes and stem cells, and use of the hydrogel thereof for treating heart failure, US20140161775 A1, 2014. http://www.google.com/patents/US20140161775 (accessed November 28, 2014).

[139] A. Viguier, C. Boyer, C. Chassenieux, L. Benyahia, J. Guicheux, P. Weiss, G. Rethore, T. Nicolai, Interpenetrated Si-HPMC/alginate hydrogels as a potential scaffold for human tissue regeneration, J. Mater. Sci. Mater. Med. 27 (2016) 99. doi:10.1007/s10856-016-5709-2.

[140] L. Moussa, G. Pattappa, B. Doix, S.-L. Benselama, C. Demarquay, M. Benderitter, A. Sémont, R. Tamarat, J. Guicheux, P. Weiss, G. Réthoré, N. Mathieu, A biomaterial-assisted mesenchymal stromal cell therapy alleviates colonic radiation-induced damage, Biomaterials. 115 (2017) 40-52. doi:10.1016/j.biomaterials.2016.11.017.

[141] E. Mathieu, G. Lamirault, C. Toquet, P. Lhommet, E. Rederstorff, S. Sourice, K. Biteau, P. Hulin, V. Forest, P. Weiss, J. Guicheux, P. Lemarchand, Intramyocardial delivery of mesenchymal stem cell-seeded hydrogel preserves cardiac function and attenuates ventricular remodeling after myocardial infarction, PloS One. 7 (2012) e51991. doi:10.1371/journal.pone.0051991.

[142] K.T. Nguyen, J.L. West, Photopolymerizable hydrogels for tissue engineering applications, Biomaterials. 23 (2002) 4307-4314.

[143] J.L. Ifkovits, J.A. Burdick, Review: Photopolymerizable and Degradable Biomaterials for Tissue Engineering Applications, Tissue Eng. $13 \quad$ (2007) 2369-2385. doi:10.1089/ten.2007.0093.

[144] A.S. Sawhney, C.P. Pathak, J.A. Hubbell, Bioerodible hydrogels based on photopolymerized poly(ethylene glycol)-co-poly(.alpha.-hydroxy acid) diacrylate macromers, Macromolecules. 26 (1993) 581-587. doi:10.1021/ma00056a005.

[145] F. Yang, C.G. Williams, D. Wang, H. Lee, P.N. Manson, J. Elisseeff, The effect of incorporating RGD adhesive peptide in polyethylene glycol diacrylate hydrogel on osteogenesis of bone marrow stromal cells, Biomaterials. 26 (2005) 5991-5998. doi:10.1016/j.biomaterials.2005.03.018.

[146] S.R. Peyton, C.B. Raub, V.P. Keschrumrus, A.J. Putnam, The use of poly(ethylene glycol) hydrogels to investigate the impact of ECM chemistry and mechanics on smooth muscle cells, Biomaterials. 27 (2006) 4881-4893. doi:10.1016/j.biomaterials.2006.05.012.

[147] L.N. Russell, K.J. Lampe, Oligodendrocyte Precursor Cell Viability, Proliferation, and Morphology is Dependent on Mesh Size and Storage Modulus in 3D Poly(ethylene glycol)Based Hydrogels, ACS Biomater. Sci. Eng. 3 (2017) 3459-3468. doi:10.1021/acsbiomaterials.7b00374.

[148] A.X. Sun, H. Lin, M.R. Fritch, H. Shen, P.G. Alexander, M. DeHart, R.S. Tuan, Chondrogenesis of human bone marrow mesenchymal stem cells in 3-dimensional, photocrosslinked hydrogel constructs: Effect of cell seeding density and material stiffness, Acta Biomater. 58 (2017) 302-311. doi:10.1016/j.actbio.2017.06.016. 
[149] H.-W. Chien, J. Yu, S.T. Li, H.-Y. Chen, W.-B. Tsai, An in situ poly(carboxybetaine) hydrogel for tissue engineering applications, Biomater Sci. 5 (2017) 322-330. doi:10.1039/C6BM00687F.

[150] R.K. Singh, D. Seliktar, A.J. Putnam, Capillary morphogenesis in PEG-collagen hydrogels., Biomaterials. 34 (2013). doi:10.1016/j.biomaterials.2013.08.016.

[151] N. Shao, J. Guo, Y. Guan, H. Zhang, X. Li, X. Chen, D. Zhou, Y. Huang, Development of Organic/Inorganic Compatible and Sustainably Bioactive Composites for Effective Bone Regeneration, Biomacromolecules. 19 (2018) 3637-3648. doi:10.1021/acs.biomac.8b00707.

[152] G. Gao, K. Hubbell, A.F. Schilling, G. Dai, X. Cui, Bioprinting Cartilage Tissue from Mesenchymal Stem Cells and PEG Hydrogel, in: Z. Koledova (Ed.), 3D Cell Cult., Springer New York, New York, NY, 2017: pp. 391-398. doi:10.1007/978-1-4939-7021-6_28.

[153] G. Gao, X.-F. Zhang, K. Hubbell, X. Cui, NR2F2 regulates chondrogenesis of human mesenchymal stem cells in bioprinted cartilage, Biotechnol. Bioeng. 114 (2017) 208-216.

[154] Y. Ma, Y. Ji, T. Zhong, W. Wan, Q. Yang, A. Li, X. Zhang, M. Lin, Bioprinting-Based PDLSC-ECM Screening for in Vivo Repair of Alveolar Bone Defect Using Cell-Laden, Injectable and Photocrosslinkable Hydrogels, ACS Biomater. Sci. Eng. 3 (2017) 3534-3545. doi:10.1021/acsbiomaterials.7b00601.

[155] D. Qi, S. Wu, M.A. Kuss, W. Shi, S. Chung, P.T. Deegan, A. Kamenskiy, Y. He, B. Duan, Mechanically robust cryogels with injectability and bioprinting supportability for adipose tissue engineering, Acta Biomater. 74 (2018) 131-142. doi:10.1016/j.actbio.2018.05.044.

[156] C. Xu, W. Lee, G. Dai, Y. Hong, Highly Elastic Biodegradable Single-Network Hydrogel for Cell Printing, ACS Appl. Mater. Interfaces. $10 \quad$ (2018) 9969-9979. doi:10.1021/acsami.8b01294.

[157] S.H. Kim, Y.K. Yeon, J.M. Lee, J.R. Chao, Y.J. Lee, Y.B. Seo, M.T. Sultan, O.J. Lee, J.S. Lee, S. Yoon, I.-S. Hong, G. Khang, S.J. Lee, J.J. Yoo, C.H. Park, Precisely printable and biocompatible silk fibroin bioink for digital light processing 3D printing, Nat. Commun. 9 (2018) 1620. doi:10.1038/s41467-018-03759-y.

[158] K. Na, S. Shin, H. Lee, D. Shin, J. Baek, H. Kwak, M. Park, J. Shin, J. Hyun, Effect of solution viscosity on retardation of cell sedimentation in DLP 3D printing of gelatin methacrylate/silk fibroin bioink, J. Ind. Eng. Chem. 61 (2018) 340-347. doi:10.1016/j.jiec.2017.12.032.

[159] Z. Wang, H. Kumar, Z. Tian, X. Jin, J.F. Holzman, F. Menard, K. Kim, Visible Light Photoinitiation of Cell Adhesive Gelatin Methacryloyl Hydrogels for Stereolithography 3D Bioprinting, ACS Appl. Mater. Interfaces. $10 \quad$ (2018) 26859-26869. doi:10.1021/acsami.8b06607.

[160] W. Zhu, X. Qu, J. Zhu, X. Ma, S. Patel, J. Liu, P. Wang, C.S.E. Lai, M. Gou, Y. Xu, K. Zhang, S. Chen, Direct 3D bioprinting of prevascularized tissue constructs with complex microarchitecture, Biomaterials. 124 (2017) 106-115. doi:10.1016/j.biomaterials.2017.01.042.

[161] S.J. Bryant, C.R. Nuttelman, K.S. Anseth, Cytocompatibility of UV and visible light photoinitiating systems on cultured NIH/3T3 fibroblasts in vitro, J. Biomater. Sci. Polym. Ed. 11 (2000) 439-457.

[162] C.G. Williams, A.N. Malik, T.K. Kim, P.N. Manson, J.H. Elisseeff, Variable cytocompatibility of six cell lines with photoinitiators used for polymerizing hydrogels and cell encapsulation, Biomaterials. 26 (2005) 1211-1218. doi:10.1016/j.biomaterials.2004.04.024.

[163] D. Wang, C.G. Williams, Q. Li, B. Sharma, J.H. Elisseeff, Synthesis and characterization of a novel degradable phosphate-containing hydrogel, Biomaterials. 24 (2003) 3969-3980. doi:10.1016/S0142-9612(03)00280-1.

[164] N.E. Fedorovich, M.H. Oudshoorn, D. van Geemen, W.E. Hennink, J. Alblas, W.J.A. Dhert, The effect of photopolymerization on stem cells embedded in hydrogels, Biomaterials. 30 (2009) 344-353. doi:10.1016/j.biomaterials.2008.09.037. 
[165] H.W. Ooi, C. Mota, A.T. ten Cate, A. Calore, L. Moroni, M.B. Baker, Thiol-Ene Alginate Hydrogels as Versatile Bioinks for Bioprinting, Biomacromolecules. 19 (2018) 3390-3400. doi:10.1021/acs.biomac.8b00696.

[166] J.D. McCall, K.S. Anseth, Thiol-Ene Photopolymerizations Provide a Facile Method To Encapsulate Proteins and Maintain Their Bioactivity, Biomacromolecules. 13 (2012) 2410 2417. doi:10.1021/bm300671s.

[167] D.I. Pattison, M.J. Davies, Actions of ultraviolet light on cellular structures, EXS. (2006) 131157.

[168] D. Zhou, Y. Ito, Visible light-curable polymers for biomedical applications, Sci. China Chem. 57 (2014) 510-521. doi:10.1007/s11426-014-5069-z.

[169] S. Mishra, F.J. Scarano, P. Calvert, Entrapment of Saccharomyces cerevisiae and 3T3 fibroblast cells into blue light cured hydrogels, J. Biomed. Mater. Res. A. 100A (2012) 28292838. doi:10.1002/jbm.a.34204.

[170] C.S. Bahney, T.J. Lujan, C.W. Hsu, M. Bottlang, J.L. West, B. Johnstone, Visible light photoinitiation of mesenchymal stem cell-laden bioresponsive hydrogels, Eur Cell Mater. 22 (2011) 43-55.

[171] A. Hoshikawa, Y. Nakayama, T. Matsuda, H. Oda, K. Nakamura, K. Mabuchi, Encapsulation of Chondrocytes in Photopolymerizable Styrenated Gelatin for Cartilage Tissue Engineering, Tissue Eng. 12 (2006) 2333-2341. doi:10.1089/ten.2006.12.2333.

[172] M. Schieber, N.S. Chandel, ROS Function in Redox Signaling and Oxidative Stress, Curr. Biol. 24 (2014) R453-R462. doi:10.1016/j.cub.2014.03.034.

[173] J.J. Roberts, S.J. Bryant, Comparison of photopolymerizable thiol-ene PEG and acrylate-based PEG hydrogels for cartilage development, Biomaterials. 34 (2013) 9969-9979. doi:10.1016/j.biomaterials.2013.09.020.

[174] C.E. Hoyle, C.N. Bowman, Thiol-Ene Click Chemistry, Angew. Chem. Int. Ed. 49 (2010) 1540-1573. doi:10.1002/anie.200903924.

[175] C.-C. Lin, A. Raza, H. Shih, PEG hydrogels formed by thiol-ene photo-click chemistry and their effect on the formation and recovery of insulin-secreting cell spheroids, Biomaterials. 32 (2011) 9685-9695. doi:10.1016/j.biomaterials.2011.08.083.

[176] A.E. Rydholm, C.N. Bowman, K.S. Anseth, Degradable thiol-acrylate photopolymers: polymerization and degradation behavior of an in situ forming biomaterial, Biomaterials. 26 (2005) 4495-4506. doi:10.1016/j.biomaterials.2004.11.046.

[177] C.N. Salinas, K.S. Anseth, The enhancement of chondrogenic differentiation of human mesenchymal stem cells by enzymatically regulated RGD functionalities, Biomaterials. 29 (2008) 2370-2377. doi:10.1016/j.biomaterials.2008.01.035.

[178] Y. Hao, C.-C. Lin, Degradable thiol-acrylate hydrogels as tunable matrices for threedimensional hepatic culture: Degradable Thiol-Acrylate Hydrogels, J. Biomed. Mater. Res. A. 102 (2014) 3813-3827. doi:10.1002/jbm.a.35044.

[179] Y. Hao, H. Shih, Z. Muňoz, A. Kemp, C.-C. Lin, Visible light cured thiol-vinyl hydrogels with tunable degradation for 3D cell culture, Acta Biomater. 10 (2014). doi:10.1016/j.actbio.2013.08.044.

[180] K. Gwon, E. Kim, G. Tae, Heparin-hyaluronic acid hydrogel in support of cellular activities of 3D encapsulated adipose derived stem cells, Acta Biomater. 49 (2017) 284-295. doi:10.1016/j.actbio.2016.12.001.

[181] J. Li, Y. Huang, J. Song, X. Li, X. Zhang, Z. Zhou, D. Chen, P.X. Ma, W. Peng, W. Wang, G. Zhou, Cartilage regeneration using arthroscopic flushing fluid-derived mesenchymal stem cells encapsulated in a one-step rapid cross-linked hydrogel, Acta Biomater. (2018). doi:10.1016/j.actbio.2018.08.029.

[182] E.A. Kiyotake, A.W. Douglas, E.E. Thomas, S.L. Nimmo, M.S. Detamore, Development and quantitative characterization of the precursor rheology of hyaluronic acid hydrogels for bioprinting, Acta Biomater. (2019). doi:10.1016/j.actbio.2019.01.041. 
[183] S. Bertlein, G. Brown, K.S. Lim, T. Jungst, T. Boeck, T. Blunk, J. Tessmar, G.J. Hooper, T.B.F. Woodfield, J. Groll, Thiol-Ene Clickable Gelatin: A Platform Bioink for Multiple 3D Biofabrication Technologies, Adv. Mater. 29 (2017) 1703404. doi:10.1002/adma.201703404.

[184] C.-C. Lin, C.S. Ki, H. Shih, Thiol-norbornene photoclick hydrogels for tissue engineering applications, J. Appl. Polym. Sci. 132 (2015) n/a-n/a. doi:10.1002/app.41563.

[185] A.H. Aziz, S.J. Bryant, A comparison of human mesenchymal stem cell osteogenesis in poly(ethylene glycol) hydrogels as a function of MMP-sensitive crosslinker and crosslink density in chemically defined medium: AZIZ AND BRYANT, Biotechnol. Bioeng. (2019). doi:10.1002/bit.26957.

[186] H. Shih, C.-C. Lin, Visible-light-mediated thiol-ene hydrogelation using eosin-Y as the only photoinitiator, Macromol. Rapid Commun. 34 (2013) 269-273. doi:10.1002/marc.201200605.

[187] H. Shih, R.G. Mirmira, C.-C. Lin, Visible light-initiated interfacial thiol-norbornene photopolymerization for forming islet surface conformal coating, J. Mater. Chem. B Mater. Biol. Med. 3 (2015) 170-175. doi:10.1039/C4TB01593B.

[188] L.A. Sawicki, L.H. Choe, K.L. Wiley, K.H. Lee, A.M. Kloxin, Isolation and Identification of Proteins Secreted by Cells Cultured within Synthetic Hydrogel-Based Matrices, ACS Biomater. Sci. Eng. (2018). doi:10.1021/acsbiomaterials.7b00647.

[189] H.C. Kolb, M.G. Finn, K.B. Sharpless, Click Chemistry: Diverse Chemical Function from a Few Good Reactions, Angew. Chem. Int. Ed. 40 (2001) 2004-2021. doi:10.1002/15213773(20010601)40:11<2004::AID-ANIE2004>3.0.CO;2-5.

[190] S. Liu, K.T. Dicker, X. Jia, Modular and orthogonal synthesis of hybrid polymers and networks, Chem Commun. 51 (2015) 5218-5237. doi:10.1039/C4CC09568E.

[191] Y. Jiang, J. Chen, C. Deng, E.J. Suuronen, Z. Zhong, Click hydrogels, microgels and nanogels: Emerging platforms for drug delivery and tissue engineering, Biomaterials. 35 (2014) 49694985. doi:10.1016/j.biomaterials.2014.03.001.

[192] M.A. Azagarsamy, K.S. Anseth, Bioorthogonal Click Chemistry: An Indispensable Tool to Create Multifaceted Cell Culture Scaffolds, ACS Macro Lett. 2 (2013) 5-9. doi: $10.1021 / \mathrm{mz} 300585 \mathrm{q}$.

[193] C.M. Nimmo, M.S. Shoichet, Regenerative Biomaterials that "Click": Simple, Aqueous-Based Protocols for Hydrogel Synthesis, Surface Immobilization, and 3D Patterning, Bioconjug. Chem. 22 (2011) 2199-2209. doi:10.1021/bc200281k.

[194] H. Zhu, X. Cai, L. Wu, Z. Gu, A facile one-step gelation approach simultaneously combining physical and chemical cross-linking for the preparation of injectable hydrogels, J Mater Chem B. 5 (2017) 3145-3153. doi:10.1039/C7TB00396J.

[195] A. Michael, Ueber die Addition von Natriumacetessig- und Natriummalonsäureäthern zu den Aethern ungesättigter Säuren, J. Für Prakt. Chem. 35 (1887) 349-356. doi:10.1002/prac.18870350136.

[196] M. Friedman, J.F. Cavins, J.S. Wall, Relative nucleophilic reactivities of amino groups and mercaptide ions in addition reactions with $\alpha, \beta$-unsaturated compounds1, 2, J. Am. Chem. Soc. 87 (1965) 3672-3682.

[197] D.P. Nair, M. Podgórski, S. Chatani, T. Gong, W. Xi, C.R. Fenoli, C.N. Bowman, The ThiolMichael Addition Click Reaction: A Powerful and Widely Used Tool in Materials Chemistry, Chem. Mater. 26 (2014) 724-744. doi:10.1021/cm402180t.

[198] M.P. Lutolf, J.L. Lauer-Fields, H.G. Schmoekel, A.T. Metters, F.E. Weber, G.B. Fields, J.A. Hubbell, Synthetic matrix metalloproteinase-sensitive hydrogels for the conduction of tissue regeneration: Engineering cell-invasion characteristics, Proc. Natl. Acad. Sci. 100 (2003) 5413-5418. doi:10.1073/pnas.0737381100.

[199] Y. Park, M.P. Lutolf, J.A. Hubbell, E.B. Hunziker, M. Wong, Bovine primary chondrocyte culture in synthetic matrix metalloproteinase-sensitive poly(ethylene glycol)-based hydrogels as a scaffold for cartilage repair, Tissue Eng. 10 (2004) 515-522. doi:10.1089/107632704323061870. 
[200] F. Cellesi, N. Tirelli, J.A. Hubbell, Towards a fully-synthetic substitute of alginate: development of a new process using thermal gelation and chemical cross-linking, Biomaterials. 25 (2004) 5115-5124. doi:10.1016/j.biomaterials.2003.12.015.

[201] J.M. Jukes, L.J. van der Aa, C. Hiemstra, T. van Veen, P.J. Dijkstra, Z. Zhong, J. Feijen, C.A. van Blitterswijk, J. de Boer, A newly developed chemically crosslinked dextran-poly(ethylene glycol) hydrogel for cartilage tissue engineering, Tissue Eng. Part A. 16 (2010) 565-573. doi:10.1089/ten.TEA.2009.0173.

[202] X. Zheng Shu, Y. Liu, F.S. Palumbo, Y. Luo, G.D. Prestwich, In situ crosslinkable hyaluronan hydrogels for tissue engineering, Biomaterials. 25 (2004) 1339-1348. doi:10.1016/j.biomaterials.2003.08.014.

[203] A.T. Speidel, D.J. Stuckey, L.W. Chow, L.H. Jackson, M. Noseda, M. Abreu Paiva, M.D. Schneider, M.M. Stevens, Multimodal Hydrogel-Based Platform To Deliver and Monitor Cardiac Progenitor/Stem Cell Engraftment, ACS Cent. Sci. 3 (2017) 338-348. doi:10.1021/acscentsci.7b00039.

[204] P.A. Parmar, L.W. Chow, J.-P. St-Pierre, C.-M. Horejs, Y.Y. Peng, J.A. Werkmeister, J.A.M. Ramshaw, M.M. Stevens, Collagen-mimetic peptide-modifiable hydrogels for articular $\begin{array}{lllll}\text { cartilage } & \text { regeneration, } & \text { Biomaterials. } & 54 & \text { (2015) } 225 .\end{array}$ doi:10.1016/j.biomaterials.2015.02.079.

[205] P.A. Parmar, J.-P. St-Pierre, L.W. Chow, C.D. Spicer, V. Stoichevska, Y.Y. Peng, J.A. Werkmeister, J.A.M. Ramshaw, M.M. Stevens, Enhanced articular cartilage by human mesenchymal stem cells in enzymatically mediated transiently RGDS-functionalized collagenmimetic hydrogels, Acta Biomater. 51 (2017) 75-88. doi:10.1016/j.actbio.2017.01.028.

[206] G.-Z. Li, R.K. Randev, A.H. Soeriyadi, G. Rees, C. Boyer, Z. Tong, T.P. Davis, C.R. Becer, D.M. Haddleton, Investigation into thiol-(meth)acrylate Michael addition reactions using amine and phosphine catalysts, Polym. Chem. 1 (2010) 1196-1204. doi:10.1039/COPY00100G

[207] S. Lim, G.A. Jung, R.J. Muckom, D.J. Glover, D.S. Clark, Engineering bioorthogonal proteinpolymer hybrid hydrogel as a functional protein immobilization platform, Chem. Commun. 55 (2019) 806-809. doi:10.1039/C8CC08720B.

[208] S.K. Seidlits, J. Liang, R.D. Bierman, A. Sohrabi, J. Karam, S.M. Holley, C. Cepeda, C.M. Walthers, Peptide-modified, hyaluronic acid-based hydrogels as a 3D culture platform for neural stem/progenitor cell engineering: PEPTIDE-MODIFIED, HYALURONIC ACIDBASED HYDROGELS, J. Biomed. Mater. Res. A. 107 (2019) 704-718. doi:10.1002/jbm.a.36603.

[209] A.D. Baldwin, K.L. Kiick, Tunable Degradation of Maleimide-Thiol Adducts in Reducing Environments, Bioconjug. Chem. 22 (2011) 1946-1953. doi:10.1021/bc200148v.

[210] V.V. Rostovtsev, L.G. Green, V.V. Fokin, K.B. Sharpless, A Stepwise Huisgen Cycloaddition Process: Copper(I)-Catalyzed Regioselective "Ligation" of Azides and Terminal Alkynes, Angew. Chem. Int. Ed. 41 (2002) 2596-2599. doi:10.1002/15213773(20020715)41:14<2596::AID-ANIE2596>3.0.CO;2-4.

[211] B.J. Adzima, Y. Tao, C.J. Kloxin, C.A. DeForest, K.S. Anseth, C.N. Bowman, Spatial and temporal control of the alkyne-azide cycloaddition by photoinitiated $\mathrm{Cu}(\mathrm{II})$ reduction, $\mathrm{Nat}$. Chem. 3 (2011) 256-259. doi:10.1038/nchem.980.

[212] F. Himo, T. Lovell, R. Hilgraf, V.V. Rostovtsev, L. Noodleman, K.B. Sharpless, V.V. Fokin, Copper(I)-Catalyzed Synthesis of Azoles. DFT Study Predicts Unprecedented Reactivity and Intermediates, J. Am. Chem. Soc. 127 (2005) 210-216. doi:10.1021/ja0471525.

[213] D.A. Ossipov, J. Hilborn, Poly(vinyl alcohol)-Based Hydrogels Formed by "Click Chemistry," Macromolecules. 39 (2006) 1709-1718. doi:10.1021/ma052545p.

[214] B.D. Polizzotti, B.D. Fairbanks, K.S. Anseth, Three-Dimensional Biochemical Patterning of Click-Based Composite Hydrogels via Thiolene Photopolymerization, Biomacromolecules. 9 (2008) 1084-1087. doi:10.1021/bm7012636. 
[215] S.Q. Liu, P.L.R. Ee, C.Y. Ke, J.L. Hedrick, Y.Y. Yang, Biodegradable poly(ethylene glycol)peptide hydrogels with well-defined structure and properties for cell delivery, Biomaterials. 30 (2009) 1453-1461. doi:10.1016/j.biomaterials.2008.11.023.

[216] M. van Dijk, C.F. van Nostrum, W.E. Hennink, D.T.S. Rijkers, R.M.J. Liskamp, Synthesis and Characterization of Enzymatically Biodegradable PEG and Peptide-Based Hydrogels Prepared by Click Chemistry, Biomacromolecules. 11 (2010) 1608-1614. doi:10.1021/bm1002637.

[217] X. Hu, D. Li, F. Zhou, C. Gao, Biological hydrogel synthesized from hyaluronic acid, gelatin and chondroitin sulfate by click chemistry, Acta Biomater. 7 (2011) 1618-1626. doi:10.1016/j.actbio.2010.12.005.

[218] S. Tan, A. Blencowe, K. Ladewig, G.G. Qiao, A novel one-pot approach towards dynamically cross-linked hydrogels, Soft Matter. 9 (2013) 5239. doi:10.1039/c3sm50638j.

[219] V. Crescenzi, L. Cornelio, C. Di Meo, S. Nardecchia, R. Lamanna, Novel Hydrogels via Click Chemistry: Synthesis and Potential Biomedical Applications, Biomacromolecules. 8 (2007) 1844-1850. doi:10.1021/bm0700800.

[220] E. Lallana, R. Riguera, E. Fernandez-Megia, Reliable and Efficient Procedures for the Conjugation of Biomolecules through Huisgen Azide-Alkyne Cycloadditions, Angew. Chem. Int. Ed. 50 (2011) 8794-8804. doi:10.1002/anie.201101019.

[221] N.J. Agard, J.A. Prescher, C.R. Bertozzi, A Strain-Promoted [3 + 2] Azide-Alkyne Cycloaddition for Covalent Modification of Biomolecules in Living Systems, J. Am. Chem. Soc. 126 (2004) 15046-15047. doi:10.1021/ja044996f.

[222] J.M. Baskin, J.A. Prescher, S.T. Laughlin, N.J. Agard, P.V. Chang, I.A. Miller, A. Lo, J.A. Codelli, C.R. Bertozzi, Copper-free click chemistry for dynamic in vivo imaging, Proc. Natl. Acad. Sci. U. S. A. 104 (2007) 16793-16797. doi:10.1073/pnas.0707090104.

[223] Z. Li, T.S. Seo, J. Ju, 1,3-Dipolar cycloaddition of azides with electron-deficient alkynes under mild condition in water, Tetrahedron Lett. 45 (2004) 3143-3146. doi:10.1016/j.tetlet.2004.02.089.

[224] V.X. Truong, M.P. Ablett, H.T.J. Gilbert, J. Bowen, S.M. Richardson, J.A. Hoyland, A.P. Dove, In situ-forming robust chitosan-poly(ethylene glycol) hydrogels prepared by copper-free azide-alkyne click reaction for tissue engineering, Biomater Sci. 2 (2014) 167-175. doi:10.1039/C3BM60159E.

[225] O. Diels, K. Alder, Synthesen in der hydroaromatischen Reihe, Justus Liebigs Ann. Chem. 460 (1928) 98-122. doi:10.1002/jlac.19284600106.

[226] D.C. Rideout, R. Breslow, Hydrophobic acceleration of Diels-Alder reactions, J. Am. Chem. Soc. 102 (1980) 7816-7817.

[227] W. Blokzijl, J.B.F.N. Engberts, Enforced Hydrophobic Interactions and Hydrogen Bonding in the Acceleration of Diels-Alder Reactions in Water, in: C.J. Cramer, D.G. Truhlar (Eds.), Struct. React. Aqueous Solut., American Chemical Society, Washington, DC, 1994: pp. 303317. http://pubs.acs.org/doi/abs/10.1021/bk-1994-0568.ch021 (accessed August 17, 2016).

[228] H.-L. Wei, K. Yao, Z. Yang, H.-J. Chu, J. Zhu, C.-C. Ma, Z.-X. Zhao, Preparation of thermosensitive hydrogels by means of tandem physical and chemical crosslinking, Macromol. Res. 19 (2011) 294-299. doi:10.1007/s13233-011-0308-z.

[229] S.A. Stewart, M. Backholm, N.A.D. Burke, H.D.H. Stöver, Cross-Linked Hydrogels Formed through Diels-Alder Coupling of Furan- and Maleimide-Modified Poly(methyl vinyl ether-alt -maleic acid), Langmuir. 32 (2016) 1863-1870. doi:10.1021/acs.langmuir.5b04450.

[230] A. Sanyal, Diels-Alder Cycloaddition-Cycloreversion: A Powerful Combo in Materials Design, Macromol. Chem. Phys. 211 (2010) 1417-1425. doi:10.1002/macp.201000108.

[231] K.C. Koehler, D.L. Alge, K.S. Anseth, C.N. Bowman, A diels-alder modulated approach to control and sustain the release of dexamethasone and induce osteogenic differentiation of human mesenchymal stem cells, Biomaterials. $34 \quad$ (2013) 4150-4158. doi:10.1016/j.biomaterials.2013.02.020. 
[232] K.C. Koehler, K.S. Anseth, C.N. Bowman, Diels-Alder Mediated Controlled Release from a Poly(ethylene glycol) Based Hydrogel, Biomacromolecules. 14 (2013) 538-547. doi:10.1021/bm301789d.

[233] N.K. Devaraj, R. Weissleder, Biomedical applications of tetrazine cycloadditions, Acc. Chem. Res. 44 (2011) 816-827. doi:10.1021/ar200037t.

[234] A.-C. Knall, C. Slugovc, Inverse electron demand Diels-Alder (iEDDA)-initiated conjugation: a (high) potential click chemistry scheme, Chem. Soc. Rev. 42 (2013) 5131-5142. doi:10.1039/C3CS60049A.

[235] P.E. Dawson, T.W. Muir, I. Clark-Lewis, S.B. Kent, Synthesis of proteins by native chemical ligation, Science. 266 (1994) 776-779. doi:10.1126/science.7973629.

[236] K.W.M. Boere, B.G. Soliman, D.T.S. Rijkers, W.E. Hennink, T. Vermonden, Thermoresponsive Injectable Hydrogels Cross-Linked by Native Chemical Ligation, Macromolecules. 47 (2014) 2430-2438. doi:10.1021/ma5000927.

[237] Q. Wan, J. Chen, Y. Yuan, S.J. Danishefsky, Oxo-ester Mediated Native Chemical Ligation: Concept and Applications, J. Am. Chem. Soc. 130 (2008) 15814-15816. doi:10.1021/ja804993y.

[238] I. Strehin, D. Gourevitch, Y. Zhang, E. Heber-Katz, P.B. Messersmith, Hydrogels formed by oxo-ester mediated native chemical ligation, Biomater. Sci. 1 (2013) 603. doi:10.1039/c3bm00201b.

[239] W. Zhang, K. Zhang, S. Yan, J. Wu, J. Yin, A tough and self-healing poly( L -glutamic acid)based composite hydrogel for tissue engineering, J. Mater. Chem. B. 6 (2018) 6865-6876. doi:10.1039/C8TB01981A.

[240] D.D. McKinnon, D.W. Domaille, J.N. Cha, K.S. Anseth, Bis-Aliphatic Hydrazone-Linked Hydrogels Form Most Rapidly at Physiological pH: Identifying the Origin of Hydrogel Properties with Small Molecule Kinetic Studies, Chem. Mater. 26 (2014) 2382-2387. doi:10.1021/cm5007789.

[241] R. Zhang, Z. Huang, M. Xue, J. Yang, T. Tan, Detailed characterization of an injectable hyaluronic acid-polyaspartylhydrazide hydrogel for protein delivery, Carbohydr. Polym. 85 (2011) 717-725. doi:10.1016/j.carbpol.2011.02.014.

[242] J.J. Roberts, P. Naudiyal, L. Jugé, L.E. Bilston, A.M. Granville, P.J. Martens, Tailoring Stimuli Responsiveness using Dynamic Covalent Cross-Linking of Poly(vinyl alcohol)-Heparin Hydrogels for Controlled Cell and Growth Factor Delivery, ACS Biomater. Sci. Eng. 1 (2015) 1267-1277. doi:10.1021/acsbiomaterials.5b00321.

[243] L.L. Wang, C.B. Highley, Y.-C. Yeh, J.H. Galarraga, S. Uman, J.A. Burdick, Threedimensional extrusion bioprinting of single- and double-network hydrogels containing dynamic covalent crosslinks: 3D EXTRUSION BIOPRINTING, J. Biomed. Mater. Res. A. 106 (2018) 865-875. doi:10.1002/jbm.a.36323.

[244] D. Zhu, H. Wang, P. Trinh, S.C. Heilshorn, F. Yang, Elastin-like protein-hyaluronic acid (ELPHA) hydrogels with decoupled mechanical and biochemical cues for cartilage regeneration, Biomaterials. 127 (2017) 132-140. doi:10.1016/j.biomaterials.2017.02.010.

[245] E. Bakaic, N.M.B. Smeets, M. Badv, M. Dodd, O. Barrigar, E. Siebers, M. Lawlor, H. Sheardown, T. Hoare, Injectable and Degradable Poly(Oligoethylene glycol methacrylate) Hydrogels with Tunable Charge Densities as Adhesive Peptide-Free Cell Scaffolds, ACS Biomater. Sci. Eng. (2017). doi:10.1021/acsbiomaterials.7b00397.

[246] C.R. Silva, P.S. Babo, M. Gulino, L. Costa, J.M. Oliveira, J. Silva-Correia, R.M.A. Domingues, R.L. Reis, M.E. Gomes, Injectable and tunable hyaluronic acid hydrogels releasing chemotactic and angiogenic growth factors for endodontic regeneration, Acta Biomater. (2018). doi:10.1016/j.actbio.2018.07.035.

[247] J. Kalia, R.T. Raines, Hydrolytic Stability of Hydrazones and Oximes, Angew. Chem. Int. Ed Engl. 47 (2008) 7523-7526. doi:10.1002/anie.200802651. 
[248] H.W. Sun, R.J. Feigal, H.H. Messer, Cytotoxicity of glutaraldehyde and formaldehyde in relation to time of exposure and concentration, Pediatr Dent. 12 (1990) 303-7.

[249] J.E. Gough, C.A. Scotchford, S. Downes, Cytotoxicity of glutaraldehyde crosslinked collagen/poly(vinyl alcohol) films is by the mechanism of apoptosis, J. Biomed. Mater. Res. 61 (2002) 121-130. doi:10.1002/jbm.10145.

[250] H. Wang, S.C. Heilshorn, Adaptable Hydrogel Networks with Reversible Linkages for Tissue Engineering, Adv. Mater. 27 (2015) 3717-3736. doi:10.1002/adma.201501558.

[251] C.S. Sevier, C.A. Kaiser, Formation and transfer of disulphide bonds in living cells, Nat. Rev. Mol. Cell Biol. 3 (2002) 836-847. doi:10.1038/nrm954.

[252] B.P. Tu, J.S. Weissman, Oxidative protein folding in eukaryotes mechanisms and consequences, J. Cell Biol. 164 (2004) 341-346. doi:10.1083/jcb.200311055.

[253] K.P. Vercruysse, D.M. Marecak, J.F. Marecek, G.D. Prestwich, Synthesis and in Vitro Degradation of New Polyvalent Hydrazide Cross-Linked Hydrogels of Hyaluronic Acid, Bioconjug. Chem. 8 (1997) 686-694. doi:10.1021/bc9701095.

[254] Y. Liu, J. Yang, Z. Luo, D. Li, Q. Wang, Y. Xiao, X. Zhang, Development of an injectable thiolated icariin functionalized collagen/hyaluronic hydrogel to promote cartilage formation in vitro and in vivo, J. Mater. Chem. B. (2019). doi:10.1039/C9TB00211A.

[255] R. Singh, G.M. Whitesides, Thiol — disulfide interchange, in: S. Patai, Z. Rappoport (Eds.), Sulphur-Contain. Funct. Groups 1993, John Wiley \& Sons, Inc., 1993: pp. 633-658. http://onlinelibrary.wiley.com/doi/10.1002/9780470034408.ch13/summary (accessed August 23, 2016).

[256] S.-Y. Choh, D. Cross, C. Wang, Facile Synthesis and Characterization of Disulfide-CrossLinked Hyaluronic Acid Hydrogels for Protein Delivery and Cell Encapsulation, Biomacromolecules. 12 (2011) 1126-1136. doi:10.1021/bm101451k.

[257] K.M. Gattás-Asfura, C.L. Stabler, Chemoselective Cross-Linking and Functionalization of Alginate via Staudinger Ligation, Biomacromolecules. $10 \quad$ (2009) 3122-3129. doi:10.1021/bm900789a.

[258] K.K. Hall, K.M. Gattás-Asfura, C.L. Stabler, Microencapsulation of islets within alginate/poly(ethylene glycol) gels cross-linked via Staudinger ligation, Acta Biomater. 7 (2011) 614-624. doi:10.1016/j.actbio.2010.07.016.

[259] R. Tamate, T. Ueki, Y. Kitazawa, M. Kuzunuki, M. Watanabe, A.M. Akimoto, R. Yoshida, Photo-Dimerization Induced Dynamic Viscoelastic Changes in ABA Triblock CopolymerBased Hydrogels for 3D Cell Culture, Chem. Mater. (2016). doi:10.1021/acs.chemmater.6b02839.

[260] Y. Fan, C. Deng, R. Cheng, F. Meng, Z. Zhong, In Situ Forming Hydrogels via Catalyst-Free and Bioorthogonal "Tetrazole-Alkene" Photo-Click Chemistry, Biomacromolecules. 14 (2013) 2814-2821. doi:10.1021/bm400637s.

[261] Y. Jiang, C. Deng, F. Meng, R. Cheng, Z. Zhong, Injectable hydrogels formed via catalyst-free "tetrazole-alkene" photo-click chemistry, J. Controlled Release. 172 (2013) e146-e147. doi:10.1016/j.jconrel.2013.08.239.

[262] Special Issue "Hydrogels Based on Dynamic Covalent Chemistry," Gels. 3 (2017). https://www.mdpi.com/journal/gels/special_issues/gels_DCvC\#published.

[263] K.M. Koeller, C.H. Wong, Enzymes for chemical synthesis, Nature. 409 (2001) 232-240. doi:10.1038/35051706.

[264] K. Drauz, Enzyme Catalysis in Organic Synthesis: A Comprehensive Handbook, John Wiley \& Sons, 2012.

[265] L.S. Moreira Teixeira, J. Feijen, C.A. van Blitterswijk, P.J. Dijkstra, M. Karperien, Enzymecatalyzed crosslinkable hydrogels: Emerging strategies for tissue engineering, Biomaterials. 33 (2012) 1281-1290. doi:10.1016/j.biomaterials.2011.10.067. 
[266] L.M. Johnson, C.A. DeForest, A. Pendurti, K.S. Anseth, C.N. Bowman, Formation of threedimensional hydrogel multilayers using enzyme-mediated redox chain initiation, ACS Appl. Mater. Interfaces. 2 (2010) 1963-1972. doi:10.1021/am100275n.

[267] P.S. Hume, C.N. Bowman, K.S. Anseth, Functionalized PEG hydrogels through reactive dipcoating for the formation of immunoactive barriers, Biomaterials. 32 (2011) 6204-6212. doi:10.1016/j.biomaterials.2011.04.049.

[268] R. Shenoy, M.W. Tibbitt, K.S. Anseth, C.N. Bowman, Formation of Core-Shell Particles by Interfacial Radical Polymerization Initiated by a Glucose Oxidase-Mediated Redox System, Chem. Mater. 25 (2013) 761-767. doi:10.1021/cm303913f.

[269] Q. Wei, W. Xu, M. Liu, Q. Wu, L. Cheng, Q. Wang, Viscosity-controlled printing of supramolecular-polymeric hydrogels via dual-enzyme catalysis, J Mater Chem B. (2016). doi:10.1039/C6TB01792D.

[270] L.-S. Wang, J.E. Chung, P. Pui-Yik Chan, M. Kurisawa, Injectable biodegradable hydrogels with tunable mechanical properties for the stimulation of neurogenesic differentiation of human mesenchymal stem cells in 3D culture, Biomaterials. 31 (2010) 1148-1157. doi:10.1016/j.biomaterials.2009.10.042.

[271] D.J. Menzies, A. Cameron, T. Munro, E. Wolvetang, L. Grøndahl, J.J. Cooper-White, Tailorable Cell Culture Platforms from Enzymatically Cross-Linked Multifunctional Poly(ethylene glycol)-Based Hydrogels, Biomacromolecules. 14 (2013) 413-423. doi:10.1021/bm301652q.

[272] R. Jin, C. Hiemstra, Z. Zhong, J. Feijen, Enzyme-mediated fast in situ formation of hydrogels from dextran-tyramine conjugates, Biomaterials. 28 (2007) 2791-2800. doi:10.1016/j.biomaterials.2007.02.032.

[273] F. Lee, J.E. Chung, M. Kurisawa, An injectable enzymatically crosslinked hyaluronic acidtyramine hydrogel system with independent tuning of mechanical strength and gelation rate, Soft Matter. 4 (2008) 880-887. doi:10.1039/B719557E.

[274] S.W. Liao, T.-B. Yu, Z. Guan, De Novo Design of Saccharide-Peptide Hydrogels as Synthetic Scaffolds for Tailored Cell Responses, J. Am. Chem. Soc. 131 (2009) 17638-17646. doi:10.1021/ja907097t.

[275] F. Chen, S. Yu, B. Liu, Y. Ni, C. Yu, Y. Su, X. Zhu, X. Yu, Y. Zhou, D. Yan, An Injectable Enzymatically Crosslinked Carboxymethylated Pullulan/Chondroitin Sulfate Hydrogel for Cartilage Tissue Engineering, Sci. Rep. 6 (2016). doi:10.1038/srep20014.

[276] C. Loebel, T. Stauber, M. D’Este, M. Alini, M. Zenobi-Wong, D. Eglin, Fabrication of cellcompatible hyaluronan hydrogels with a wide range of biophysical properties through high tyramine functionalization, J Mater Chem B. 5 (2017) 2355-2363. doi:10.1039/C6TB03161G.

[277] H.D. Nguyen, H.-Y. Liu, B.N. Hudson, C.-C. Lin, Enzymatic Cross-Linking of Dynamic Thiol-Norbornene Click Hydrogels, ACS Biomater. Sci. Eng. 5 (2019) 1247-1256. doi:10.1021/acsbiomaterials.8b01607.

[278] B.P. Lee, J.L. Dalsin, P.B. Messersmith, Synthesis and Gelation of DOPA-Modified Poly(ethylene glycol) Hydrogels, Biomacromolecules. 3 (2002) 1038-1047. doi:10.1021/bm025546n.

[279] T. Chen, H.D. Embree, E.M. Brown, M.M. Taylor, G.F. Payne, Enzyme-catalyzed gel formation of gelatin and chitosan: potential for in situ applications, Biomaterials. 24 (2003) 2831-2841. doi:10.1016/S0142-9612(03)00096-6.

[280] S.H. Lee, Y. Lee, S.-W. Lee, H.-Y. Ji, J.-H. Lee, D.S. Lee, T.G. Park, Enzyme-mediated crosslinking of Pluronic copolymer micelles for injectable and in situ forming hydrogels, Acta Biomater. 7 (2011) 1468-1476. doi:10.1016/j.actbio.2010.11.029.

[281] S. Das, F. Pati, Y.-J. Choi, G. Rijal, J.-H. Shim, S.W. Kim, A.R. Ray, D.-W. Cho, S. Ghosh, Bioprintable, cell-laden silk fibroin-gelatin hydrogel supporting multilineage differentiation of stem cells for fabrication of three-dimensional tissue constructs, Acta Biomater. 11 (2015) 233-246. doi:10.1016/j.actbio.2014.09.023. 
[282] C.E. Brubaker, H. Kissler, L. Wang, D.B. Kaufman, P.B. Messersmith, Biological performance of mussel-inspired adhesive in extrahepatic islet transplantation, Biomaterials. 31 (2010) 420 427. doi:10.1016/j.biomaterials.2009.09.062.

[283] S. Hong, K. Yang, B. Kang, C. Lee, I.T. Song, E. Byun, K.I. Park, S.-W. Cho, H. Lee, Hyaluronic Acid Catechol: A Biopolymer Exhibiting a pH-Dependent Adhesive or Cohesive Property for Human Neural Stem Cell Engineering, Adv. Funct. Mater. 23 (2013) 1774-1780. doi:10.1002/adfm.201202365.

[284] M. Cencer, Y. Liu, A. Winter, M. Murley, H. Meng, B.P. Lee, Effect of pH on the Rate of Curing and Bioadhesive Properties of Dopamine Functionalized Poly(ethylene glycol) Hydrogels, Biomacromolecules. 15 (2014) 2861-2869. doi:10.1021/bm500701u.

[285] B.-H. Hu, P.B. Messersmith, Rational Design of Transglutaminase Substrate Peptides for Rapid Enzymatic Formation of Hydrogels, J. Am. Chem. Soc. 125 (2003) 14298-14299. doi:10.1021/ja038593b.

[286] J.J. Sperinde, L.G. Griffith, Synthesis and characterization of enzymatically-cross-linked poly (ethylene glycol) hydrogels, Macromolecules. 30 (1997) 5255-5264.

[287] M.K. McHale, L.A. Setton, A. Chilkoti, Synthesis and in vitro evaluation of enzymatically cross-linked elastin-like polypeptide gels for cartilaginous tissue repair, Tissue Eng. 11 (2005) 1768-1779. doi:10.1089/ten.2005.11.1768.

[288] T.J. Sanborn, P.B. Messersmith, A.E. Barron, In situ crosslinking of a biomimetic peptidePEG hydrogel via thermally triggered activation of factor XIII, Biomaterials. 23 (2002) 2703 2710. doi:10.1016/S0142-9612(02)00002-9.

[289] M. Ehrbar, S.C. Rizzi, R.G. Schoenmakers, B. San Miguel, J.A. Hubbell, F.E. Weber, M.P. Lutolf, Biomolecular Hydrogels Formed and Degraded via Site-Specific Enzymatic Reactions, Biomacromolecules. 8 (2007) 3000-3007. doi:10.1021/bm070228f.

[290] M. Ehrbar, S.C. Rizzi, R. Hlushchuk, V. Djonov, A.H. Zisch, J.A. Hubbell, F.E. Weber, M.P. Lutolf, Enzymatic formation of modular cell-instructive fibrin analogs for tissue engineering, Biomaterials. 28 (2007) 3856-3866. doi:10.1016/j.biomaterials.2007.03.027.

[291] P.S. Lienemann, M. Karlsson, A. Sala, H.M. Wischhusen, F.E. Weber, R. Zimmermann, W. Weber, M.P. Lutolf, M. Ehrbar, A Versatile Approach to Engineering Biomolecule-Presenting Cellular Microenvironments, Adv. Healthc. Mater. 2 (2013) 292-296. doi:10.1002/adhm.201200280.

[292] M. Zhou, B.H. Lee, Y.J. Tan, L.P. Tan, Microbial transglutaminase induced controlled crosslinking of gelatin methacryloyl to tailor rheological properties for 3D printing, Biofabrication. (2019). doi:10.1088/1758-5090/ab063f.

[293] S. Cox, M. Cole, B. Tawil, Behavior of Human Dermal Fibroblasts in Three-Dimensional Fibrin Clots: Dependence on Fibrinogen and Thrombin Concentration, (n.d.) 13.

[294] E.V. Dare, S.G. Vascotto, D.J. Carlsson, M.T. Hincke, M. Griffith, Differentiation of a Fibrin Gel Encapsulated Chondrogenic Cell Line, (n.d.) 9.

[295] K.A. Mosiewicz, K. Johnsson, M.P. Lutolf, Phosphopantetheinyl Transferase-Catalyzed Formation of Bioactive Hydrogels for Tissue Engineering, J. Am. Chem. Soc. 132 (2010) 5972-5974. doi:10.1021/ja9098164.

[296] D.R. Gough, T.G. Cotter, Hydrogen peroxide: a Jekyll and Hyde signalling molecule, Cell Death Dis. 2 (2011) e213. doi:10.1038/cddis.2011.96.

[297] C. Wang, T.T. Lau, W.L. Loh, K. Su, D.-A. Wang, Cytocompatibility study of a natural biomaterial crosslinker-Genipin with therapeutic model cells, J. Biomed. Mater. Res. B Appl. Biomater. 97B (2011) 58-65. doi:10.1002/jbm.b.31786.

[298] D. Macaya, K.K. Ng, M. Spector, Injectable Collagen-Genipin Gel for the Treatment of Spinal Cord Injury: In Vitro Studies, Adv. Funct. Mater. 21 (2011) 4788-4797. doi:10.1002/adfm.201101720. 
[299] J.S. Yoo, Y.J. Kim, S.H. Kim, S.H. Choi, Study on Genipin: A New Alternative Natural Crosslinking Agent for Fixing Heterograft Tissue, Korean J. Thorac. Cardiovasc. Surg. 44 (2011) 197-207. doi:10.5090/kjtcs.2011.44.3.197.

[300] J. Alfredo Uquillas, V. Kishore, O. Akkus, Genipin crosslinking elevates the strength of electrochemically aligned collagen to the level of tendons, J. Mech. Behav. Biomed. Mater. 15 (2012) 176-189. doi:10.1016/j.jmbbm.2012.06.012.

[301] F. Mwale, M. Iordanova, C.N. Demers, T. Steffen, P. Roughley, J. Antoniou, Biological Evaluation of Chitosan Salts Cross-Linked to Genipin as a Cell Scaffold for Disk Tissue Engineering, Tissue Eng. 11 (2005) 130-140. doi:10.1089/ten.2005.11.130.

[302] R.A.A. Muzzarelli, Genipin-crosslinked chitosan hydrogels as biomedical and pharmaceutical aids, Carbohydr. Polym. 77 (2009) 1-9. doi:10.1016/j.carbpol.2009.01.016.

[303] R.A.A. Muzzarelli, M. El Mehtedi, C. Bottegoni, A. Gigante, Physical properties imparted by genipin to chitosan for tissue regeneration with human stem cells: A review, Int. J. Biol. Macromol. 93 (2016) 1366-1381. doi:10.1016/j.ijbiomac.2016.03.075.

[304] E.V. Dare, M. Griffith, P. Poitras, J.A. Kaupp, S.D. Waldman, D.J. Carlsson, G. Dervin, C. Mayoux, M.T. Hincke, Genipin Cross-Linked Fibrin Hydrogels for in vitro Human Articular Cartilage Tissue-Engineered Regeneration, Cells Tissues Organs. 190 (2009) 313-325. doi:10.1159/000209230.

[305] M. Ebelmen, Recherches sur les combinaisons des acides boriques et siliciques avec les éthers., Ann Chim. Phys. 16 (1846) 129.

[306] M. Ebelmen, Sur l'hyalite artificielle et l'hydrophane, C R Acad Sci. 25 (1847) 854.

[307] T. Graham, On the properties of silicic acid and other analogous colloidal substances, J. Chem. Soc. 17 (1864) 318-327.

[308] A.E. Danks, S.R. Hall, Z. Schnepp, The evolution of 'sol-gel' chemistry as a technique for materials synthesis, Mater Horiz. 3 (2016) 91-112. doi:10.1039/C5MH00260E.

[309] J. Livage, Vers une chimie écologique. Quand l'air et l'eau remplacent le pétrole, Le Monde. (1977).

[310] C.J. Brinker, G.W. Scherer, Sol-gel Science: The Physics and Chemistry of Sol-gel Processing, Gulf Professional Publishing, 1990.

[311] F. Carre, C. Chuit, R.J.P. Corriu, A. Fanta, A. Mehdi, C. Reye, Use of the 2,6Bis[(dimethylamino)methyl]phenyl Ligand for the Study of Nucleophilic Substitution at Hexacoordinate Silicon Centers. Evidence Suggestive of a Heptacoordinate Silicon Transition State, Organometallics. 14 (1995) 194-198. doi:10.1021/om00001a030.

[312] G. Carturan, R. Campostrini, S. Diré, V. Scardi, E. De Alteriis, Inorganic gels for immobilization of biocatalysts: inclusion of invertase-active whole cells of yeast (saccharomyces cerevisiae) into thin layers of $\mathrm{SiO} 2$ gel deposited on glass sheets, J. Mol. Catal. 57 (1989) L13-L16. doi:10.1016/0304-5102(89)80121-X.

[313] G. Carturan, R. Dal Toso, S. Boninsegna, R. Dal Monte, Encapsulation of functional cells by sol-gel silica: actual progress and perspectives for cell therapy, J Mater Chem. 14 (2004) 20872098. doi:10.1039/B401450B.

[314] S. Fennouh, S. Guyon, J. Catherine, J. Livage, C. Roux, Encapsulation of bacteria in silica gels, Comptes Rendus Académie Sci. - Ser. IIC - Chem. 2 (1999) 625-630. doi:10.1016/S13871609(00)88575-8.

[315] S. Fennouh, S. Guyon, J. Livage, C. Roux, Sol-Gel Entrapment of Escherichia coli, J. Sol-Gel Sci. Technol. 19 (2000) 647-649. doi:10.1023/A:1008733916175.

[316] N. Nassif, O. Bouvet, M. Noelle Rager, C. Roux, T. Coradin, J. Livage, Living bacteria in silica gels, Nat. Mater. 1 (2002) 42-44. doi:10.1038/nmat709.

[317] N. Nassif, C. Roux, T. Coradin, M.-N. Rager, O.M.M. Bouvet, J. Livage, A sol-gel matrix to preserve the viability of encapsulated bacteria, J. Mater. Chem. 13 (2003) 203-208. doi:10.1039/B210167J. 
[318] C. Fruijtier-Pölloth, The toxicological mode of action and the safety of synthetic amorphous silica-A nanostructured material, Toxicology. 294 (2012) 61-79. doi:10.1016/j.tox.2012.02.001.

[319] L. Gabrielli, L. Connell, L. Russo, J. Jiménez-Barbero, F. Nicotra, L. Cipolla, J.R. Jones, Exploring GPTMS reactivity against simple nucleophiles: chemistry beyond hybrid materials fabrication, RSC Adv. 4 (2013) 1841-1848. doi:10.1039/C3RA44748K.

[320] X. Guillory, A. Tessier, G.-O. Gratien, P. Weiss, S. Colliec-Jouault, D. Dubreuil, J. Lebreton, J.L. Bideau, Glycidyl alkoxysilane reactivities towards simple nucleophiles in organic media for improved molecular structure definition in hybrid materials, RSC Adv. 6 (2016) 74087 74099. doi:10.1039/C6RA01658H.

[321] X. Bourges, P. Weiss, A. Coudreuse, G. Daculsi, G. Legeay, General properties of silated hydroxyethylcellulose for potential biomedical applications, Biopolymers. 63 (2002) 232-238. doi:10.1002/bip.10053.

[322] X. Bourges, P. Weiss, G. Daculsi, G. Legeay, Synthesis and general properties of silatedhydroxypropyl methylcellulose in prospect of biomedical use, Adv. Colloid Interface Sci. 99 (2002) 215-228. doi:10.1016/S0001-8686(02)00035-0.

[323] P. Weiss, B.J. Le, J. Recho, A. Fatimi, J. GUICHEUX, Method for the silanisation of $\begin{array}{llll}\text { polysaccharides, } & \text { WO2010037986 } & \text { A1, }\end{array}$ http://www.google.com/patents/WO2010037986A1 (accessed November 28, 2014).

[324] J. Zhang, W. Liu, O. Gauthier, S. Sourice, P. Pilet, G. Rethore, K. Khairoun, J.-M. Bouler, F. Tancret, P. Weiss, A simple and effective approach to prepare injectable macroporous calcium phosphate cement for bone repair: Syringe-foaming using a viscous hydrophilic polymeric solution, Acta Biomater. 31 (2016) 326-338. doi:10.1016/j.actbio.2015.11.055.

[325] W. Liu, J. Zhang, G. Rethore, K. Khairoun, P. Pilet, F. Tancret, J.-M. Bouler, P. Weiss, A novel injectable, cohesive and toughened Si-HPMC (silanized-hydroxypropyl methylcellulose) composite calcium phosphate cement for bone substitution, Acta Biomater. 10 (2014) 3335-3345. doi:10.1016/j.actbio.2014.03.009.

[326] Y. Feng, G. Melacini, J.P. Taulane, M. Goodman, Acetyl-terminated and template-assembled collagen-based polypeptides composed of Gly-Pro-Hyp sequences. 2. Synthesis and conformational analysis by circular dichroism, ultraviolet absorbance, and optical rotation, J. Am. Chem. Soc. 118 (1996) 10351-10358. 